\title{
Sensitive Detection of Broad-Spectrum Bacteria with Small-Molecule Fluorescent Excimer Chemosensors
}

Supplementary Information

Aaron D. Cabral, ${ }^{\dagger,}$ Nafiseh Rafiei, ${ }^{\dagger}, \S$ Elvin D. de Araujo, ${ }^{\dagger}$ Tudor B. Radu, ${ }^{\dagger,}$ Krimo Toutah, ${ }^{\dagger}$ Daniel Nino, ${ }^{\dagger}, \|$ Joshua N. Milstein, ${ }^{\dagger}, \|$ Dziyana Kraskouskaya ${ }^{* \dagger}$ and Patrick T. Gunning* ${ }^{* \dagger, \dagger}$

${ }^{\dagger}$ Department of Chemical \& Physical Sciences, University of Toronto Mississauga, 3359 Mississauga Road North, Mississauga, Ontario L5L 1C6,Canada.

* Department of Chemistry, University of Toronto, 80 St. George Street, Toronto, Ontario M5S 3H6, Canada.

$\S$ Institute of Biomaterials and Biomedical Engineering, University of Toronto, 164 College Street, Toronto, Ontario M5S 3G9, Canada.

\| Department of Physics, University of Toronto, 60 St. George Street, Toronto, Ontario, M5S 1A7 Canada

\section{Contents}

$\begin{array}{lr}\text { S1. Experimental Methods } & 2\end{array}$

$\begin{array}{lr}\text { S2. Supplementary Figures } & 7\end{array}$

$\begin{array}{ll}\text { S2.1 Introduction } & 7\end{array}$

S2.2 Proof-of-concept Bacteria Detection 8

S2.3 Probing the Sensitivity Towards Bacterial Cells 14

S2.4 Determining the Mechanism of Action 20

$\begin{array}{ll}\text { S2.5 Selectivity to Bacteria over Mammalian Cells } & 28\end{array}$

S2.6 Detection of Bacterial Cells in Physiological Fluids 32

$\begin{array}{ll}\text { S2.7 Supplementary Videos } & 32\end{array}$

$\begin{array}{lr}\text { S3. Supplementary Notes } & 33\end{array}$

$\begin{array}{lr}\text { S4. Supplementary Tables } & 33\end{array}$

S5. Compound synthesis protocols and characterization $\quad 34$

$\begin{array}{ll}\text { S5.1 General Information } & 34\end{array}$

S5.2 Synthesis of 7-C Chemosensors

S5.3 Synthesis of 1-(4-Aminobutyl)pyrene 41 
S5.5 HRMS Spectra 53

S5.6 Analytical HPLC Spectra 56

S6. References $\quad 62$

\section{S1. Experimental Methods}

General. Fluorimeter experiments were performed on a Tecan Infinite M1000 instrument with black, 384well, non-binding, flat bottom polystyrene plates (Greiner-BioOne 781900). Lipopolysaccharide from Escherichia coli O55:B5 (L2880) and Lipoteichoic acid from Bacillus subtilis (L3265) were purchased from MilliporeSigma. Sterile human CSF was purchased from Lee Biosolutions, Inc. All bacterial strains tested are listed in Supplementary Note 1. Chemosensors were prepared as described in previous reports, ${ }^{1,2}$ except for 7-C variants which are described in Supplementary Note 2. Sensor solutions were typically prepared from $10 \mathrm{mg} / \mathrm{mL}$ DMSO stocks in $50 \mathrm{mM}$ HEPES buffer, $\mathrm{pH} 7.5,75 \mathrm{mM} \mathrm{NaCl}$ and minimal DMSO $(0.04-2.9 \%)$.

Bacterial Growth Protocol. Bacteria were typically prepared from frozen concentrated stocks and grown in $10 \mathrm{~mL}$ of freshly prepared $\mathrm{M} 9$ minimal media supplemented with $0.1 \%[\mathrm{v} / \mathrm{v}]$ glucose, $1 \mathrm{mM} \mathrm{MgSO}_{4}$, $0.1 \mathrm{mM} \mathrm{CaCl} 2,10 \mu \mathrm{g} / \mathrm{mL}$ biotin and thiamine and allowed to incubate overnight at $37{ }^{\circ} \mathrm{C}$ with shaking $(150 \mathrm{rpm})$. The cultures were centrifuged for $10 \mathrm{~min}$ at $5000 \mathrm{rpm}$, washed three times with buffer $(50 \mathrm{mM}$ HEPES, $\mathrm{pH} 7.5,75 \mathrm{mM} \mathrm{NaCl}$ ) and resuspended in buffer. A $1 \mathrm{~mL}$ aliquot of the solution was placed in a cuvette, and the absorbance at $600 \mathrm{~nm}\left(\mathrm{OD}_{600}\right)$ was measured and related to the concentration of CFUs $/ \mathrm{mL}$ of the solution.

Fluorescence Microscopy of Bacteria. All wide-field fluorescence microscopy was conducted in epifluorescence mode with an inverted Olympus IX-81 microscope equipped with a $60 \times, 1.49$ N.A. oilimmersion objective (Olympus, APON 60XOTIRF). An arc lamp (X-Cite, series 120Q, $120 \mathrm{~W}$ ) was employed as the excitation light source for all sensors. A 320/50 nm excitation and 447/60 nm (387/11 nm) emission band-pass filter was used to image ProxyPhos (PSVue ${ }^{\mathrm{TM} 380)}$ ) sensors. Images were magnified an additional $2.3 \times$ with an external telescope for a final magnification of $137 \times$ and an effective 
pixel size of $\sim 73 \mathrm{~nm}$. All images were collected with an exposure time of $30 \mathrm{~ms}$ by an electron multiplying charge-coupled device (EMCCD) (Andor iXon3) controlled by $\mu$ Manager. ${ }^{3}$

Samples were prepared in $30 \mathrm{~mm}$ culture dishes by placing a $30 \mu \mathrm{L}$ droplet containing bacterial cells $(3 \times$ $10^{6}$ CFUs, HEPES buffer, pH 7.5) on a glass Poly-L-lysine (PLL) coated coverslip (Fisher scientific, 0.17 to $0.25 \mathrm{~mm}$ ) and allowed to rest for $5 \mathrm{~min}$. With the UV excitation active, a $30 \mu \mathrm{L}$ droplet of sensor (20 $\mu \mathrm{M}$ in HEPES buffer, $\mathrm{pH} 7.0$ - 7.5) was added and 1000 frames of video were taken to observe the onset of sensor activity. Image averages were processed using ImageJ software by averaging the image intensity over 200 frames or a $6 \mathrm{~s}$ exposure. Where quantitative fluorescence signals were calculated, all images were taken with the same gain and their background noise was subtracted to normalize. Regions of interest (ROIs) of several cells were manually selected and their mean signal intensity was measured through ImageJ.

Two-Colour Fluorescence Microscopy. A $1 \mathrm{~mL}$ sample of bacterial cells $\left(1.0 \times 10^{8} \mathrm{CFUs} / \mathrm{mL}, 50 \mathrm{mM}\right.$ HEPES buffer, pH 7.5) was pre-incubated with 2 drops NucRed® Live 647 Reagent. After 20 min, a 30 $\mu \mathrm{L}$ droplet of the bacterial cells $\left(3 \times 10^{6} \mathrm{CFUs}\right)$ was placed on a PLL-coated glass coverslip within a 30 $\mathrm{mm}$ culture dish and allowed to rest for $5 \mathrm{~min}$. A $30 \mu \mathrm{L}$ droplet of sensor (10 $\mu \mathrm{M}$ final) was added. Images were taken in the blue channel after UV excitation as described previously (excitation $=325 / 50 \mathrm{~nm}$, emission $=447 / 60 \mathrm{~nm}$ ). NucRed ${ }^{\circledR}$ stained chromosome was imaged in the red channel using $637 \mathrm{~nm}$ laser (World Star Tech, NRC B-2) as the excitation laser along with applying the $638 \mathrm{~nm}$ excitation band-pass filter $\mathrm{nm}$ and the $686 \mathrm{~nm}$ emission band-pass filter. Image averages were processed using ImageJ software by averaging the image intensity over 200 frames or a 6 s exposure.

Confocal Microscopy of Bacteria and Mammalian Cells. MCF-7 breast cancer cells were grown, and $1.0 \times 10^{4}$ cells were added to a sterile, tissue culture treated 8-chamber cell imaging cover glass (Eppendorf, cat. \#0030742036) followed by incubation overnight at $37{ }^{\circ} \mathrm{C}$. The media was removed and washed three times with HEPES buffer. Separately, bacteria were grown using standard procedures. A sample of bacteria $\left(4.0 \times 10^{8} \mathrm{CFUs} / \mathrm{mL}, \mathrm{OD}_{600}=0.5\right)$ was added to the glass slide. Sensor $(40 \mu \mathrm{M}$ final $)$ was added concurrently with propidium iodide at a final concentration of $3 \mu \mathrm{M}$. Slides were immediately imaged using a Zeiss LSM 800 confocal laser scanning microscope using brightfield, blue channel (405 $\mathrm{nm}(5 \mathrm{mw})$ and red channel $(639 \mathrm{~nm}(5 \mathrm{mw}))$. 
Pixel-Intensity Analysis of Fluorescence Microscopy. Single cell intensities were extracted and analyzed using Image J. ${ }^{4}$ Cells were initially rotated such that they are aligned with their long axis, and the minor (short) and major (long) axes were then normalized. To display the spatial intensity distribution within the cellular interior, two types of cross-sections were presented: 1) a single-pixel and 2) a weighted (average) cross-section along the major or minor axis. Cross-sections for multiple single cells were acquired and averaged over the population (Figure S23, S24).

Fluorimetry Detection of Bacteria in Buffer Solutions. Bacteria were diluted from stock culture to 1.0 $\times 10^{8} \mathrm{CFUs} / \mathrm{mL}$ (50 mM HEPES buffer, $\left.\mathrm{pH} 7.5,75 \mathrm{mM} \mathrm{NaCl}\right)$. The bacteria solutions were serially diluted 1:10 from $1 \times 10^{8} \mathrm{CFUs} / \mathrm{mL}$ to $1 \times 10^{0} \mathrm{CFUs} / \mathrm{mL}$ with buffer in a 96-well plate. In a 384-well plate, 30 $\mu \mathrm{L}$ of sensor was combined with $30 \mu \mathrm{L}$ of analyte (last row contained $30 \mu \mathrm{L}$ buffer), the mixtures were incubated for $10 \mathrm{~min}$ away from light, and the fluorescence intensity was recorded at $476 \mathrm{~nm}(10 \mathrm{~nm}$ bandwidth) following excitation at $350 \mathrm{~nm}$ (5 $\mathrm{nm}$ bandwidth). Fluorescence intensities were used to calculate the excimer emission in response to the bacteria.

Bacterial Growth Stages Detection. During bacteria growth, every hour over six hours, a $1 \mathrm{~mL}$ aliquot was removed from the culture. The aliquots were immediately centrifuged for $10 \mathrm{~min}$ at $5000 \mathrm{rpm}$, washed three times with $1 \mathrm{~mL}$ buffer (50 mM HEPES, pH 7.5, $75 \mathrm{mM} \mathrm{NaCl}$ ) and resuspended in buffer. The 1 $\mathrm{mL}$ aliquot was placed in a cuvette, and the absorbance at $600 \mathrm{~nm}\left(\mathrm{OD}_{600}\right)$ was measured to determine the concentration of CFUs/mL. In a 384-well plate, $30 \mu \mathrm{L}$ of sensor $(20 \mu \mathrm{M}$, same buffer) was combined with $30 \mu \mathrm{L}$ of bacterial aliquot (last row contained $30 \mu \mathrm{L}$ buffer), the mixtures were incubated for 10 min away from light, and the fluorescence intensity was recorded at $476 \mathrm{~nm}$ (10 nm bandwidth) following excitation at $350 \mathrm{~nm}$ ( $5 \mathrm{~nm}$ bandwidth). Fluorescence intensities were used to calculate the excimer emission in response to the absorbance response of bacterial aliquots $\left(\Delta \mathrm{FI} / \mathrm{OD}_{600}\right)$.

Flow Cytometry Detection of Bacteria. Bacterial samples $\left(1 \times 10^{3} \mathrm{CFUs} / \mathrm{mL}-1 \times 10^{8} \mathrm{CFUs} / \mathrm{mL}\right)$ were treated with sensor (50 mM HEPES, $75 \mathrm{mM} \mathrm{NaCl}, 0.4 \%$ DMSO, [sensor $]_{\text {final }}=50 \mu \mathrm{M}$ ). Samples were run on a CytoFLEX S Flow Cytometer (Beckman Coulter) using a NUV laser (405 nm) and DAPI filter (emission: $450 / 45 \mathrm{~nm}$ ) with $10 \mathrm{~s}$ injections at a flow rate of $60 \mu \mathrm{L} / \mathrm{min}(10 \mu \mathrm{L}$ injected).

Fluorimetry Detection of LPS and LTA in Buffer Solutions. The molecular weight of both LPS and LTA were assumed as $10 \mathrm{kDa}$. LPS and LTA solutions were prepared at $20 \mu \mathrm{M}$ in the same buffer without DMSO. The LPS or LTA solutions were serially diluted 1:1 from $20 \mu \mathrm{M}$ to $0.01 \mu \mathrm{M}$ with buffer in a 96- 
well plate. In a $384-w e l l$ plate, $30 \mu \mathrm{L}$ of sensor $(20 \mu \mathrm{M})$ was combined with $30 \mu \mathrm{L}$ of analyte (last row contained $30 \mu \mathrm{L}$ buffer), the mixtures were incubated for 10 min away from light, and the fluorescence intensity was recorded at $476 \mathrm{~nm}$ (10 nm bandwidth) following excitation at $350 \mathrm{~nm}$ (5 nm bandwidth). Fluorescence intensities were used to calculate the excimer emission in response to LPS or LTA.

SDS-PAGE / Western Blot of whole-cell lysates. After overnight growth, bacteria were diluted to $\mathrm{OD}_{600}$ $=0.4$ in a $10 \mathrm{~mL}$ aliquot and centrifuged at $5000 \mathrm{~g}$ for $10 \mathrm{~min}$. The supernatant was decanted, and the cell pellets were flash-frozen in liquid $\mathrm{N}_{2}$. Pellets for preparation of whole-cell lysates were stored at $-80{ }^{\circ} \mathrm{C}$ until necessary. The cell pellets were thawed and resuspended in lysis buffer $(10 \mathrm{mM}$ Tris- $\mathrm{HCl} \mathrm{pH} 8.4,1$ $\mathrm{mM}$ EDTA, $10 \mathrm{mM} \mathrm{MgCl}$, $1 \mathrm{mg} \mathrm{mL}^{-1}$ lysozyme, $0.3 \mathrm{mg} \mathrm{mL}^{-1} \mathrm{PMSF}, 0.1 \mathrm{mg} \mathrm{mL}^{-1}$ DNase I) and incubated at $37^{\circ} \mathrm{C}$ for $10 \mathrm{~min}$. Loading buffer with SDS was added and the samples were boiled at $95{ }^{\circ} \mathrm{C}$ for 2 min before loading onto a Criterion TGX Precast 18 well gel (Bio-Rad, cat. \#5671094). Control proteins BSA, ovalbumin and $\beta$-casein (Sigma-Aldrich) were also prepared, boiled at $95{ }^{\circ} \mathrm{C}$ and $0.5 \mu \mathrm{g}$ loaded as a control. The gel was run in 1× Tris/Glycine/SDS Buffer (Bio-Rad, cat. \#161-0732) at 120 $180 \mathrm{~V}$ until the bromophenol blue band ran off the gel. For the stained gels, the proteins were fixed in 2x30 min washes with $100 \mathrm{~mL}$ of $50 \%$ [v/v] methanol, and 10\% [v/v] acetic acid, followed by $3 \times 10 \mathrm{~min}$ washes with MilliQ water. ProxyPhos staining was performed with 4-C Cyclen (100 $\mu \mathrm{M}$ in pH 7.5, 50 $\mathrm{mM}$ HEPES, $15 \%$ [v/v] DMSO and $75 \mathrm{mM} \mathrm{NaCl}$ ) for 90 min protected from light. After destaining with $2 \times$ PBS, $20 \%$ [v/v] DMSO for $2 \times 20 \mathrm{~min}$, the gel was imaged on a Bio-Rad ChemiDoc MP using UV Trans Illumination and a standard emission filter. For total phosphorylation-total protein multiplex staining, the gel was stained with Pro-Q diamond gel stain for $90 \mathrm{~min}$, followed by $3 \times 30 \mathrm{~min}$ destains with 20\% [v/v] ACN, $50 \mathrm{mM}$ sodium acetate, $\mathrm{pH} 4$. After $2 \times 5$ min washes with MilliQ water, the gel was imaged using green epi illumination and the 605/50 filter on the ChemiDoc MP. The same gel used for Pro-Q diamond was stained with SYPRO Ruby overnight away from light. The gel was destained with 10\% [v/v] methanol, 7\% acetic acid for $30 \mathrm{~min}$, followed by imaging with UV Trans Illumination and the 605/50 filter on the ChemiDoc MP. For the western blot, the unfixed gel was soaked in transfer buffer and then transferred to a mini 0.2 $\mu$ M PVDF membrane (Bio-Rad, Cat. \#170-4156) through a Bio-Rad Trans-Blot Turbo transfer system. The blot was blocked in 3\% [w/v] BSA in TBS-T at rt for 60 min. The primary antibody Rabbit Polyclonal FtsZ (Abbexa, Cat. \#abx319936) diluted 1:1000 in 3\% [w/v] BSA and 0.02\% $[\mathrm{v} / \mathrm{v}] \mathrm{NaN}_{3}$ was incubated with the blot overnight at $4{ }^{\circ} \mathrm{C}$. The blot was washed with TBS-T $3 \times 5$ min at room temperature. The secondary antibody Goat Anti-rabbit HRP conjugate (Bio-Rad, Cat. \#170-5046) was diluted to 1:5000 with 3\% [w/v] BSA and incubated with the blot for $60 \mathrm{~min}$ at room tmeperature. 
The blot was rinsed $3 \times 5$ min with TBS-T. Clarity Western ECL substrate (Bio-Rad) was added to the blot before imaging with ChemiDoc MP on high resolution.

Bacteria Detection from Sterile Physiological Fluids. After typical growth procedures, bacteria were diluted to $1.2 \times 10^{9} \mathrm{CFUs} / \mathrm{mL}$ and serially diluted 1:10 into $1 \mathrm{~mL}$ buffer or CSF three times $\left(10^{6}-10^{8}\right.$ $\mathrm{CFUs} / \mathrm{mL}$ ). After $30 \mathrm{~min}$ incubation at room temperature, sensor in buffer ( $50 \mu \mathrm{M}$ sensor, $50 \mathrm{mM}$ HEPES, $\mathrm{pH} 7.5,75 \mathrm{mM} \mathrm{NaCl}, 5 \%$ [v/v] DMSO) was added to the sample and immediately ran on the flow cytometer as described previously. The sample was centrifuged for $10 \mathrm{~min}$ at 10,000 rpm, decanted and resuspended in assay buffer (50 mM HEPES, pH 7.5, $75 \mathrm{mM} \mathrm{NaCl}, 5 \%$ [v/v] DMSO), followed by a subsequent analysis on the flow cytometer. 


\section{S2. Supplementary Figures}

\section{S2.1 Introduction}

Figure S1. Negatively charged membrane components present in bacteria. Phosphoglycerol (PG) and cardiolipin (CL) lipid headgroups are found prevalently in bacterial membranes, while lipopolysaccharide (LPS) and lipoteichoic acid (LTA) are found in gram-negative and gram-positive membranes, respectively. Anionic residues are highlighted in red.
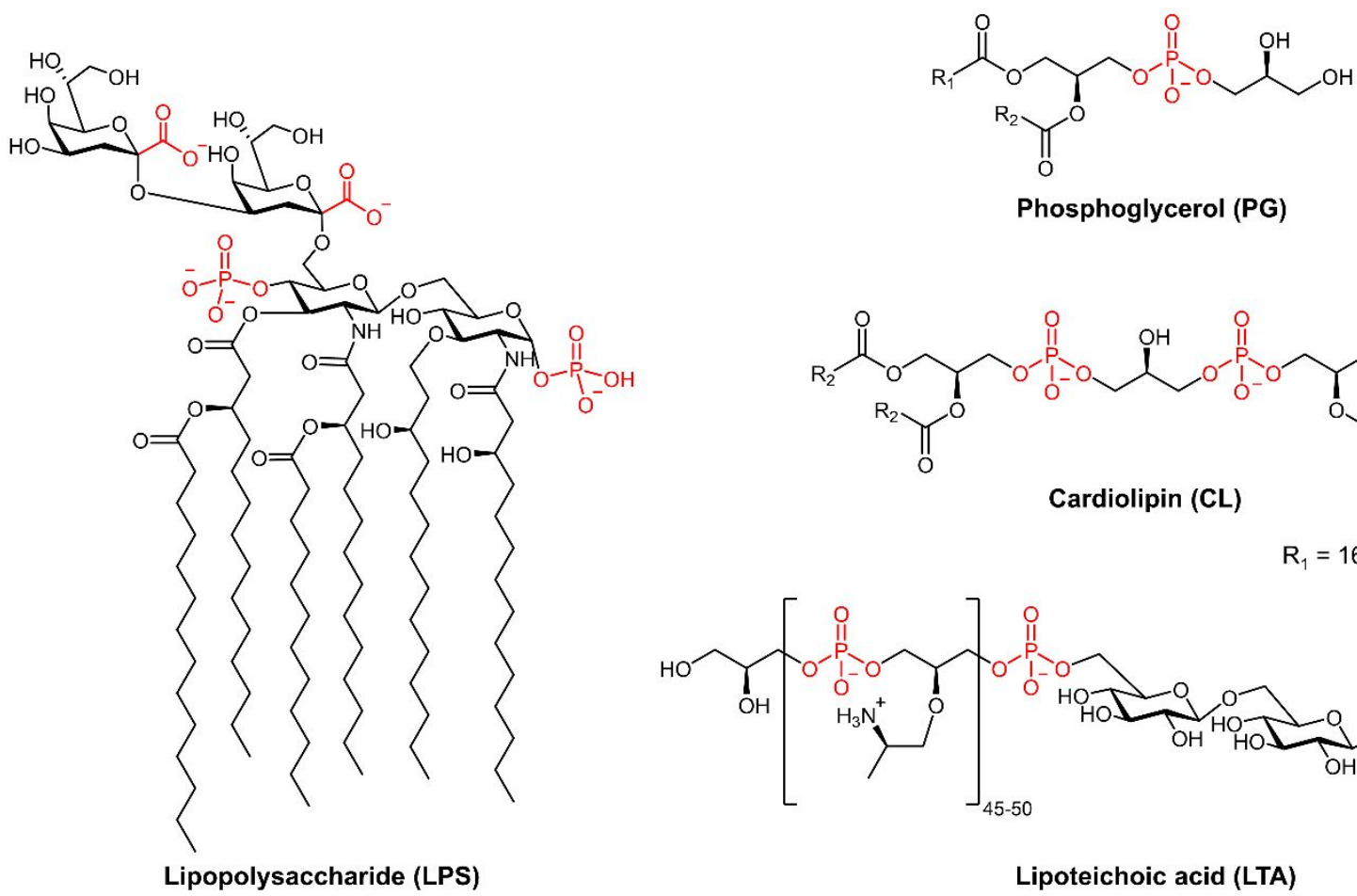

Phosphoglycerol (PG)

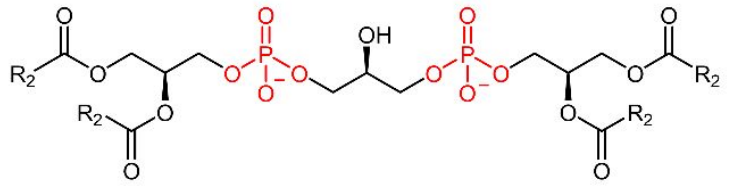

Cardiolipin (CL)
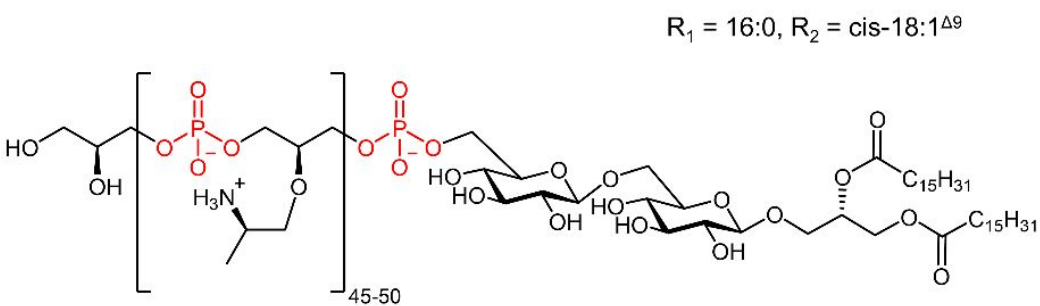

Lipoteichoic acid (LTA) 


\section{S2.2 Proof-of-concept Bacteria Detection}

Figure S2. Autofluorescence and brightfield microscopy images of A) E. coli and B) B. subtilis $(1.0 \times$ $10^{7} \mathrm{CFUs} / \mathrm{mL} ; 50 \mathrm{mM}$ HEPES buffer, $\mathrm{pH} 7.5,75 \mathrm{mM} \mathrm{NaCl} ; \lambda_{\mathrm{ex}}=325 / 50 \mathrm{~nm}, \lambda_{\mathrm{em}}=447 / 60 \mathrm{~nm}$ ). Scale bars represent $5 \mu \mathrm{m}$.

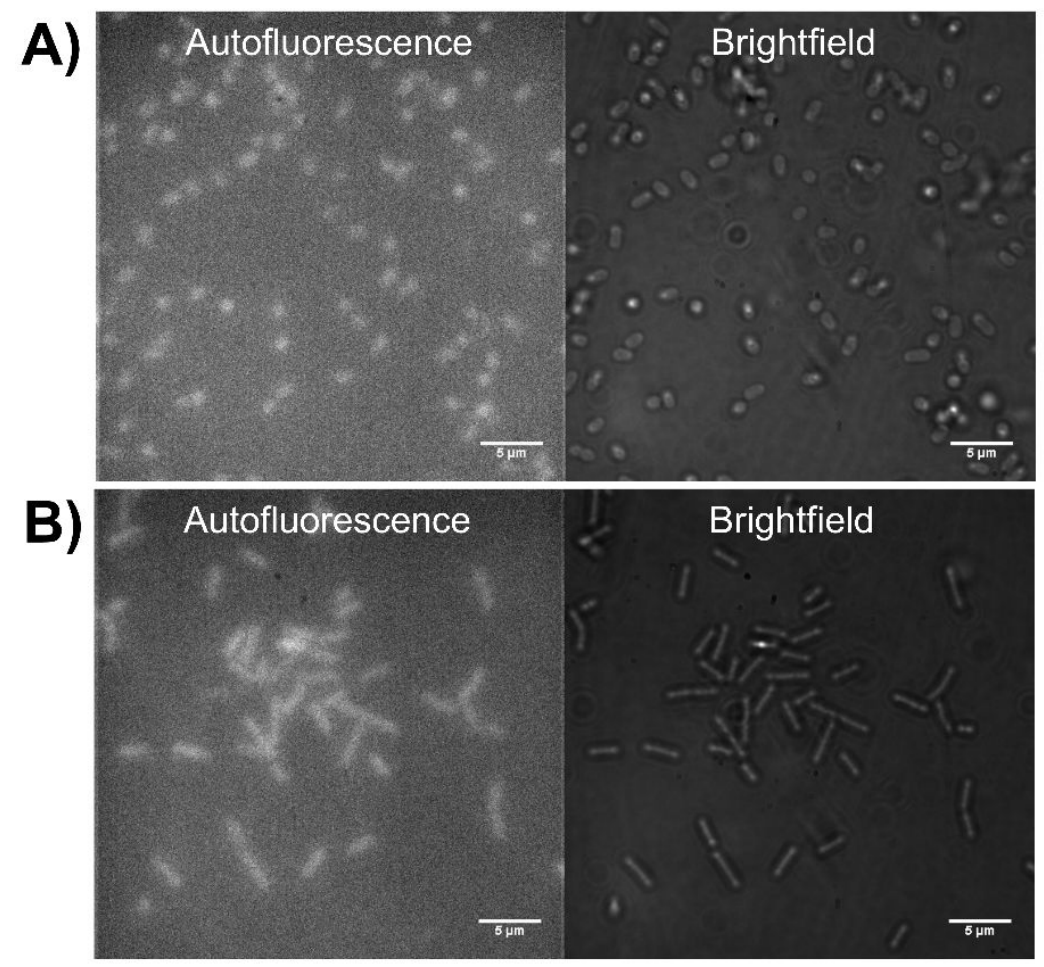


Figure S3. Fluorescence microscopy of $E$. coli. A) 1-C Cyclen; B) 1-C Cyclam; C) 1-C DPA; D) 4-C Cyclen; E) 4-C Cyclam; F) 4-C DPA; G) 4-C Cyclen (no Zn); H) 4-C Cyclam (no Zn); I) 1-(4Aminobutyl)pyrene; J) PSVue ${ }^{\mathrm{TM} 380}$; K) PSVue'TM380 (no Zn); L) E. coli autofluorescence $\left(1.0 \times 10^{7}\right.$ CFUs/mL; 50 mM HEPES buffer, pH 7.5, $75 \mathrm{mM} \mathrm{NaCl}$ buffer, $0.04-2.7 \%$ DMSO; ProxyPhos $\lambda_{\text {ex }}=$ $325 / 50 \mathrm{~nm}, \lambda_{\mathrm{em}}=447 / 60 \mathrm{~nm} ;$ PSVue ${ }^{\mathrm{TM}} 380 \lambda_{\mathrm{ex}}=387 / 11 \mathrm{~nm}, \lambda_{\mathrm{em}}=447 / 60 \mathrm{~nm}$. Scale bars represent 5 $\mu \mathrm{m}$.

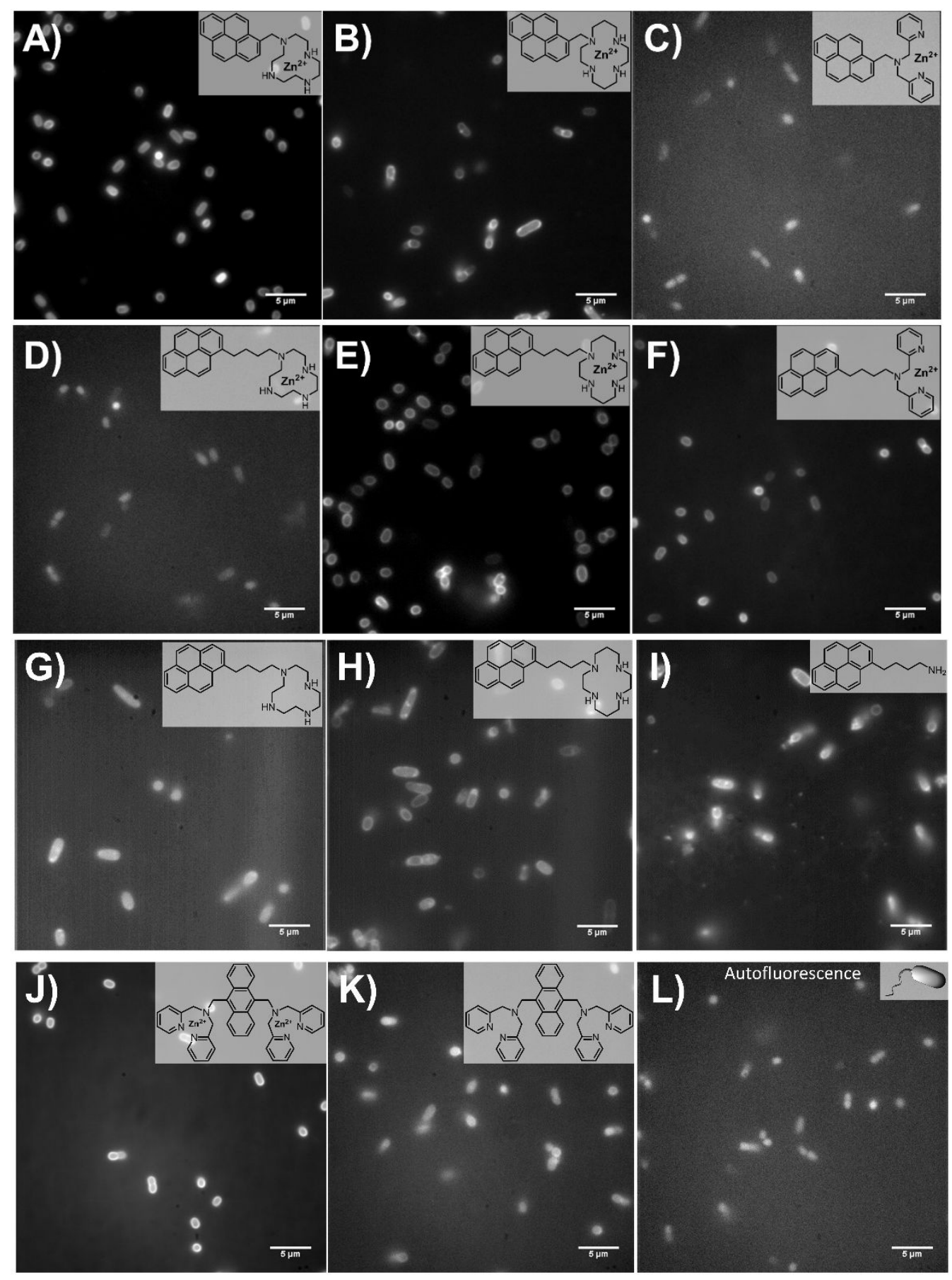


Figure S4. Bacteria detection results of ProxyPhos sensor 1-C DPA (no zinc). A) Image of fluorescence microscopy results with E. coli (10 $\mu \mathrm{M}$ sensor). B) Fluorescence titration with 1-C DPA (no zinc) (40 $\mu \mathrm{M}$ or $10 \mu \mathrm{M}$ ) with live E. coli and B. subtilis (pH 7.5, 50 mM HEPES, 20\% DMSO, ProxyPhos sensor $\lambda_{\text {ex/em }}=350 / 476 \mathrm{~nm}$ ). C) Fluorescence spectra of 1-C DPA (no zinc) with increasing concentrations of $E$. coli and B. subtilis $\left(1.0 \times 10^{0}-1.0 \times 10^{8}\right.$ CFUs; $\mathrm{pH} 7.5,50 \mathrm{mM}$ HEPES, $20 \%$ DMSO, ProxyPhos sensor $\left.\lambda_{\mathrm{ex}}=350 \mathrm{~nm}\right)$.
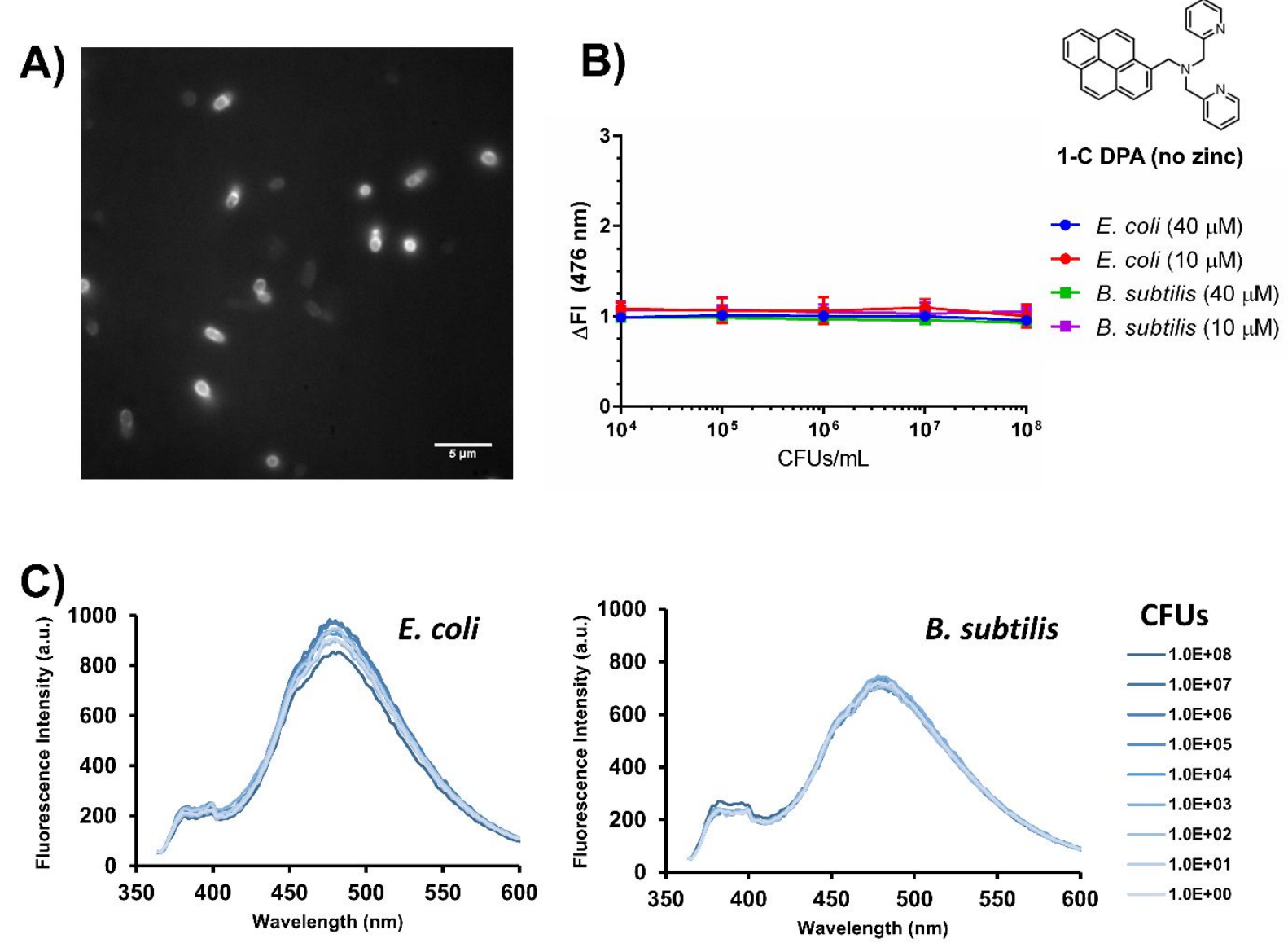
Figure S5. Fluorescence titrations of ProxyPhos sensors $(10 \mu \mathrm{M})$ and PSVue ${ }^{\mathrm{TM}} 380(1 \mu \mathrm{M})$ with live and fixed $E$. coli and B. subtilis. (pH 7.5, $50 \mathrm{mM}$ HEPES, $75 \mathrm{mM} \mathrm{NaCl}, 0.04-2.9 \%$ DMSO, ProxyPhos sensor $\lambda_{\text {ex/em }}=350 / 476 \mathrm{~nm}$, PSVue $\left.{ }^{\mathrm{TM}} 380 \lambda_{\text {ex/em }}=380 / 440 \mathrm{~nm}\right)$. Error bars denote mean \pm S.D. $(n=3)$.
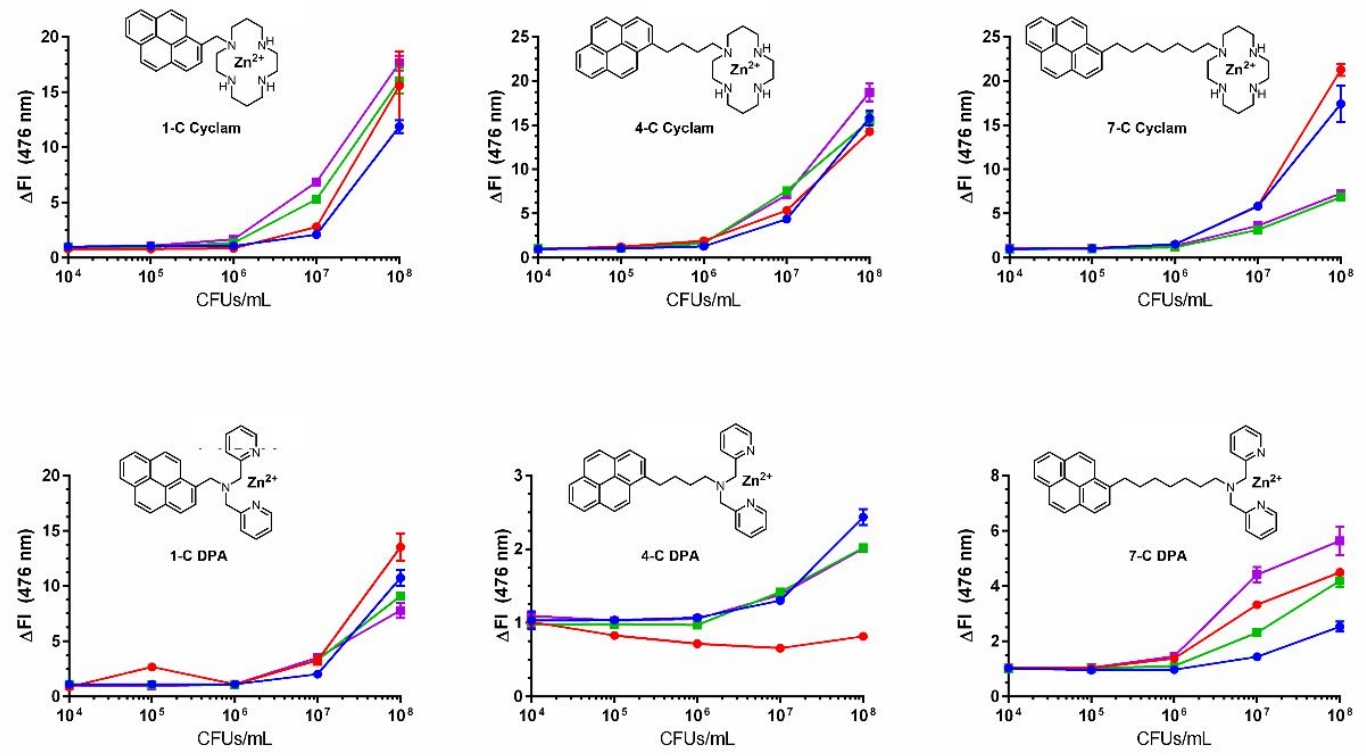

$\rightarrow$ E. coli (Live)

$\rightarrow$ E. coli (Fixed)

- B. subtilus (Live)

$\rightarrow$ B. subtilus (Fixed)
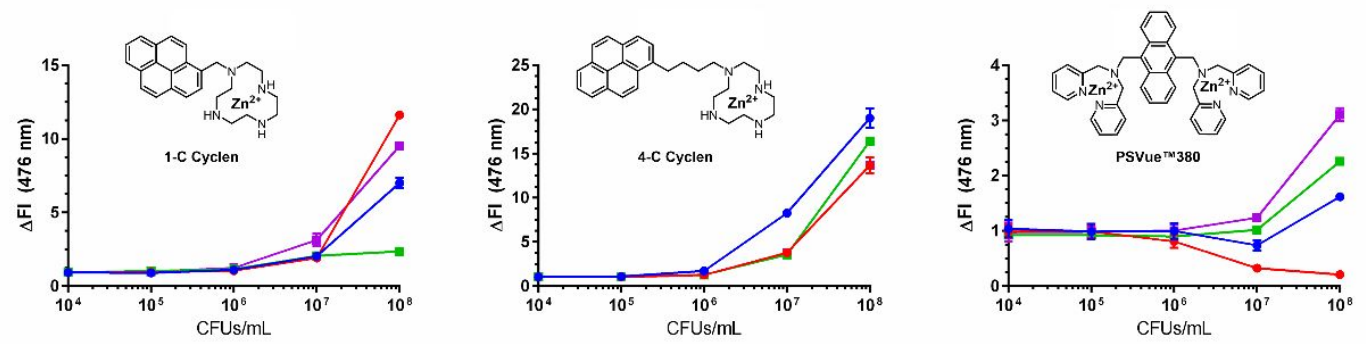
Figure S6. Fluorescence intensity measurements of ProxyPhos sensors (10 $\mu \mathrm{M}, \mathrm{pH}$ 7.5, $50 \mathrm{mM}$ HEPES, $\left.75 \mathrm{mM} \mathrm{NaCl}, 0.04 \% \mathrm{DMSO}, \lambda_{\mathrm{ex} / \mathrm{em}}=350 / 476 \mathrm{~nm}\right)$ in response to $E$. coli aliquots over a growth period of 6 hours. Aliquots were taken every hour beginning $1 \mathrm{hr}$ after culturing in M9 media. Intensity measurement is normalized to the $\mathrm{OD}_{600}$ of the aliquot $\left(\Delta \mathrm{FI} / \mathrm{OD}_{600}\right)$. A) Bar chart showing the $\Delta \mathrm{FI} /$ $\mathrm{OD}_{600}$ of ProxyPhos sensors over $6 \mathrm{hr}$; B) Bar chart showing the $\Delta \mathrm{FI} / \mathrm{OD}_{600}$ of ProxyPhos sensors over the final $3 \mathrm{hr}$; C) Growth curve of E. coli over the course of the experiment. Error bars denote mean \pm S.D. $(n=3)$.

\section{A)}
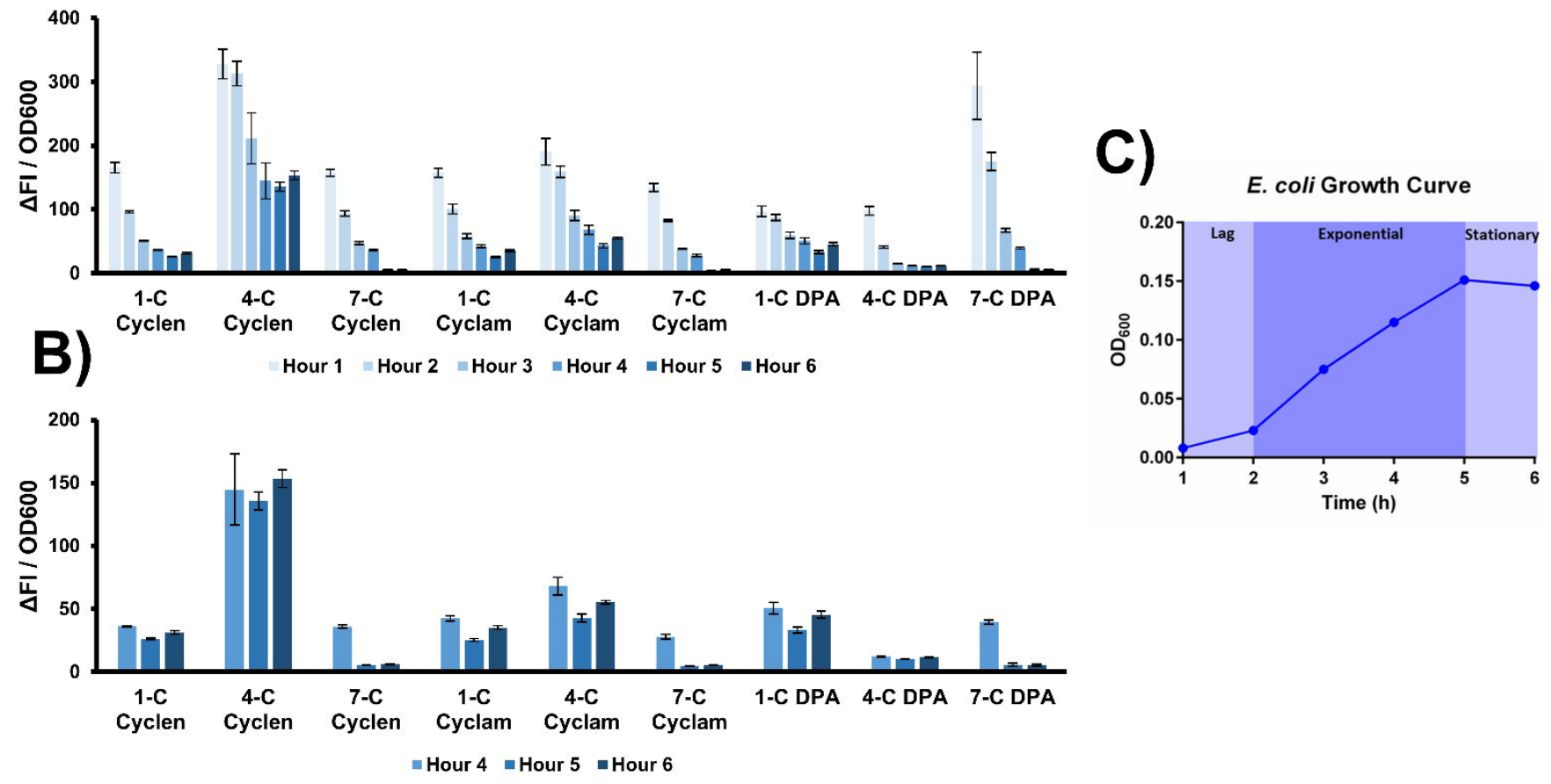

Figure S7. Fluorescence intensity measurements of ProxyPhos sensors (10 $\mu \mathrm{M}, \mathrm{pH}$ 7.5, $50 \mathrm{mM}$ HEPES, $75 \mathrm{mM} \mathrm{NaCl}, 0.04 \% \mathrm{DMSO}, \lambda_{\mathrm{ex} / \mathrm{em}}=350 / 476 \mathrm{~nm}$ ) in response to $B$. subtilis aliquots over a growth period of 6 hours. Aliquots were taken every hour beginning $1 \mathrm{hr}$ after culturing in M9 media. Intensity measurement is normalized to the $\mathrm{OD}_{600}$ of the aliquot $\left(\Delta \mathrm{FI} / \mathrm{OD}_{600}\right)$. A) Bar chart showing the $\Delta \mathrm{FI} /$ $\mathrm{OD}_{600}$ of ProxyPhos sensors over $6 \mathrm{hr}$; B) Bar chart showing the $\Delta \mathrm{FI} / \mathrm{OD}_{600}$ of ProxyPhos sensors over the final $3 \mathrm{hr}$; C) Growth curve of B. subtilis over the course of the experiment. Error bars denote mean \pm S.D. $(n=3)$. 
A)
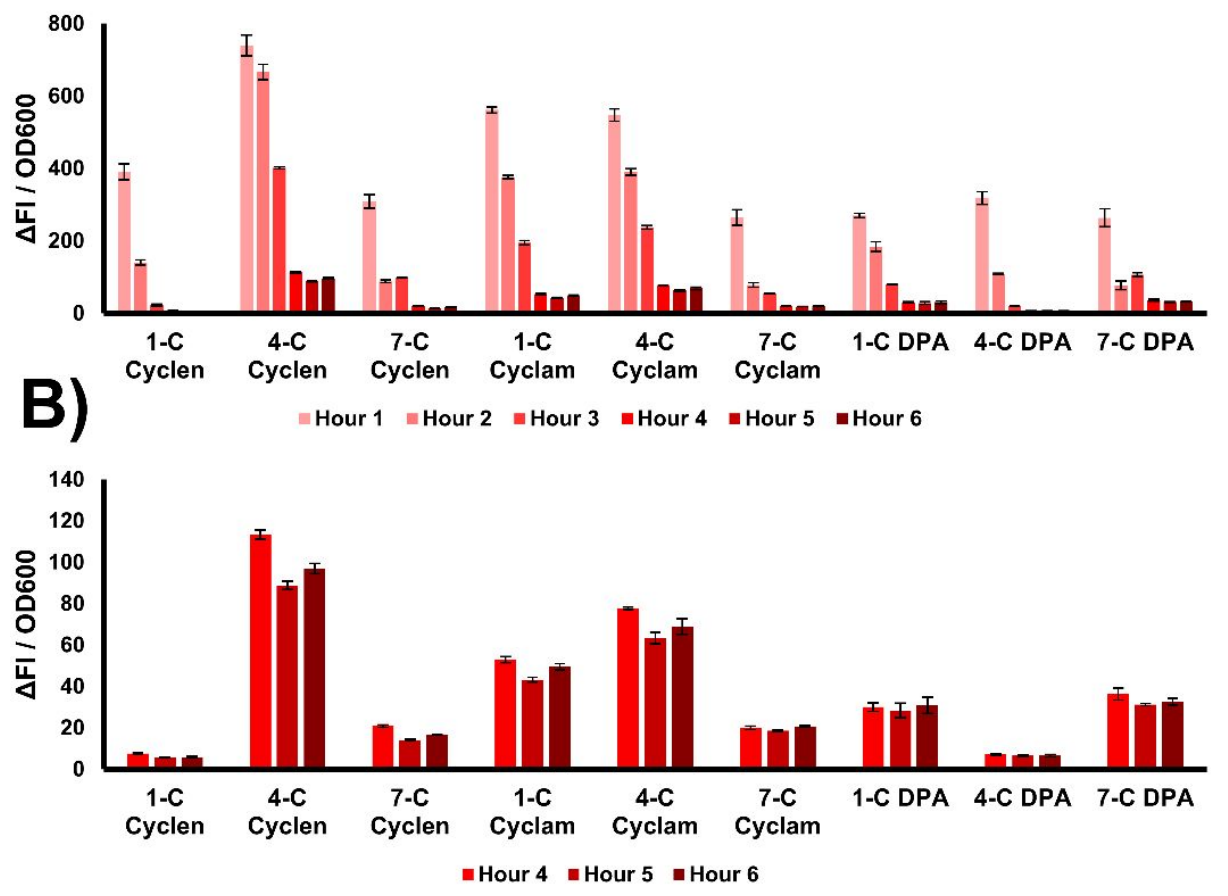

C)

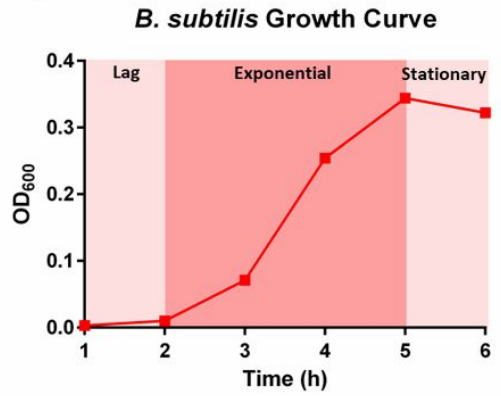




\section{S2.3 Probing the Sensitivity Towards Bacterial Cells}

Figure S8. Representative flow cytometry response of unstained E. coli cells $\left(1.0 \times 10^{6}-1.0 \times 10^{1}\right.$ CFUs injected). A) Cell counts vs DAPI-A; B) SSC-A vs FSC-A; and C) SSC-A vs DAPI-A. (DAPI filter $\lambda_{\text {ex/em }}=405 \mathrm{~nm} / 450 \mathrm{~nm} ; 50 \mathrm{mM}$ HEPES, $\mathrm{pH} 7.5,75 \mathrm{mM} \mathrm{NaCl}$ )

A)
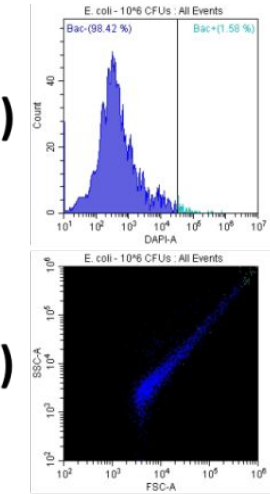

C)

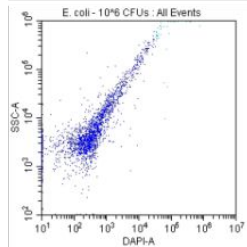

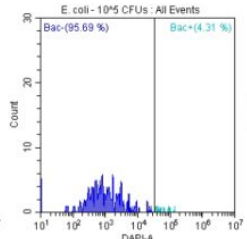
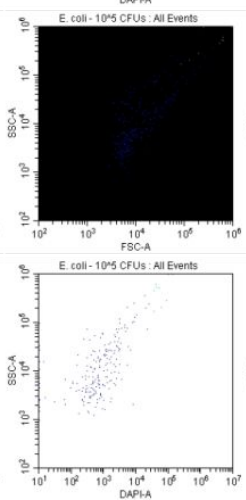
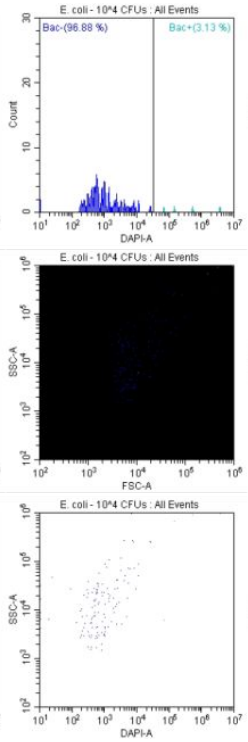
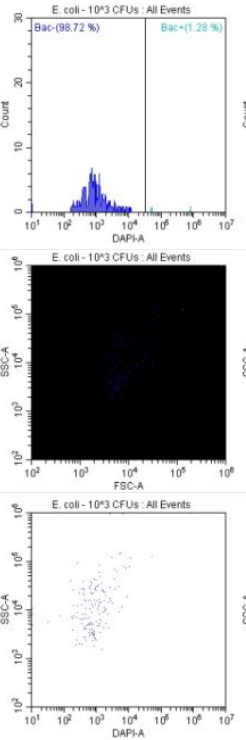
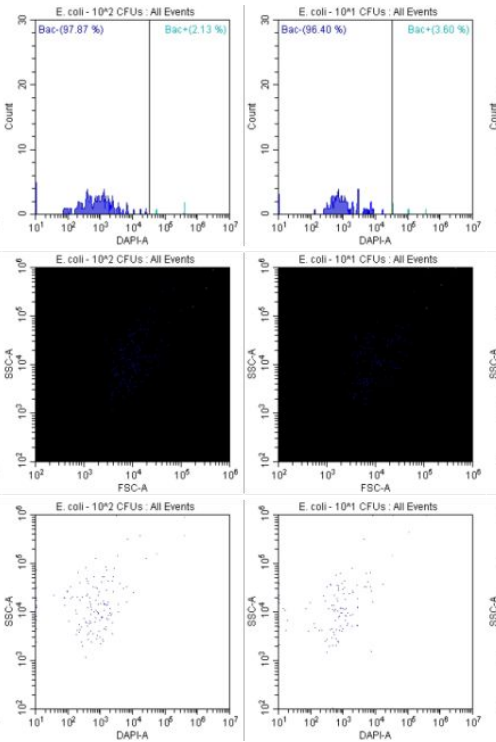
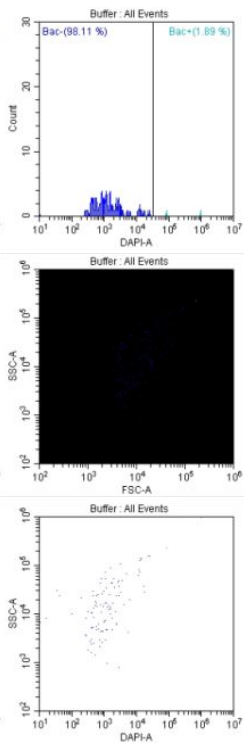

Figure S9. Representative flow cytometry response of unstained B. subtilis cells $\left(1.0 \times 10^{6}-1.0 \times 10^{1}\right.$ CFUs injected). A) Cell counts vs DAPI-A; B) SSC-A vs FSC-A; and C) SSC-A vs DAPI-A. (DAPI filter $\lambda_{\text {ex/em }}=405 \mathrm{~nm} / 450 \mathrm{~nm} ; 50 \mathrm{mM}$ HEPES, $\mathrm{pH} 7.5,75 \mathrm{mM} \mathrm{NaCl}$ )

A)
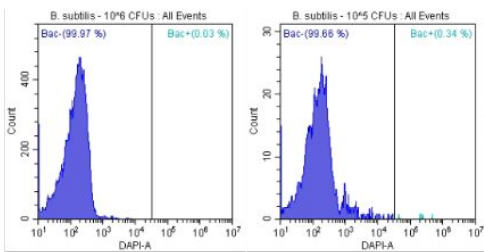

B)

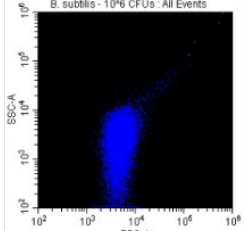

C)
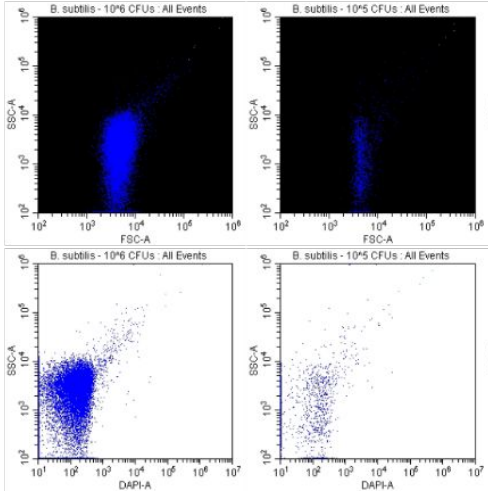
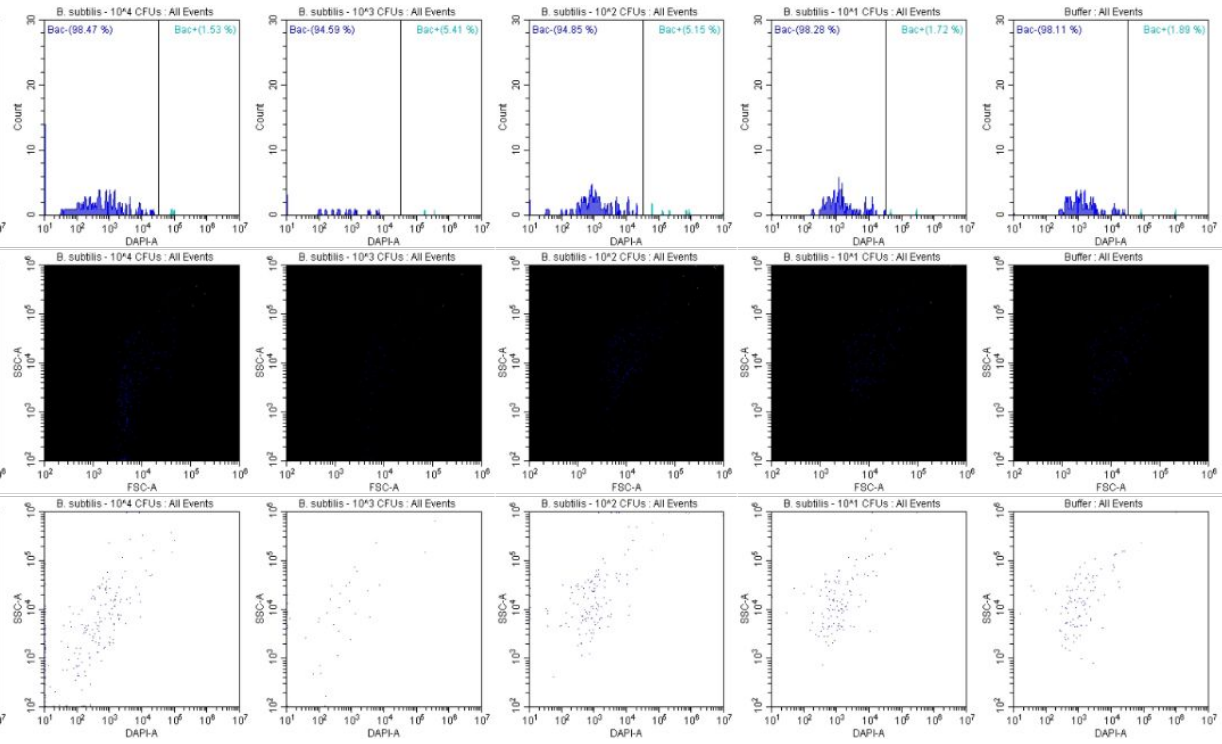
Figure S10. Representative flow cytometry response of $E$. coli cells $\left(1.0 \times 10^{6}-1.0 \times 10^{1}\right.$ CFUs injected) stained by 4-C Cyclam $(10 \mu \mathrm{M})$. A) Cell counts vs DAPI-A; B) SSC-A vs FSC-A; and C) SSC-A vs DAPI-A. (DAPI filter $\lambda_{\text {ex } / \mathrm{em}}=405 \mathrm{~nm} / 450 \mathrm{~nm} ; 50 \mathrm{mM}$ HEPES, $\mathrm{pH} 7.5,75 \mathrm{mM} \mathrm{NaCl}$ )
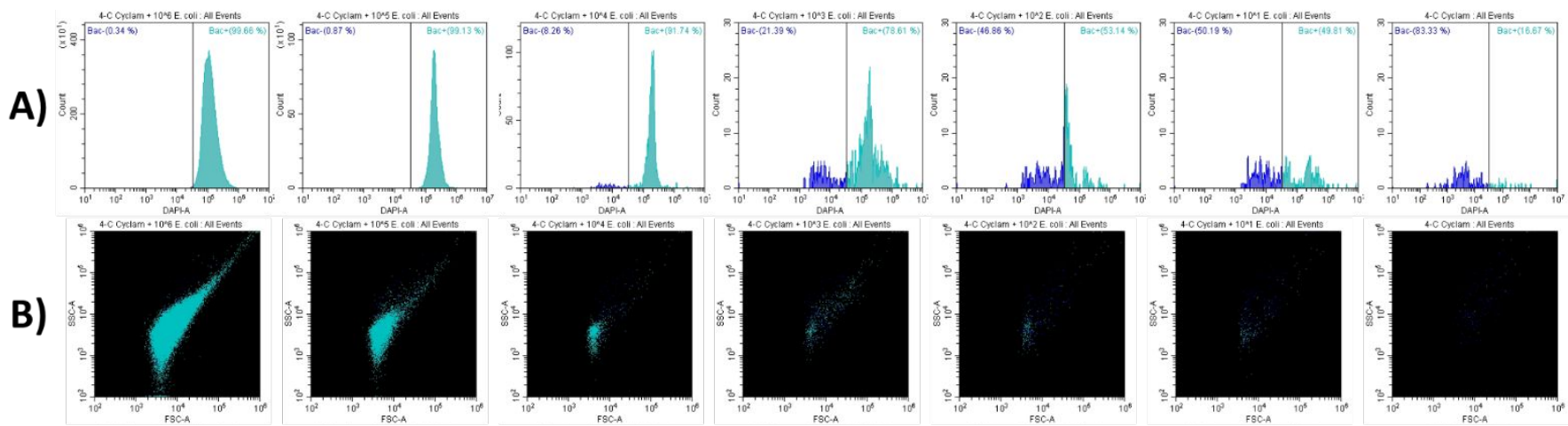

B)
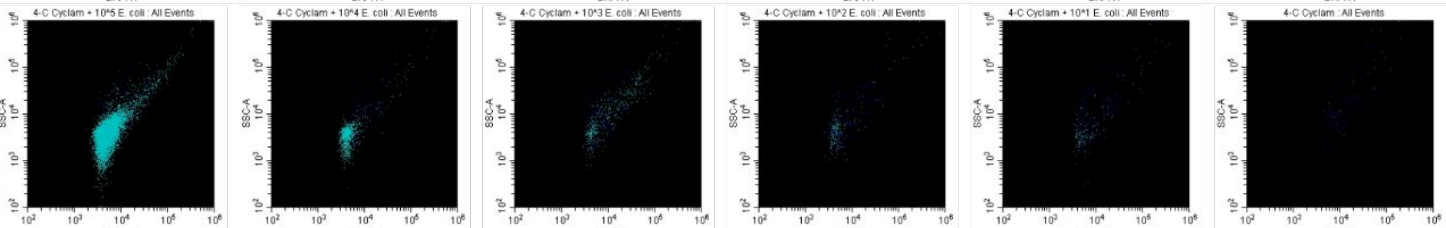

C)
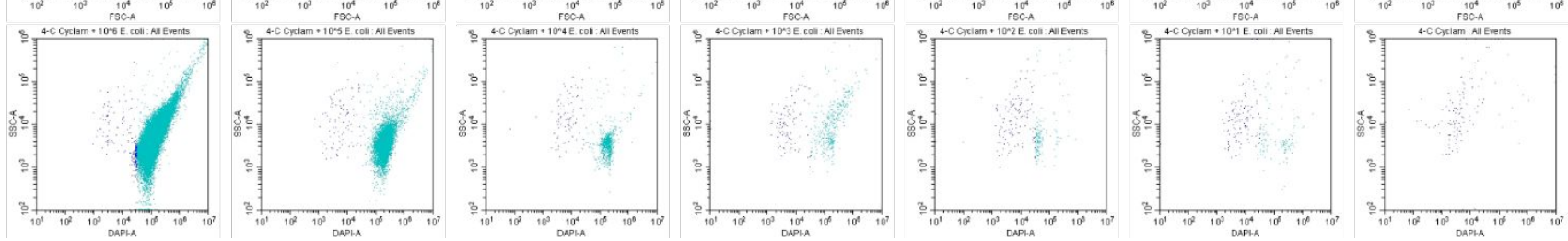

Figure S11. Representative flow cytometry response of $B$. subtilis cells $\left(1.0 \times 10^{6}-1.0 \times 10^{1} \mathrm{CFUs}\right.$ injected) stained by 4-C Cyclam $(10 \mu \mathrm{M})$. A) Cell counts vs DAPI-A; B) SSC-A vs FSC-A; and C) SSC-A vs DAPI-A. (DAPI filter $\lambda_{\text {ex } / \mathrm{em}}=405 \mathrm{~nm} / 450 \mathrm{~nm} ; 50 \mathrm{mM}$ HEPES, pH 7.5, $75 \mathrm{mM} \mathrm{NaCl}$ )

A)

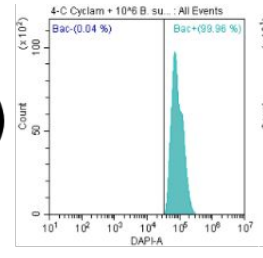

B)

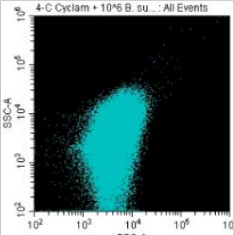

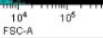

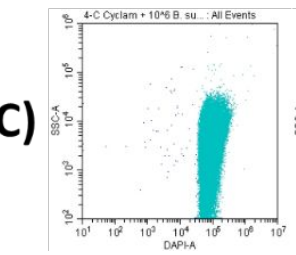

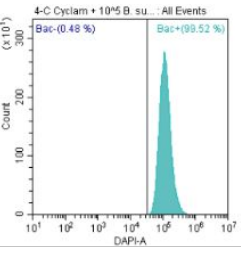
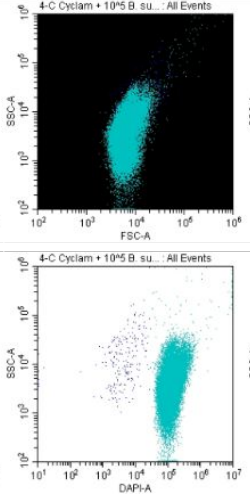
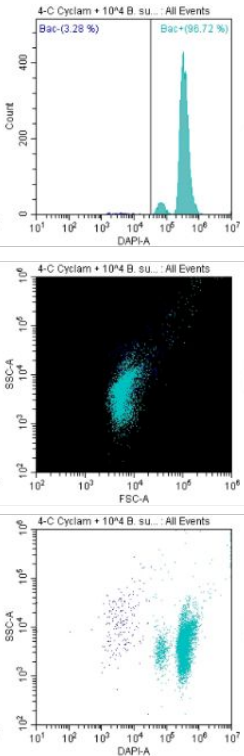
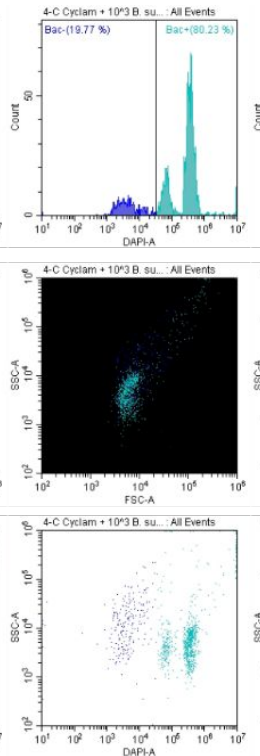
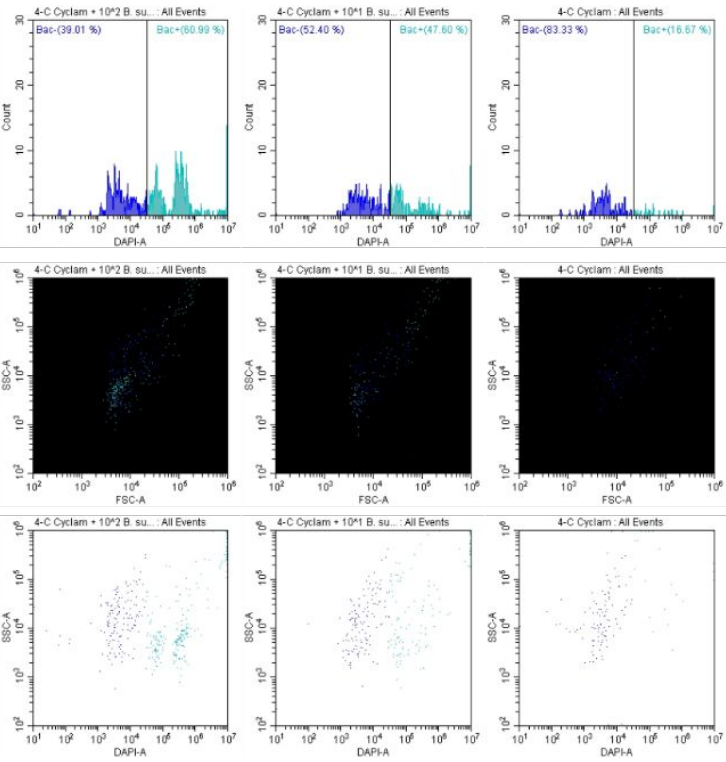
Figure S12. FSC-A vs SSC-A from flow cytometry analysis of bacteria. A) Comparison of 4-C Cyclam stained E. coli and unstained E. coli. B) Comparison of unstained E. coli and unstained B. subtilis $(1.0 \times$ $10^{6}$ CFUs; 50 mM HEPES, pH 7.5, $75 \mathrm{mM} \mathrm{NaCl}$ )

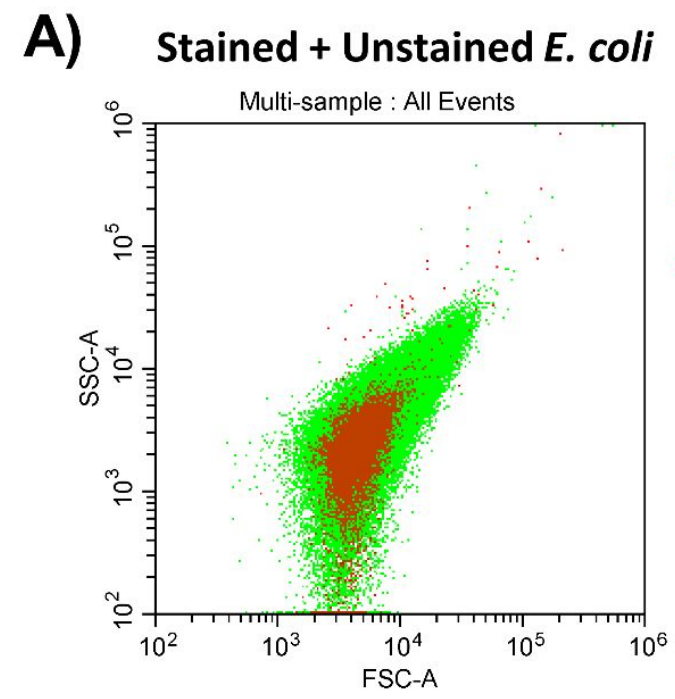

B) Unstained E. coli + B. subtilis

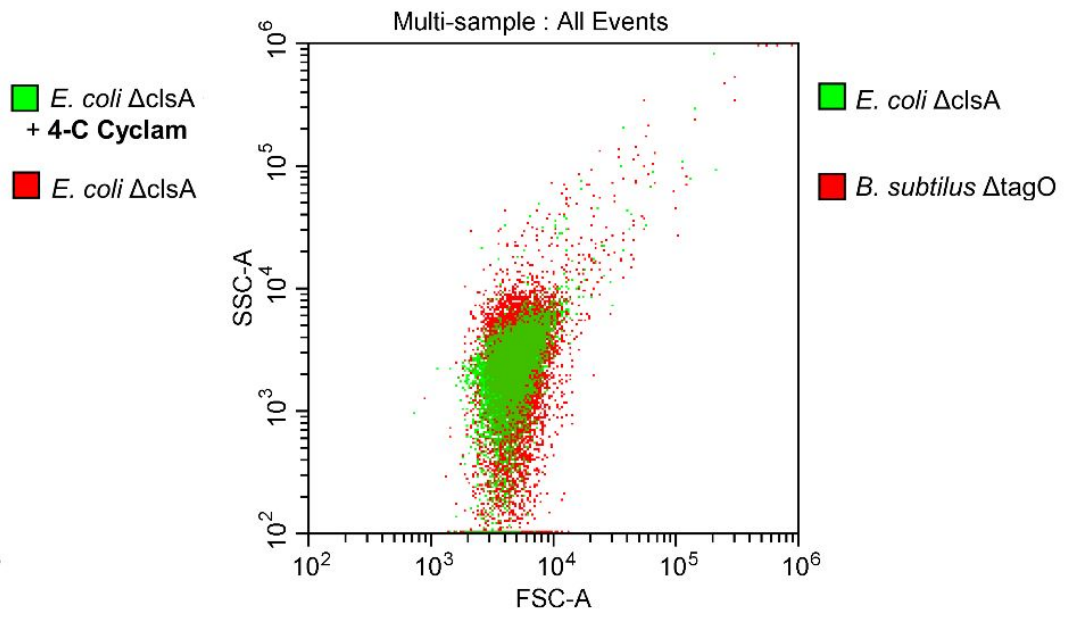

Figure S13. Flow cytometry analysis of bacterial cells stained by ProxyPhos sensors. Plotted titration of $\%$ bacteria stained by flow cytometry against number of cells injected $\left(10^{1}-10^{6} \mathrm{CFUs}\right)$, in response to 4-C Cyclam, 1-C Cyclam, 7-C Cyclam, 4-C Cyclen, PSVue ${ }^{\mathrm{TM} 380}$ and unstained. The dotted grey line represents the background signal and SD of sensor/buffer alone. Error bars denote mean \pm S.D. $(n=3)$.
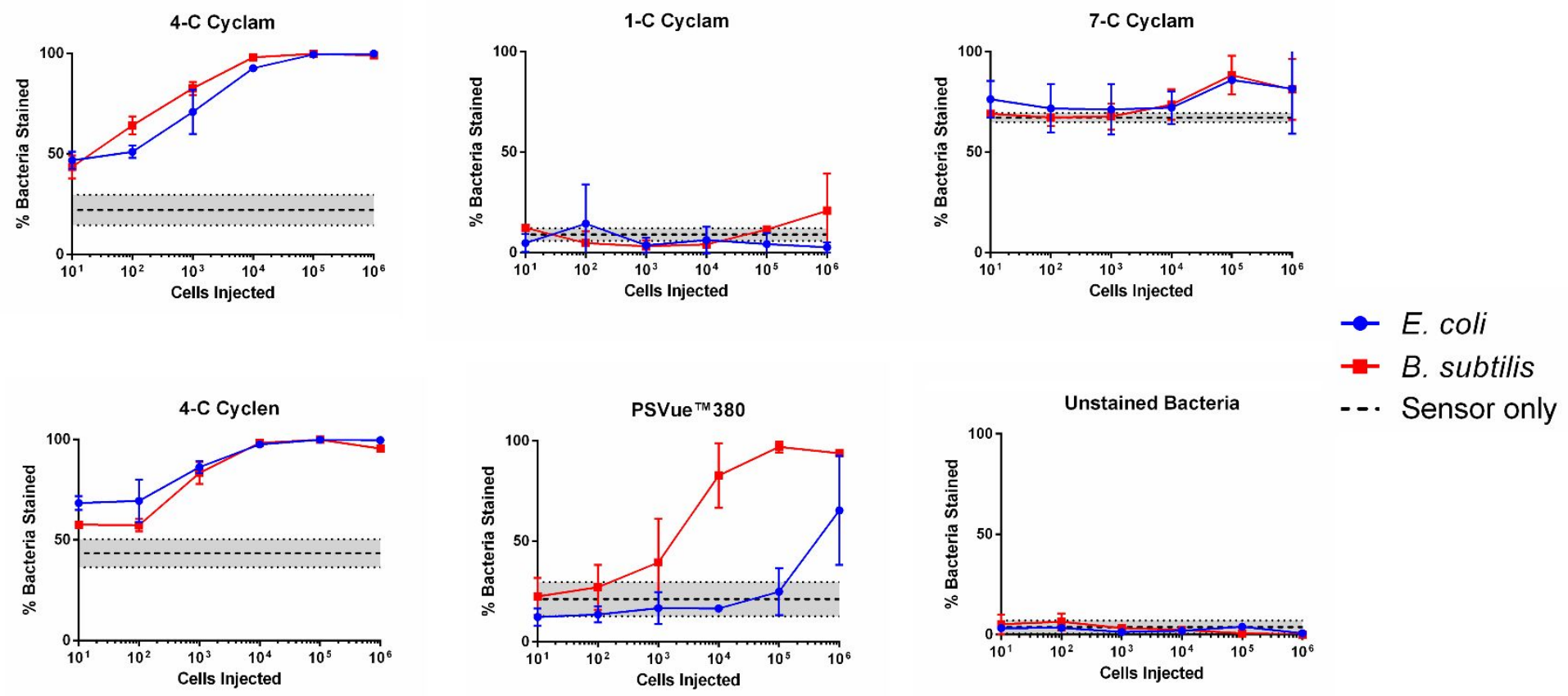
Figure S14. Flow cytometry analysis of 4-C Cyclam sensor $(50 \mu \mathrm{M})$ in response to different concentrations of $E$. coli. Plot shows cell counts vs DAPI-emission fluorescence counts $\left(\lambda_{\mathrm{ex}}=405 \mathrm{~nm}\right.$, $\lambda_{\mathrm{em}}=450 / 45 \mathrm{~nm} ; 50 \mathrm{mM}$ HEPES, $\left.\mathrm{pH} 7.5,75 \mathrm{mM} \mathrm{NaCl}\right)$.
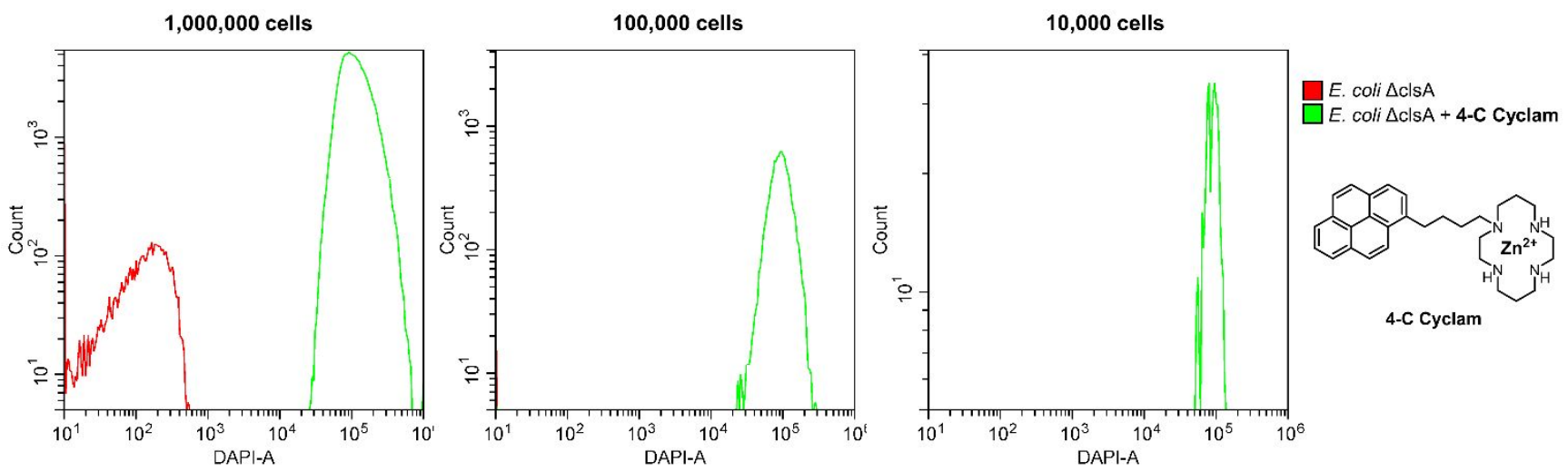

Figure S15. Flow cytometry analysis of 4-C Cyclam sensor $(50 \mu \mathrm{M})$ in response to the mutant bacteria strains of A) E. coli and B) B. subtilis $\left(1.0 \times 10^{6} \mathrm{CFUs} / \mathrm{mL}\right)$. Plot shows cell counts vs DAPI-emission fluorescence counts $\left(\lambda_{\mathrm{ex}}=405 \mathrm{~nm}, \lambda_{\mathrm{em}}=450 / 45 \mathrm{~nm} ; 50 \mathrm{mM}\right.$ HEPES, $\left.\mathrm{pH} 7.5,75 \mathrm{mM} \mathrm{NaCl}\right)$
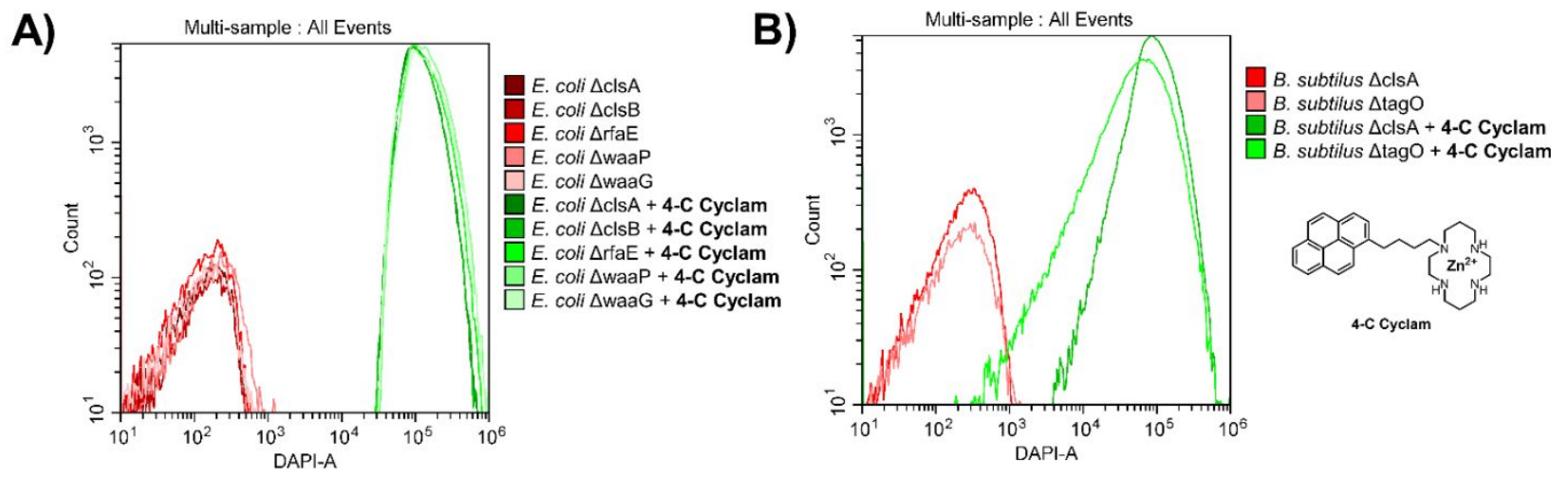
Figure S16. Flow cytometry analysis demonstrating reproducibility of detection methods between experiments. A) 4-C Cyclam sensor in response to E. coli in two experiments. Left - $10^{6}$ CFUs; Right $10^{5}$ CFUs. Plot shows cell counts vs FSC-A. B) Unstained E. coli (10 ${ }^{6}$ CFUs) detected by the flow cytometer. Left - SSC-A vs FSC-A; Right - cell counts vs FSC-A.
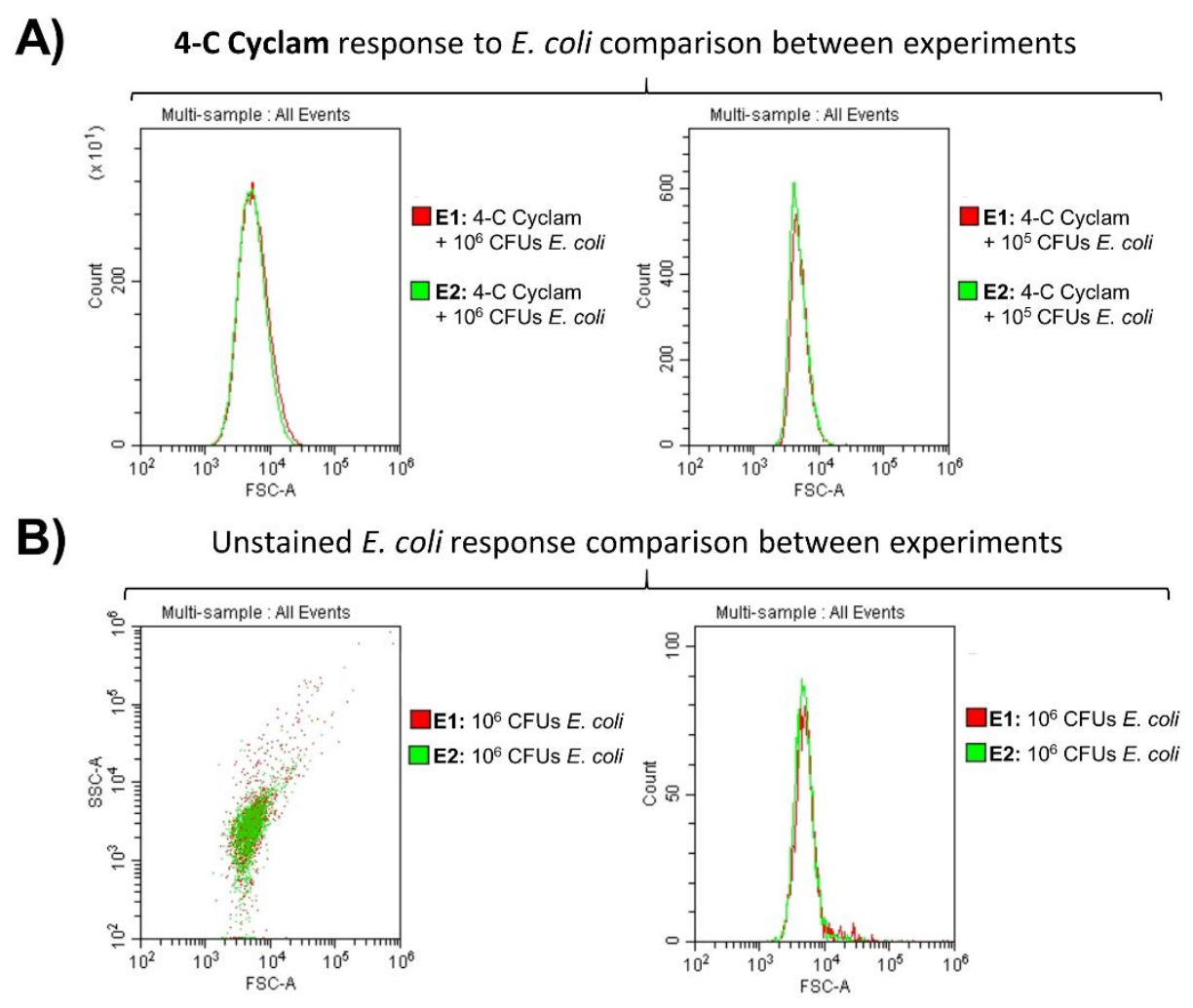

Figure S17. Flow cytometry analysis of bacterial cells stained by ProxyPhos sensor controls. Plotted titration of $\%$ bacteria stained by flow cytometry against number of cells injected $\left(10^{1}-10^{6} \mathrm{CFUs}\right)$, in response to 4-C Cyclam (no Zn), 4-C Cyclen (no Zn), and 1-(4-Aminobutyl)pyrene. The dotted grey line represents the background signal and SD of sensor/buffer alone. Error bars denote mean \pm S.D. $(n=3)$.
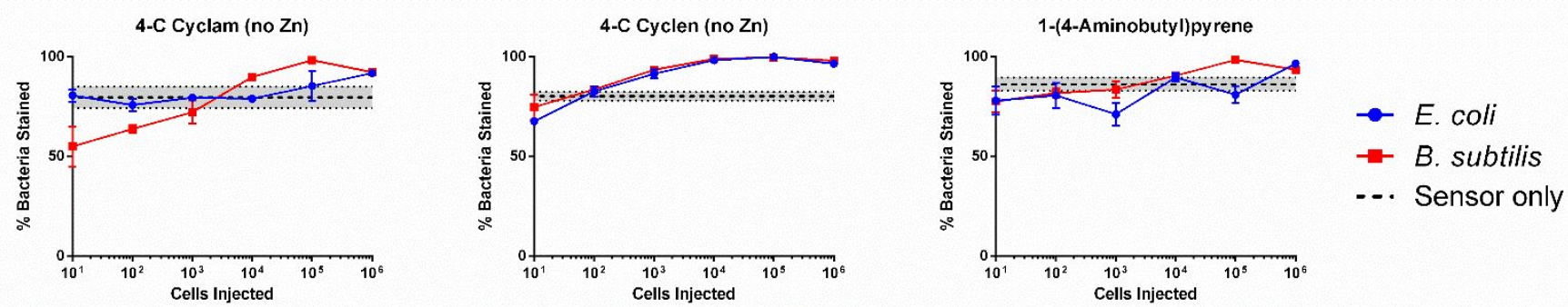
Figure S18. Comparison of flow cytometry signal (counts vs FSC-A) of ProxyPhos 4-C Cyclam (10 $\mu \mathrm{M})$ and PSVue ${ }^{\mathrm{TM}} 380(1 \mu \mathrm{M})$ in response to A) E. coli and B) B. subtilis. $\left(1.0 \times 10^{6} \mathrm{CFUs} ; 50 \mathrm{mM}\right.$ HEPES, $\mathrm{pH} 7.5,75 \mathrm{mM} \mathrm{NaCl})$.

\section{4-C Cyclam and PSVue ${ }^{\mathrm{TM}} 380$ comparison}
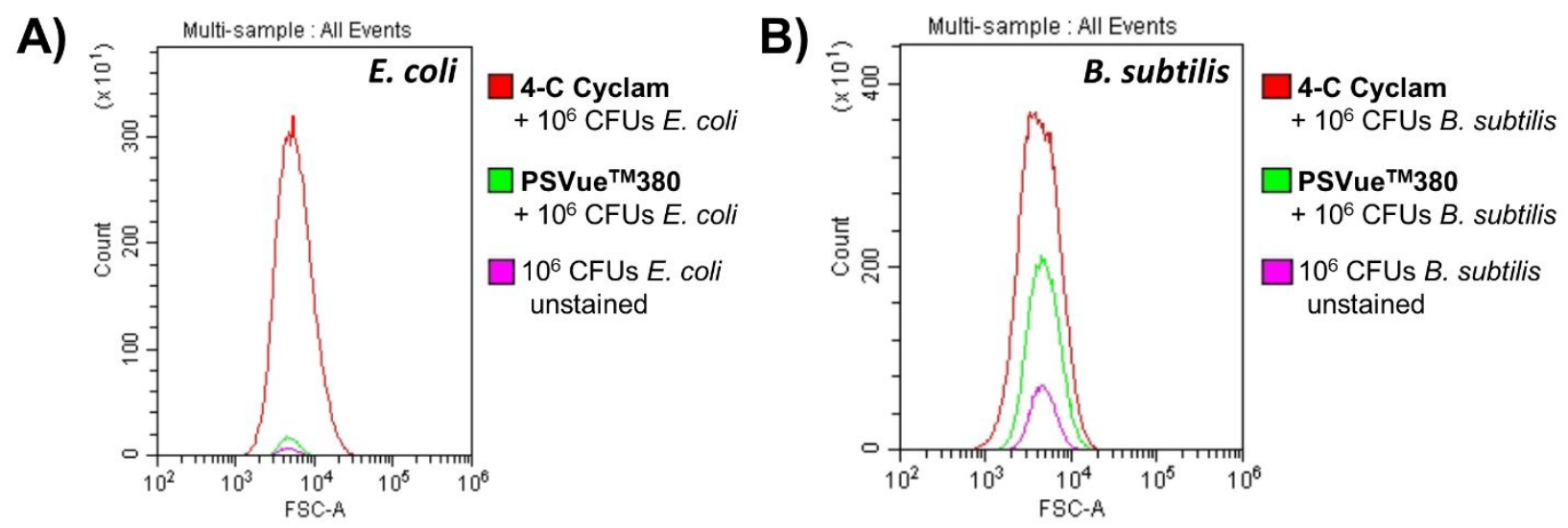


\section{S2.4 Determining the Mechanism of Action}

Figure S19. Fluorescence titrations of ProxyPhos sensors $(10 \mu \mathrm{M})$ and PSVue ${ }^{\mathrm{TM}} 380(1 \mu \mathrm{M})$ in response to isolates of LPS (E. coli O55:B5) and LTA (B. subtilis) (pH 7.5, 50 mM HEPES, 0.04 - 2.7\% DMSO, $75 \mathrm{mM} \mathrm{NaCl}$, ProxyPhos sensor $\lambda_{\text {ex } / \mathrm{em}}=350 / 476 \mathrm{~nm}, \mathrm{PSVue} \mathrm{T}^{\mathrm{TM}} 380 \lambda_{\mathrm{ex} / \mathrm{em}}=380 / 440 \mathrm{~nm}$ ). Error bars denote mean \pm S.D. $(n=3)$.
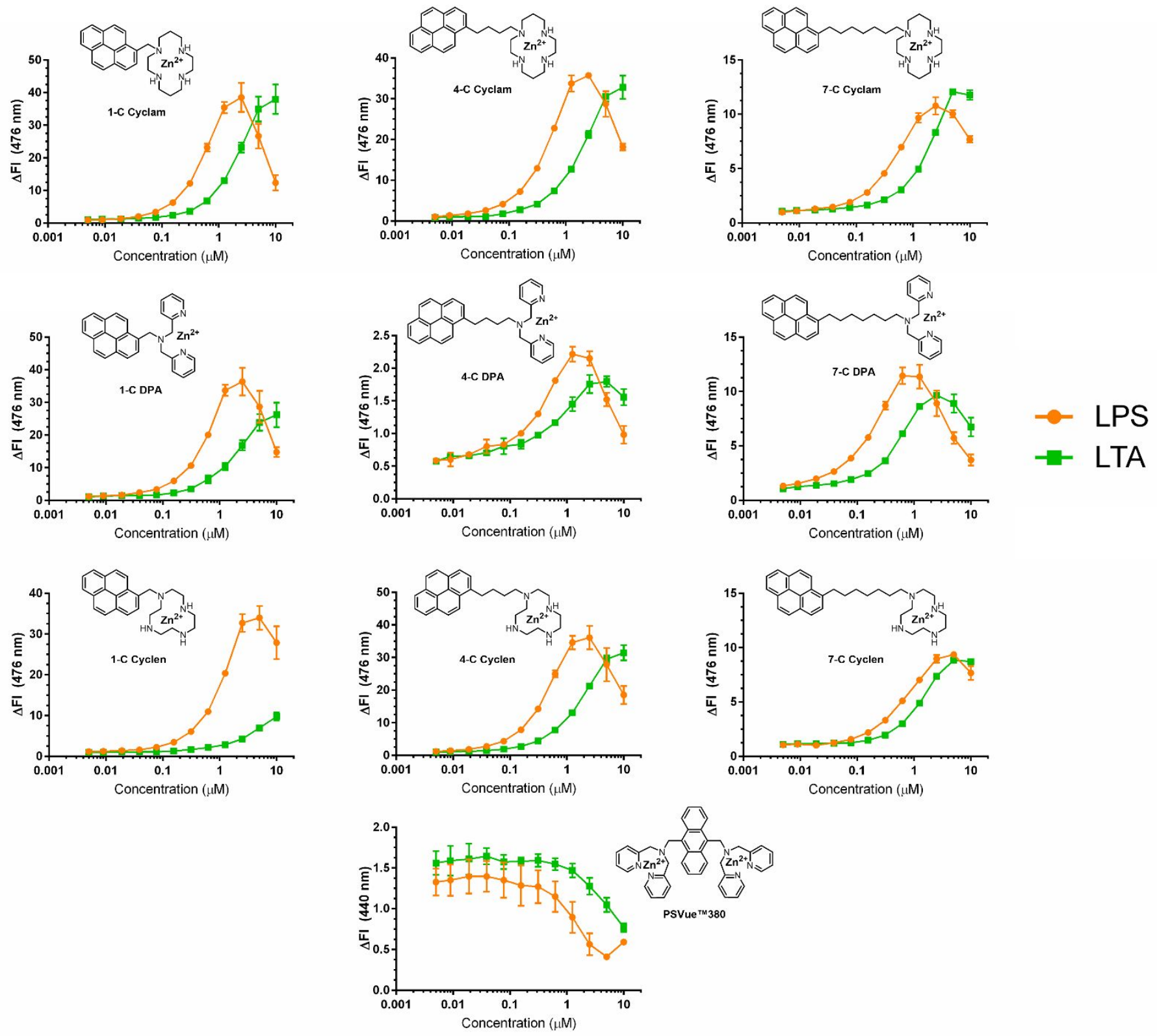
Figure S20. Fluorescence intensity results of ProxyPhos sensors in response to WT and mutant E. coli strains $\left(1.0 \times 10^{8} \mathrm{CFUs} / \mathrm{mL} ; 10 \mu \mathrm{M}\right.$ sensor; $\mathrm{pH}$ 7.5, $50 \mathrm{mM}$ HEPES, $75 \mathrm{mM} \mathrm{NaCl}, 0.04 \%$ DMSO, $\lambda_{\text {ex/em }}$ $=350 / 476 \mathrm{~nm})$. Error bars denote mean \pm S.D. $(n=3)$.
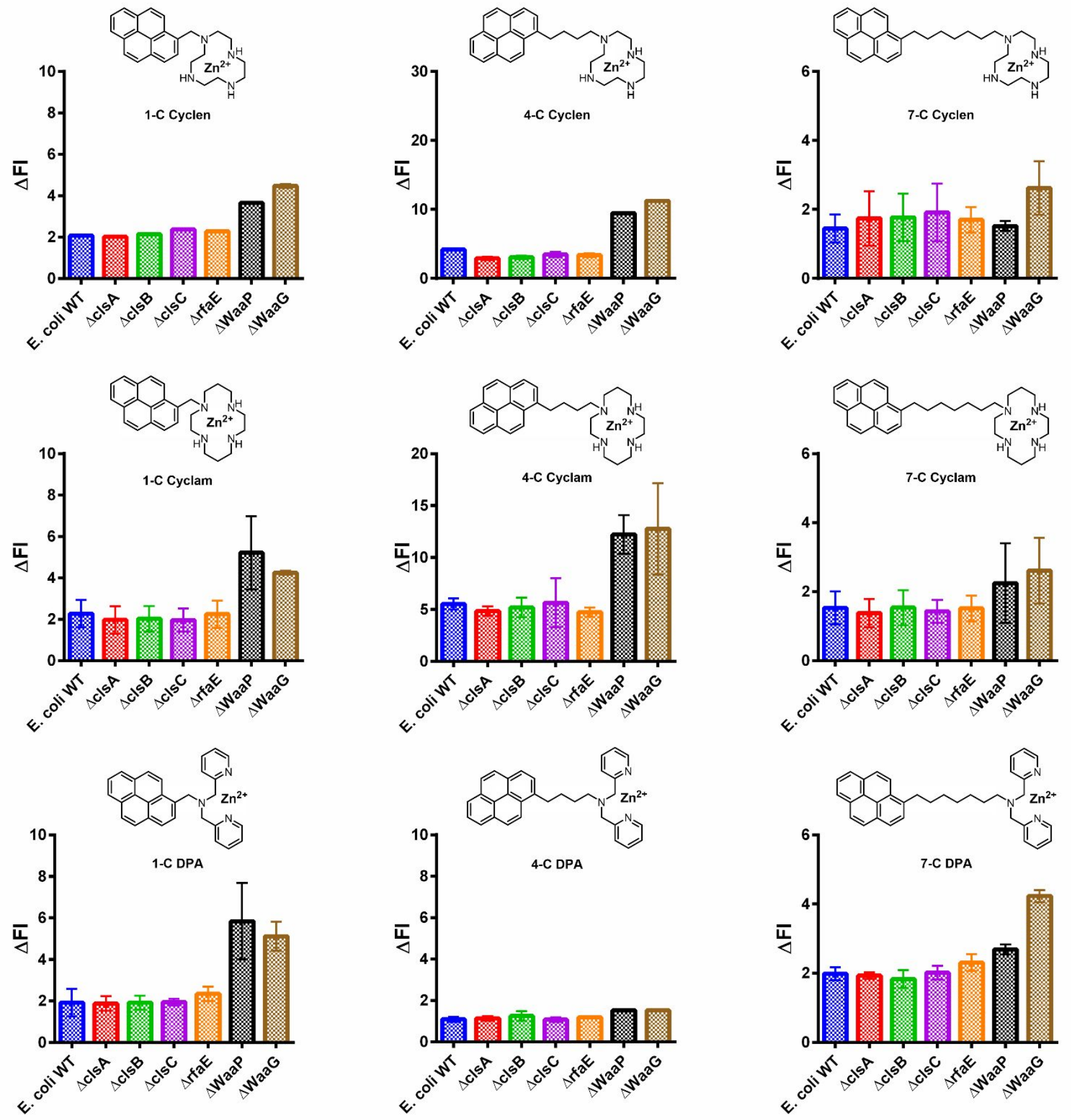
Figure S21. Fluorescence intensity results of ProxyPhos sensors in response to WT and mutant $B$. subtilis strains $\left(1.0 \times 10^{8} \mathrm{CFUs} / \mathrm{mL} ; 10 \mu \mathrm{M}\right.$ sensor; $\mathrm{pH}$ 7.5, $50 \mathrm{mM}$ HEPES, $75 \mathrm{mM} \mathrm{NaCl}, 0.04 \%$ DMSO, $\left.\lambda_{\text {ex } / \mathrm{em}}=350 / 476 \mathrm{~nm}\right)$. Error bars denote mean \pm S.D. $(n=3)$.
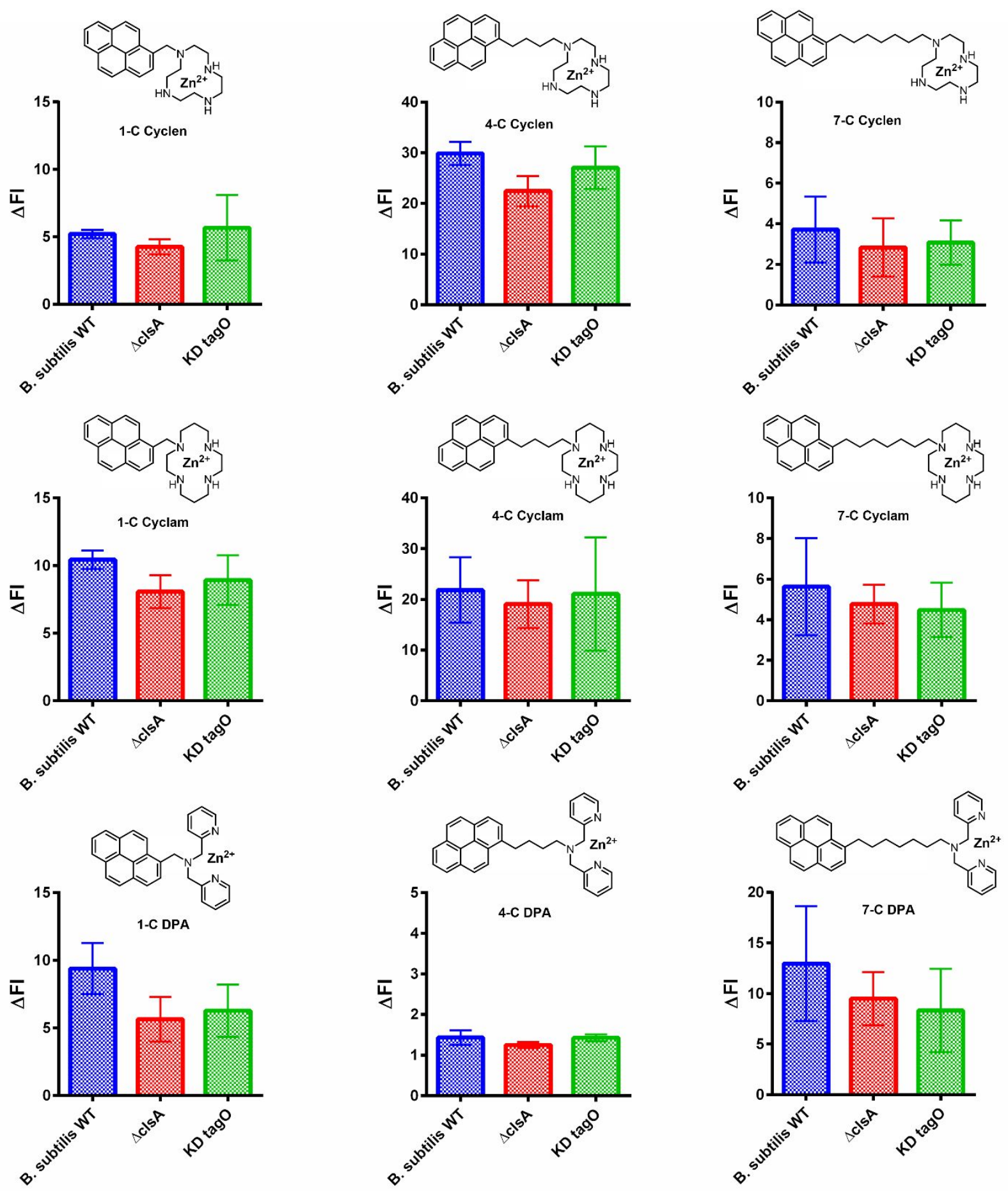
Figure S22. Fluorescence microscopy images of ProxyPhos sensor 4-C Cyclam $(10 \mu \mathrm{M})$ with different mutant/WT strains of A) E. coli and B) B. subtilis $\left(1.0 \times 10^{7} \mathrm{CFUs} / \mathrm{mL} ; 50 \mathrm{mM}\right.$ HEPES buffer, pH 7.5, $75 \mathrm{mM} \mathrm{NaCl}$ buffer, $0.04-2.7 \%$ DMSO; $\lambda_{\mathrm{ex}}=325 / 50 \mathrm{~nm}, \lambda_{\mathrm{em}}=447 / 60 \mathrm{~nm}$ ). Scale bars represent $5 \mu \mathrm{m}$.
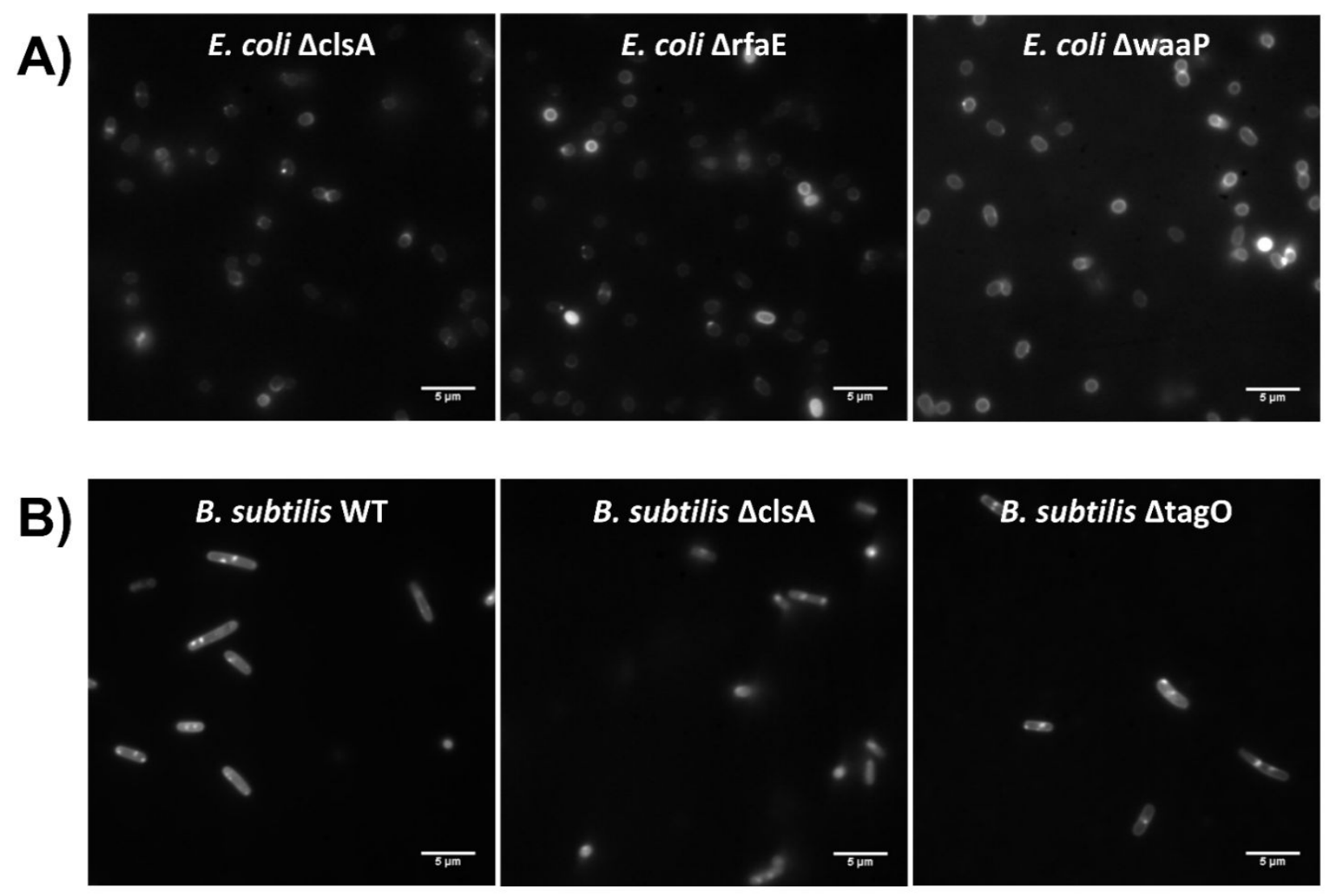
Figure S23. Fluorescence microscopy images of ProxyPhos sensor 4-C Cyclam $(10 \mu \mathrm{M})$ with different gram-positive strains $\left(\mathrm{OD}_{600}=0.1 ; 50 \mathrm{mM}\right.$ HEPES buffer, $\mathrm{pH}$ 7.5, $75 \mathrm{mM} \mathrm{NaCl}$ buffer, $0.04 \%$ DMSO; $\left.\lambda_{\mathrm{ex}}=325 / 50 \mathrm{~nm}, \lambda_{\mathrm{em}}=447 / 60 \mathrm{~nm}\right)$

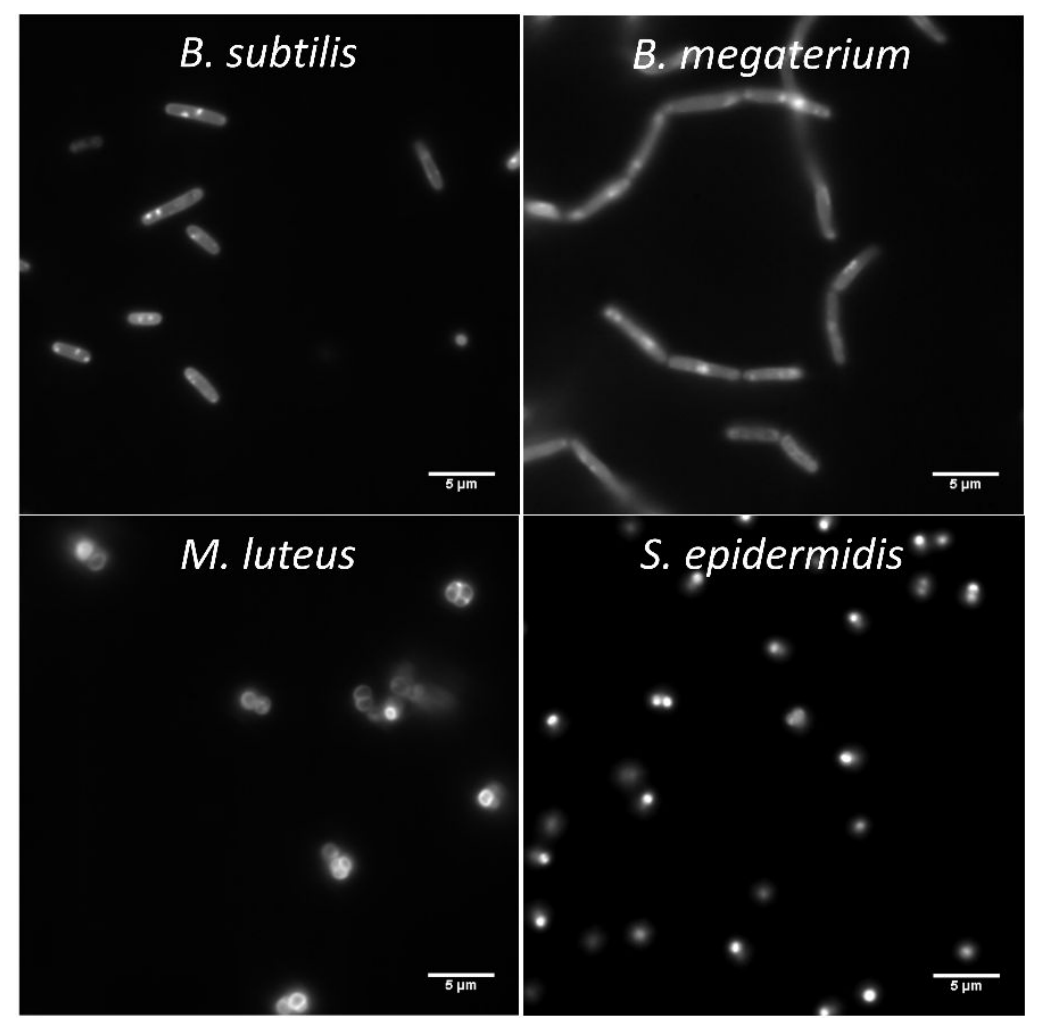


Figure S24. Pixel intensity analysis of ProxyPhos 4-C Cyclam in response to E. coli cells.
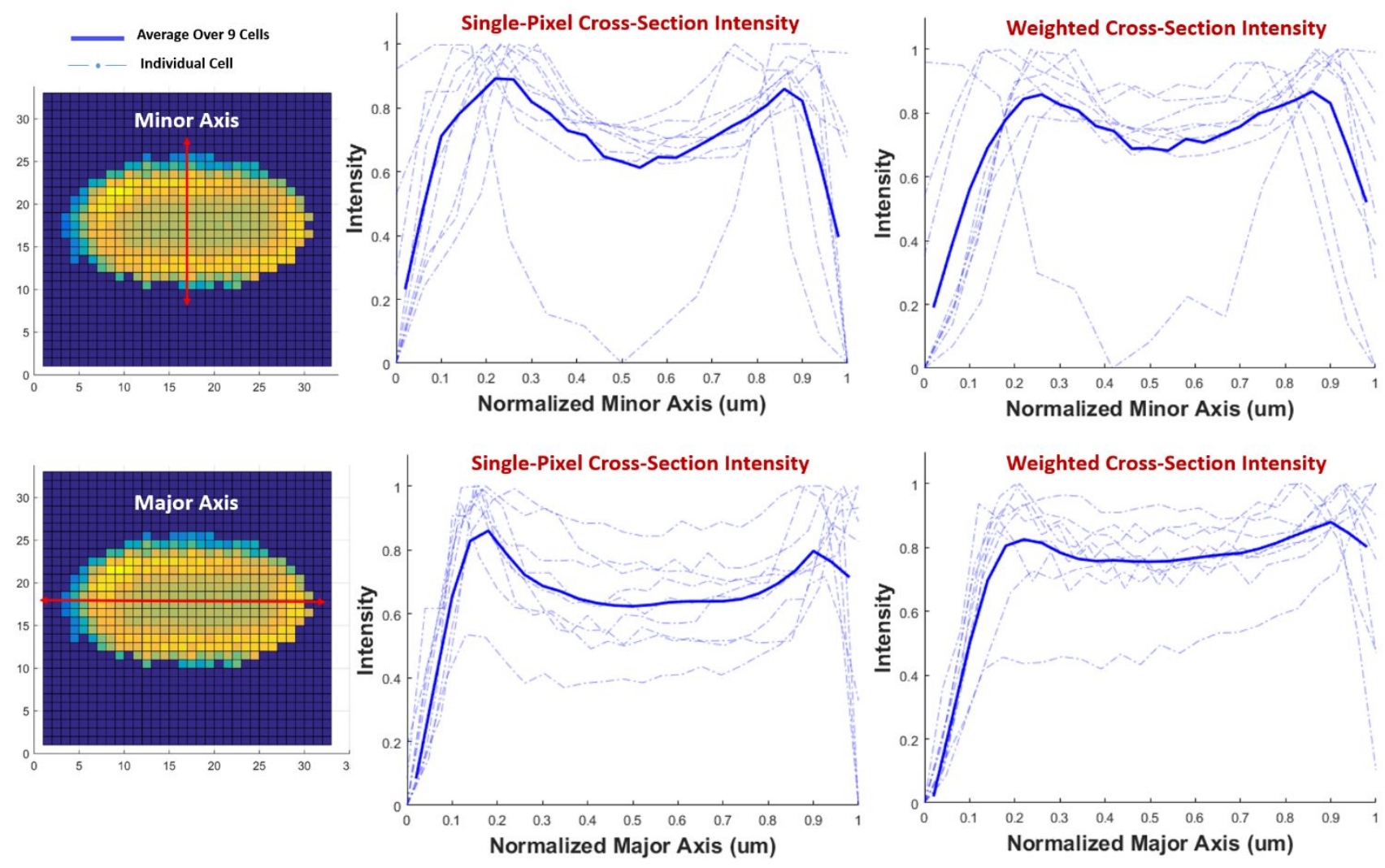
Figure S25. Pixel intensity analysis of two-colour imaging results of ProxyPhos 4-C Cyclam sensor and NucRed ${ }^{\mathrm{TM}}$ Live 647 stain in response to E. coli cells.
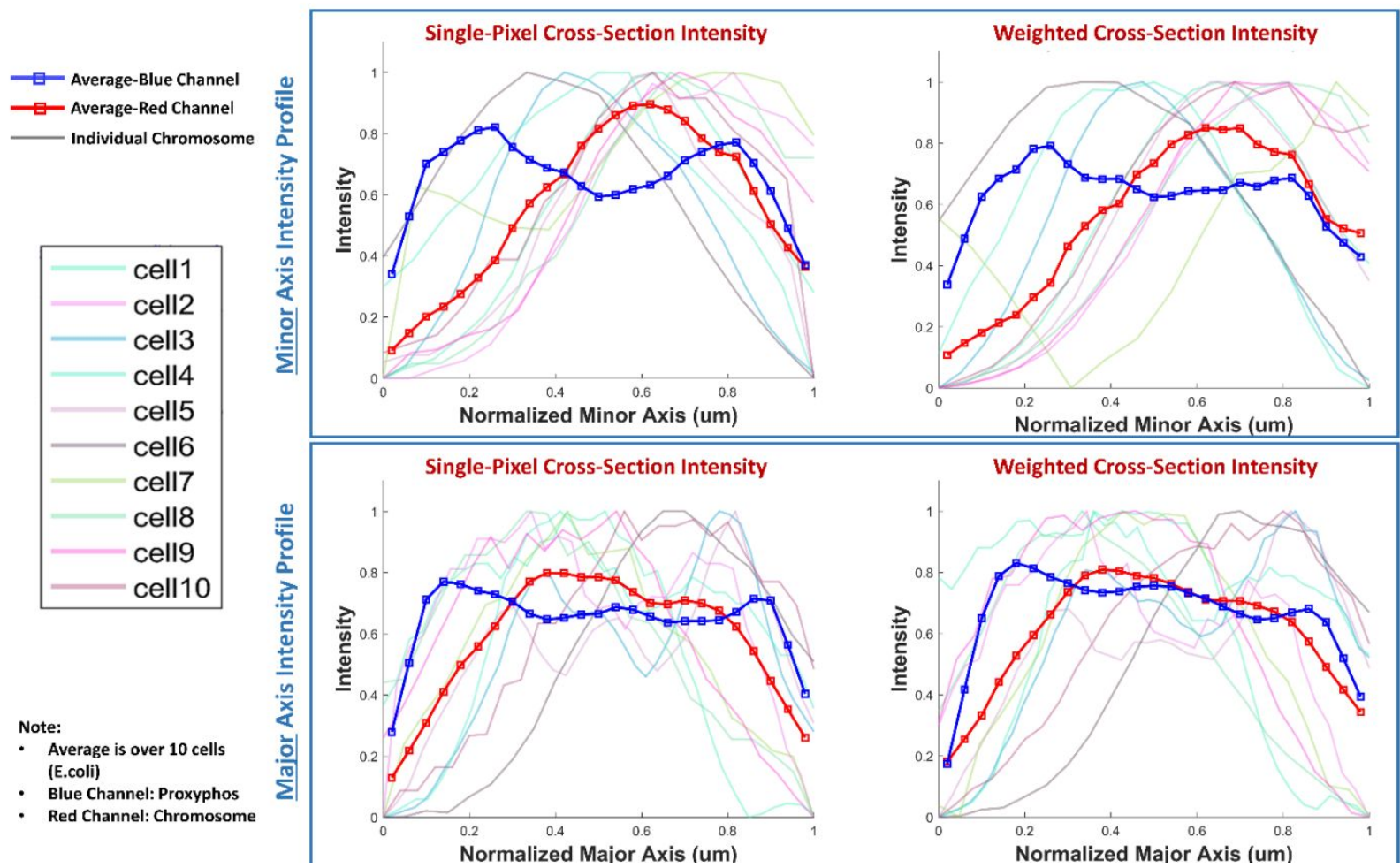

Figure S26. Fluorescence intensity of ProxyPhos sensors in response to $B$. subtilis $\left(1.0 \times 10^{8} \mathrm{CFUs}\right)$ grown in M9 media with or without L-alanine $(10 \mathrm{mM})$ to prevent sporulation (Assay buffer: $50 \mathrm{mM}$ HEPES, $\mathrm{pH} 7.5,75 \mathrm{mM} \mathrm{NaCl}, 0.04-2.9 \%$ DMSO; $\left.\lambda_{\mathrm{ex} / \mathrm{em}}=350 / 476 \mathrm{~nm}\right)$. Error bars denote mean \pm S.D. $(n=3)$.

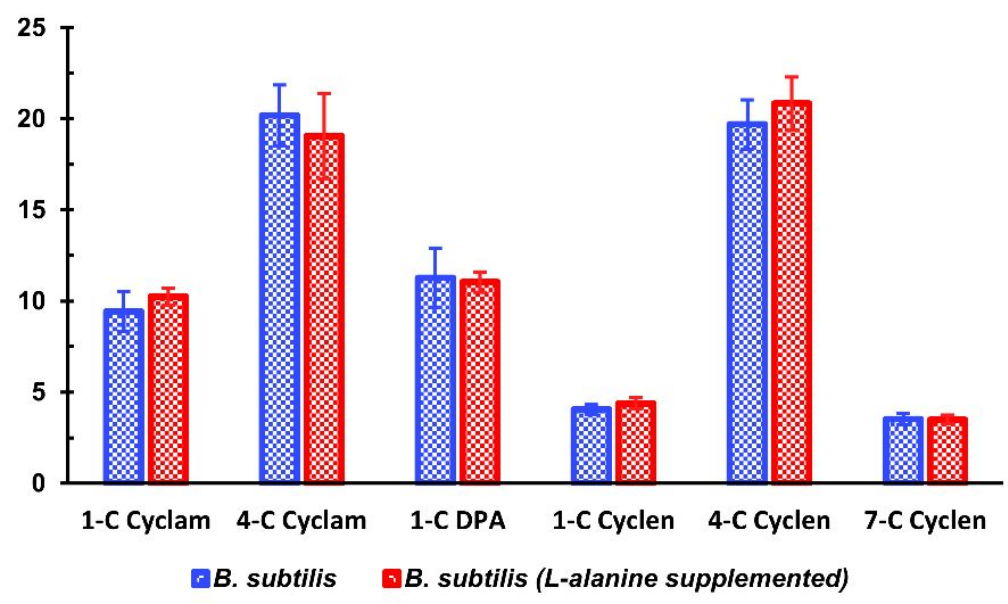


Figure S27. A) SDS-PAGE of E. coli and B. subtilis whole-cell lysates. Control proteins Controls are $\beta$ casein (24 kDa, proximally phosphorylated), ovalbumin (44 kDa mono-phosphorylated) and BSA (66 $\mathrm{kDa}$, non-phosphorylated). Cell lysates $\left(\mathrm{OD}_{600}=0.4\right)$ of $E$. coli and B. subtilis cells were loaded at full and half concentration. Gels were stained individually by: ProxyPhos 4-C Cyclen (proximal phosphorylation); Pro-Q Diamond gel (total phosphorylation); SYPRO Ruby gel (total protein). B) Western blot analysis of bacterial FtsZ for B. subtilis, imaged by secondary antibody HRP, compared to SDS-PAGE gels.
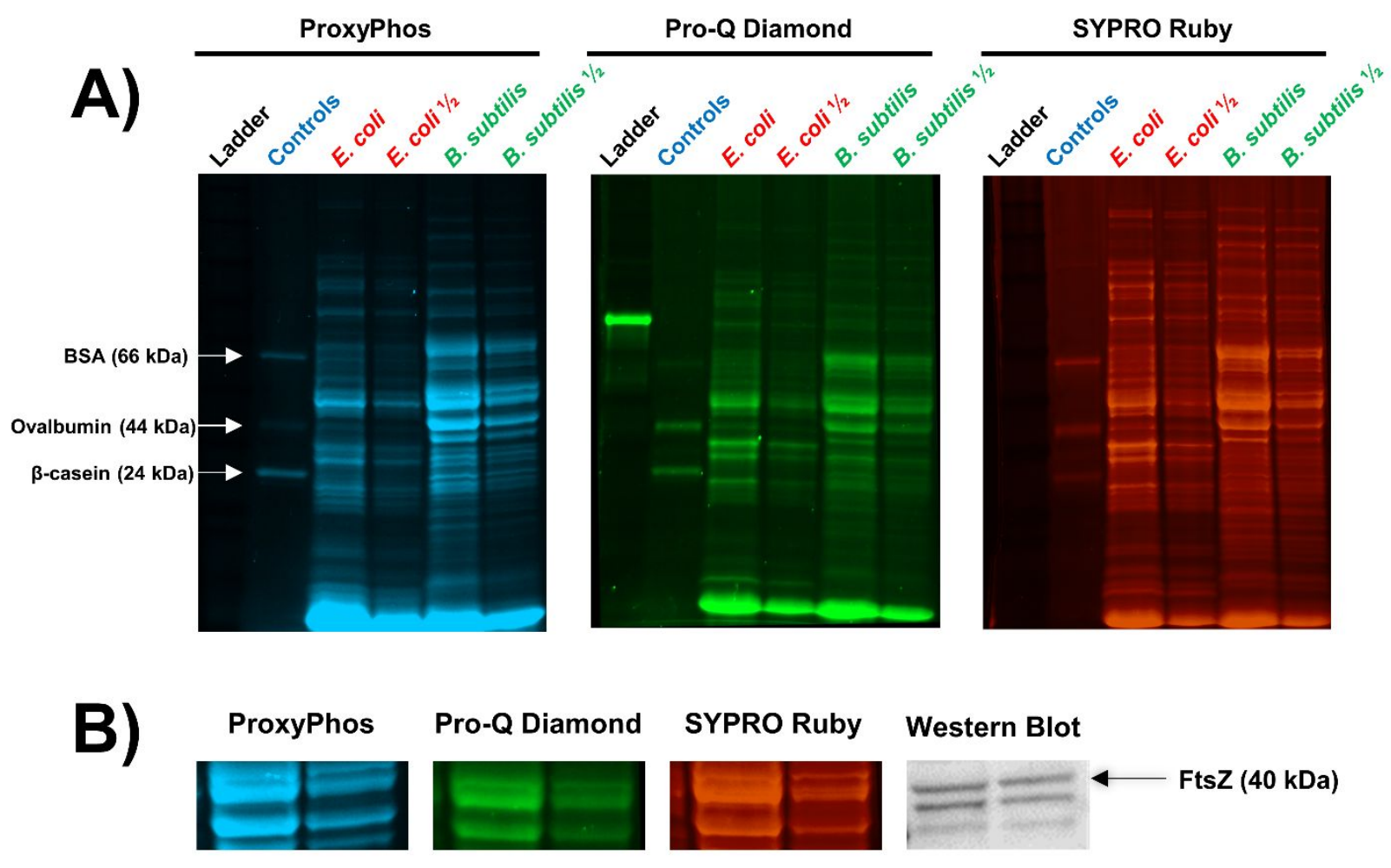


\section{S2.5 Selectivity to Bacteria over Mammalian Cells}

Figure S28. Selectivity of ProxyPhos sensor for bacteria (E. coli) over mammalian cells (MCF-7) by CLSM. A) Response of 4-C Cyclam $(40 \mu \mathrm{M})$. B) Propidium iodide live/dead stain $(3 \mu \mathrm{M})$. C) Brightfield. D) Merge $\left(1.0 \times 10^{4}\right.$ MCF-7 cells plated overnight; $4.0 \times 10^{8} \mathrm{CFUs} / \mathrm{mL}$ E. coli added; $50 \mathrm{mM}$ HEPES, $\mathrm{pH} 7.5,75 \mathrm{mM} \mathrm{NaCl}, 0.04 \%$ DMSO).

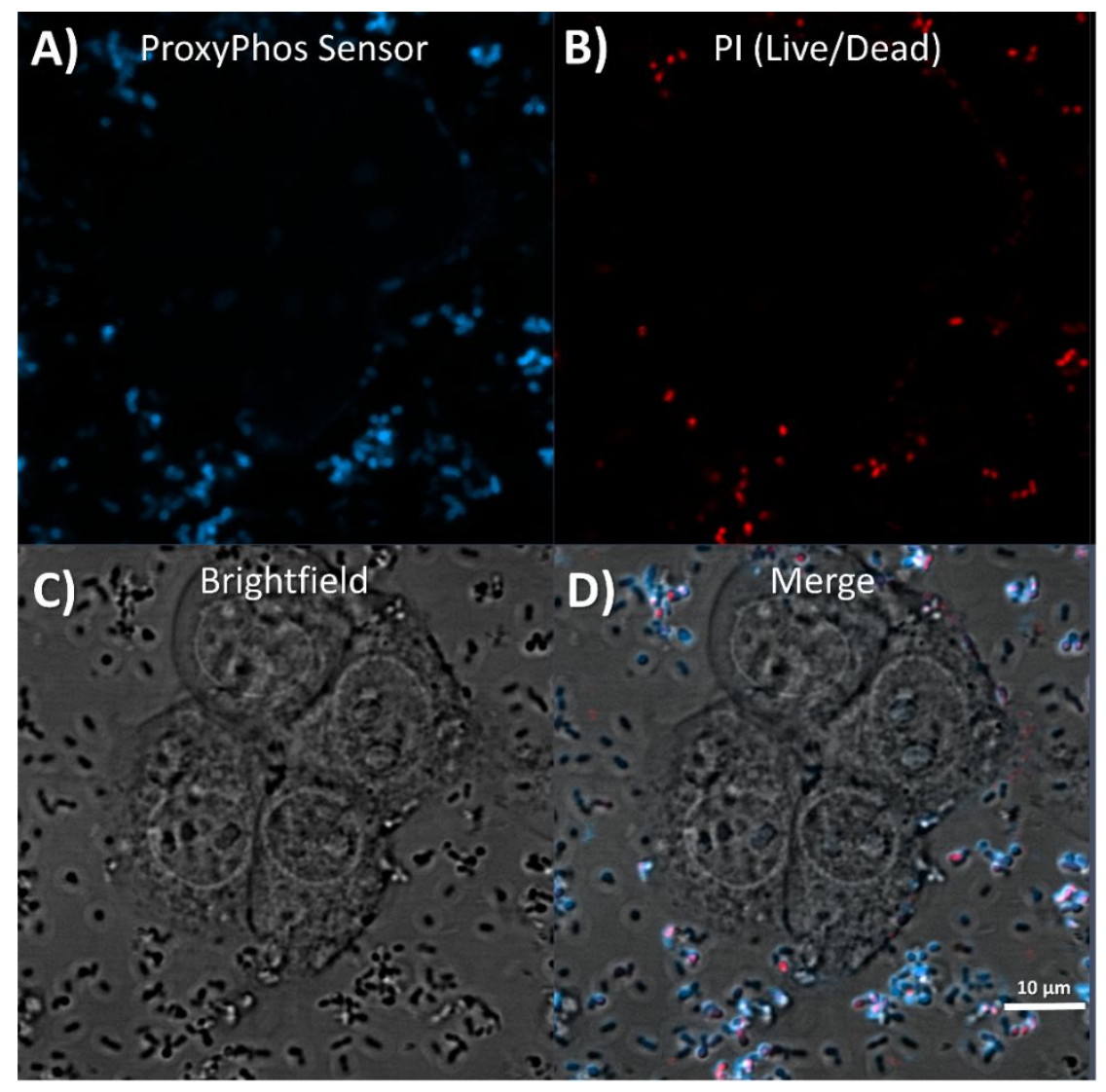


Figure S29. Response of ProxyPhos sensor towards mammalian cells (MCF-7) by CLSM. A) 4-C Cyclam stain $(40 \mu \mathrm{M})$. B) Propidium iodide live/dead stain $(3 \mu \mathrm{M})$. C) Brightfield. D) Merge $\left(1.0 \times 10^{4}\right.$ MCF-7 cells plated overnight; 50 mM HEPES, pH 7.5, 75 mM NaCl, 0.04\% DMSO).

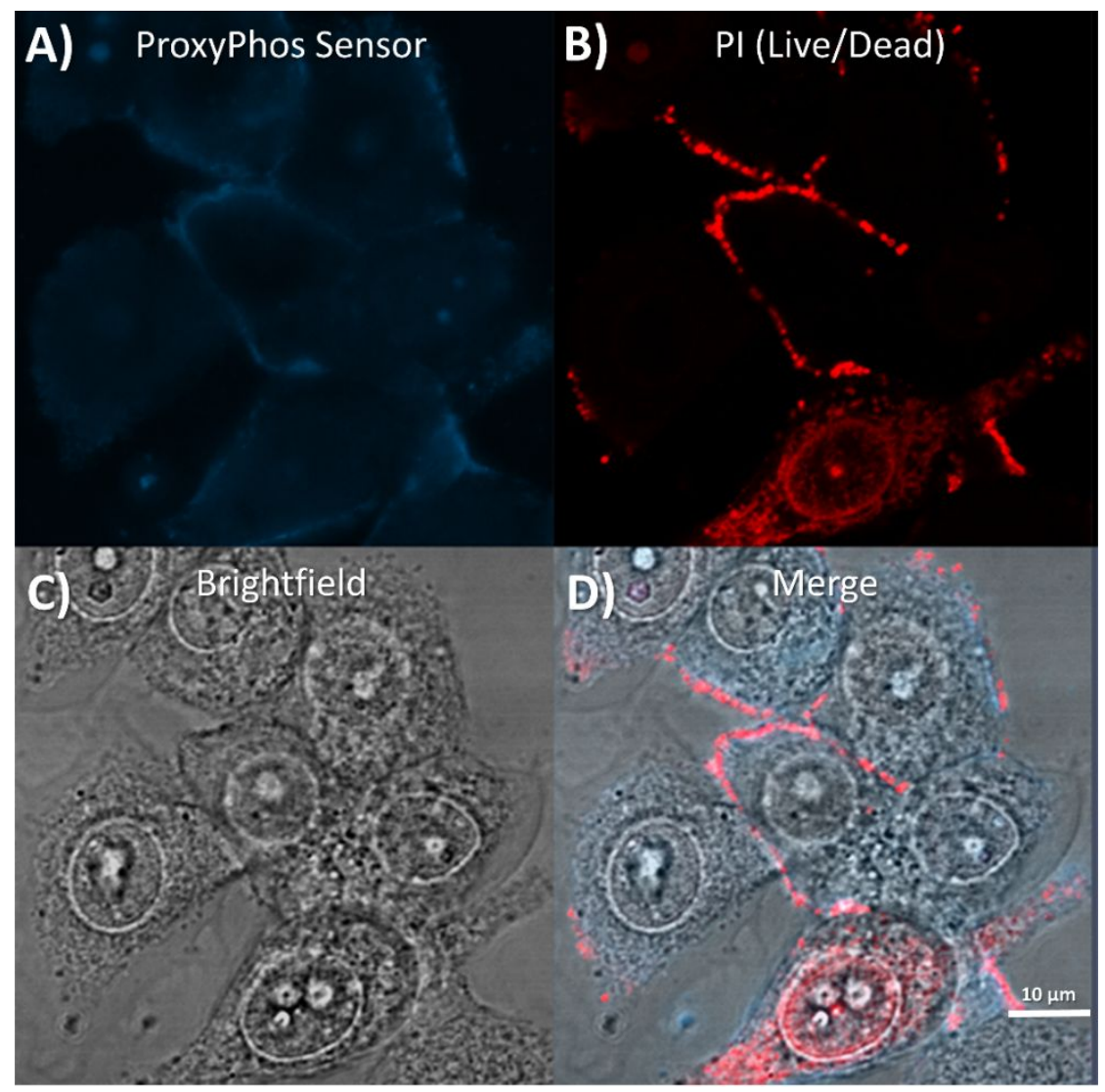


Figure S30. Response of ProxyPhos sensor towards bacteria (E. coli) by CLSM. A) 4-C Cyclam stain $(40 \mu \mathrm{M})$. B) Propidium iodide live/dead stain $(3 \mu \mathrm{M})$. C) Brightfield. D) Merge. $\left(4.0 \times 10^{8} \mathrm{CFUs} / \mathrm{mL} E\right.$. coli added; $50 \mathrm{mM}$ HEPES, pH 7.5, $75 \mathrm{mM} \mathrm{NaCl}, 0.04 \%$ DMSO).

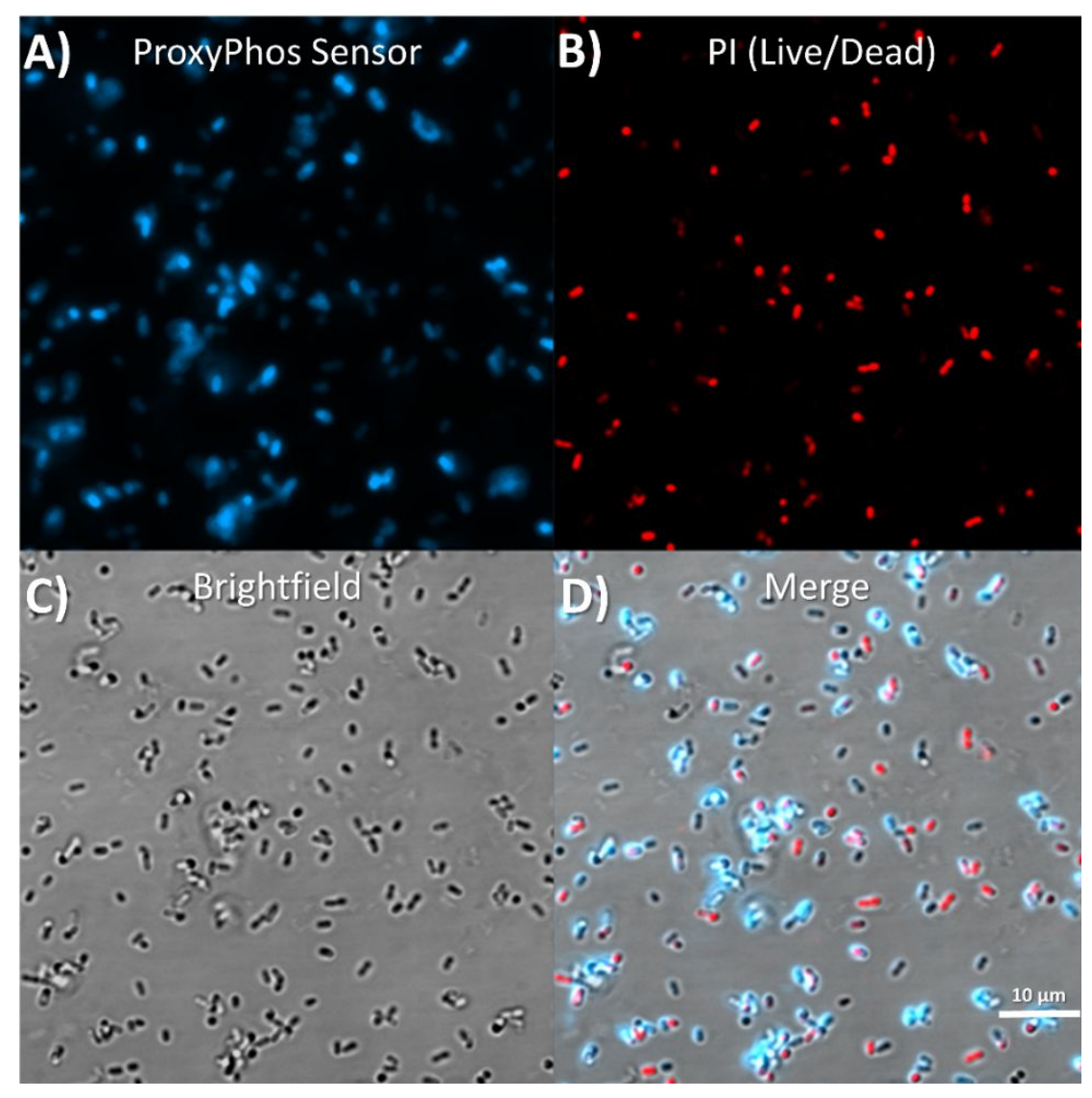


Figure S31. Fluorescence microscopy showing both pyrene emissions of 4-C Cyclam towards mammalian cells (MCF-7). A) Monomer emission (387 nm bandpass). B) Excimer (447 nm bandpass). C) Brightfield. D) Merge. (40 $\mu \mathrm{M}$ sensor, $50 \mathrm{mM}$ HEPES, $\mathrm{pH}$ 7.5, $75 \mathrm{mM} \mathrm{NaCl}, 0.04 \%$ DMSO).

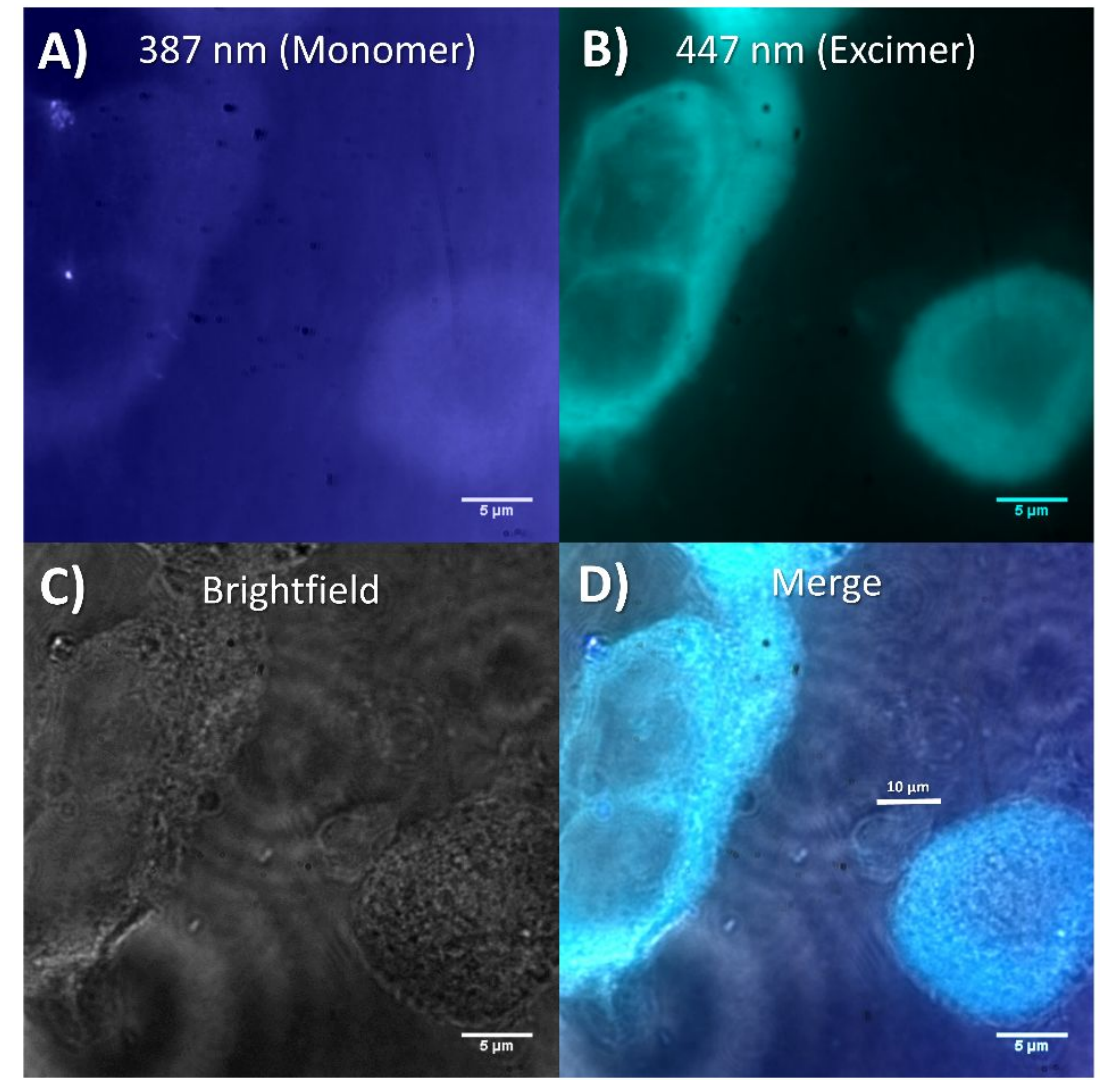




\section{S2.6 Detection of Bacterial Cells in Physiological Fluids}

Figure S32. Representative flow cytometry response of 4-C Cyclen $(10 \mu \mathrm{M})$ with or without bacterial cells $\left(10^{4}\right.$ CFUs injected) in CSF (DAPI filter $\lambda_{\text {ex } / \mathrm{em}}=405 \mathrm{~nm} / 450 \mathrm{~nm} ; 50 \mathrm{mM}$ HEPES, $\mathrm{pH} 7.5,75 \mathrm{mM}$ $\mathrm{NaCl}$ ). Top: Cell counts vs DAPI-A; Middle: SSC-A vs FSC-A; Bottom: SSC-A vs DAPI-A. A) CSF only; B) E. coli in CSF; C) B. subtilis in CSF; D) CSF only after wash; E) E. coli in CSF after wash; F) B. subtilis in CSF after wash.

\section{Before Wash}

A)
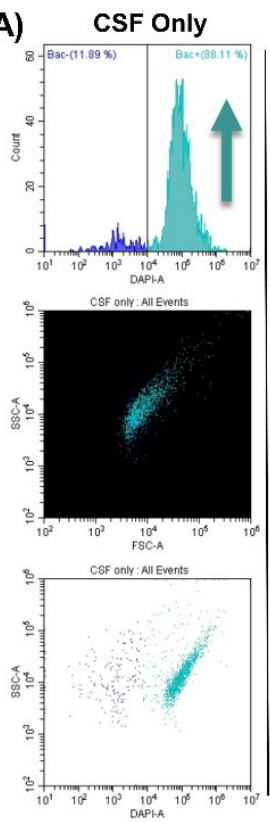

B) $10^{4} \mathrm{E}$. coli cells
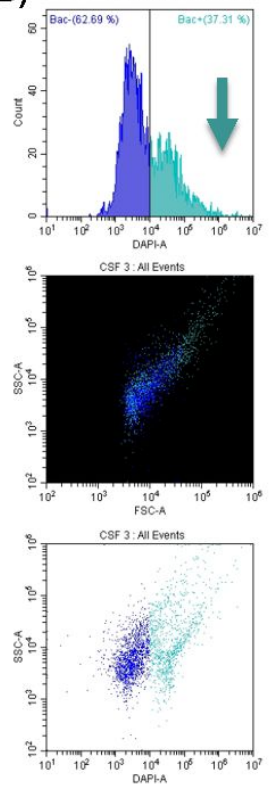

C) $10^{4}$ B. subtilis cells
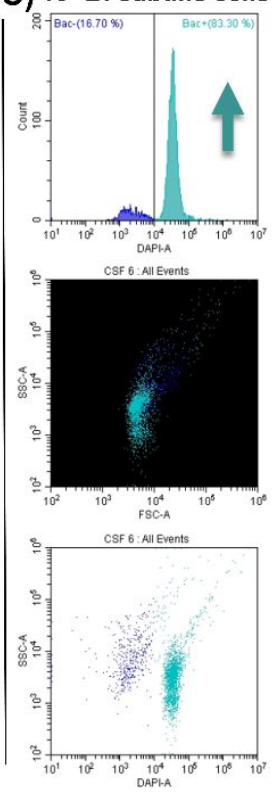

After Wash
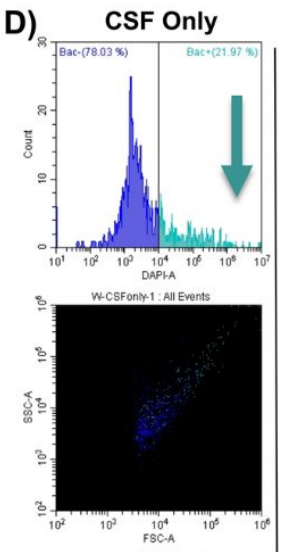

E) $10^{4}$ E. coli cells

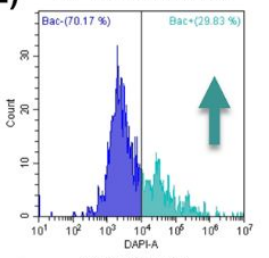

F) $10^{4}$ B. subtilis cells
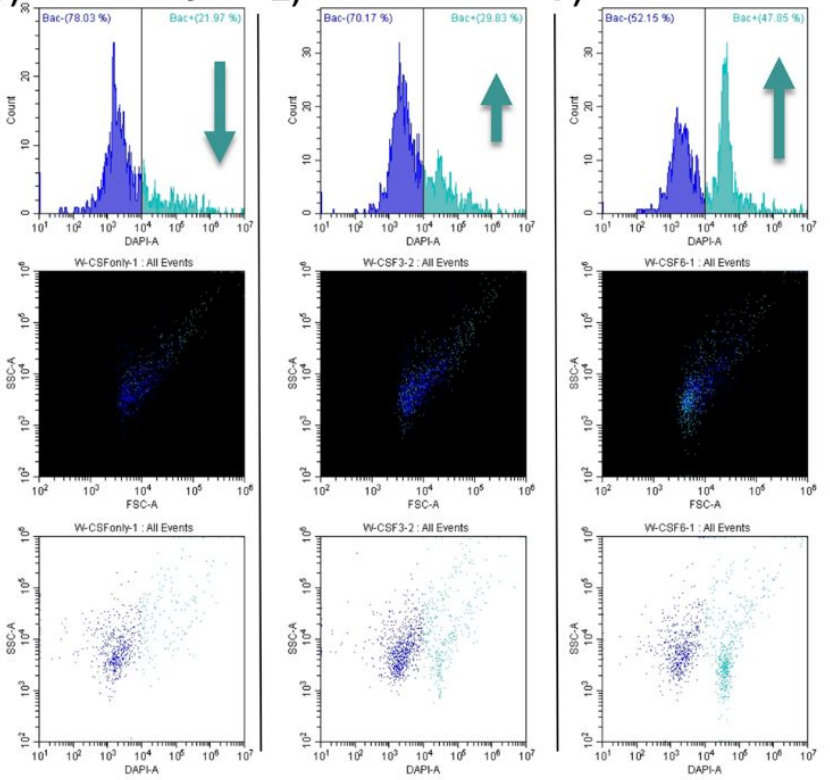

\section{S2.7 Supplementary Videos}

Supplementary Video 1. Fluorescence microscopy in real-time of 4-C Cyclam $(10 \mu \mathrm{M})$ localizing on live B. subtilis cells. A $30 \mu \mathrm{L}$ droplet of bacterial cells were placed on a PLL coated coverslip and allowed to rest for 5 min prior to video. With the UV excitation active $\left(\lambda_{\mathrm{ex}}=320 / 50 \mathrm{~nm}, \lambda_{\mathrm{em}}=447 / 60 \mathrm{~nm}\right)$, a 30 $\mu \mathrm{L}$ droplet of sensor ( $20 \mu \mathrm{M}, 50 \mathrm{mM}$ HEPES buffer, $\mathrm{pH} 7.5)$ was added at time 0 (137x magnification, $30 \mathrm{~ms}$ exposure).

Supplementary Video 2. Fluorescence microscopy in real-time of 1-C Cyclen $(10 \mu \mathrm{M})$ localizing on live E. coli cells. A $30 \mu \mathrm{L}$ droplet of bacterial cells were placed on a PLL coated coverslip and allowed to rest for 5 min prior to video. With the UV excitation active $\left(\lambda_{\text {ex }}=320 / 50 \mathrm{~nm}, \lambda_{\mathrm{em}}=447 / 60 \mathrm{~nm}\right)$, a $30 \mu \mathrm{L}$ droplet of sensor $(20 \mu \mathrm{M}, 50 \mathrm{mM}$ HEPES buffer, $\mathrm{pH} 7.5)$ was added at time 0 (137x magnification, $30 \mathrm{~ms}$ exposure). 


\section{S3. Supplementary Notes}

Supplementary Note 1. List of bacterial strains

Gram-negative:

- Escherichia coli K-12 BW25113

- Escherichia coli K-12 BW25113 $\Delta$ waaG

- Escherichia coli K-12 BW25113 $\Delta$ waaP

- Escherichia coli K-12 BW25113 $\Delta \mathrm{rfaE}$

- Escherichia coli K-12 BW25113 $\Delta \mathrm{clsA} / \mathrm{B} / \mathrm{C}$

Gram-positive:

- Bacillus subtilus

- Bacillus subtilus $\Delta$ tagO

- Bacillus subtilus $\Delta \mathrm{clsA}$

- Bacillus megaterium de Bary (ATCC $\left.{ }^{\circledR} 14581^{\mathrm{TM}}\right)$

- Staphylococcus epidermidis (Winslow and Winslow) Evans (ATCC® CRM-12228 ${ }^{\mathrm{TM}}$ )

- Micrococcus luteus

S4. Supplementary Tables

Supplementary Table 1. DLS Results with ProxyPhos sensors.

\begin{tabular}{c|c} 
Sample & Z-average (d.nm) \\
\hline Buffer & $66.2 \pm 44.0$ \\
1-C Cyclen & $173.9 \pm 61.4$ \\
4-C Cyclen & $249.1 \pm 37.5$ \\
7-C Cyclen & $5117.3 \pm 2416.8$ \\
1-C Cyclam & $288.3 \pm 60.4$ \\
4-C Cyclam & $279.5 \pm 40.9$ \\
7-C Cyclam & $658.4 \pm 69.9$ \\
1-C DPA & $176.6 \pm 12.7$
\end{tabular}



4-C DPA
$610.3 \pm 173.6$
7-C DPA
$472.6 \pm 18.9$

\section{S5. Compound synthesis protocols and characterization}

\section{S5.1 General Information}

All reagents and solvents were purchased from Sigma-Aldrich. Silica gel chromatography was performed with Silica Gel 60 (particle size 40-63 $\mu \mathrm{m}$ ) obtained from EMD. Thin layer chromatrography (TLC) plates were obtained from EMD. Care was taken to minimize exposure of compounds to light during synthesis, storage and testing. Molecular sieves were activated by heating to $125^{\circ} \mathrm{C}$ under vacuum overnight.

NMR spectra were recorded on a Bruker Avance III spectrometer at $23{ }^{\circ} \mathrm{C}$, operating at $400 \mathrm{MHz}$ for ${ }^{1} \mathrm{H}$ NMR and $100 \mathrm{MHz}$ for ${ }^{13} \mathrm{C}$ NMR spectroscopy in either $\mathrm{CDCl}_{3}$ or $\mathrm{CD}_{3} \mathrm{OD}$. Chemical shifts $(\delta)$ are reported in parts per million (ppm) referenced to residual isotopic solvent. Coupling constants $(\mathrm{J})$ are reported in Hertz (Hz). High Resolution Mass Spectrometry (HRMS) was performed on an AB/Sciex QStar mass spectrometer with an ESI source, MS/MS and accurate mass capabilities, associated with an Agilent 1100 capillary LC system. Low Resolution Mass Spectrometry (LRMS) was performed on a Waters Micromass ZQ model MM1.

Purifications by prep-HPLC were performed using Atlantis Prep T3 $10 \mu \mathrm{m} \mathrm{C18} \mathrm{(2)} 250$ x $19 \mathrm{~mm}$ column run at $20 \mathrm{~mL} / \mathrm{min}$ (preparative) using gradient mixtures of water with $0.1 \%$ formic acid and 10:1 acetonitrile/water with $0.1 \%$ formic acid. The crude mixture was injected as a solution $4: 10.1 \%$ formic acid in water/acetonitrile. Analysis by rpHPLC was performed using a Phenomex Luna 5 um C18 (2) 150 x $4.60 \mathrm{~mm}$ column run at $1.2 \mathrm{~mL} / \mathrm{min}$ (analytical) using gradient mixtures of $0.1 \%$ formic acid in water and acetonitrile. Condition (A) started with $0.1 \%$ formic acid water and $2 \%$ acetonitrile with a gradient going to $100 \%$ acetonitrile over $30 \mathrm{~min}$, followed by $5 \mathrm{~min}$ at 100\% acetonitrile. Condition (B) started with $0.1 \%$ formic acid in water with $2 \%$ acetonitrile with a gradient going to $100 \%$ acetonitrile over 50 min, followed by $5 \mathrm{~min}$ at $100 \%$ acetonitrile.

All final metal-ligand complexes were prepared in a water/acetonitrile mixture with 1:1 zinc triflate and lyophylized. 1-C Cyclen was synthesized by methods described previously. ${ }^{2}$ 4-C Cyclen, 1C Cyclam, 4-C Cyclam, 1-C DPA, 4-C DPA were synthesized by methods described previously. ${ }^{1}$ PSVue ${ }^{\text {TM380 }}$ was synthesized by methods described previously. ${ }^{5}$ 


\section{S5.2 Synthesis of 7-C Chemosensors}

\section{Pyrene precursors}

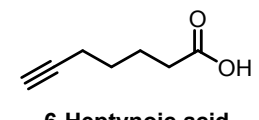

6-Heptynoic acid

1) $\mathrm{H}_{2}, \mathrm{Pd} / \mathrm{C}, \mathrm{THF}, \mathrm{rt}$

2) $\mathrm{LiAlH}_{4}, \mathrm{THF}, 0^{\circ} \mathrm{C}$
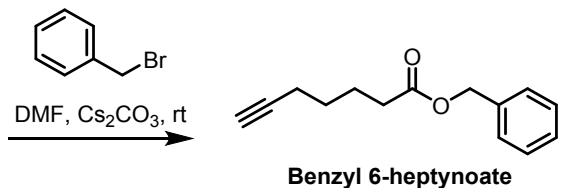

Benzyl 6-heptynoate
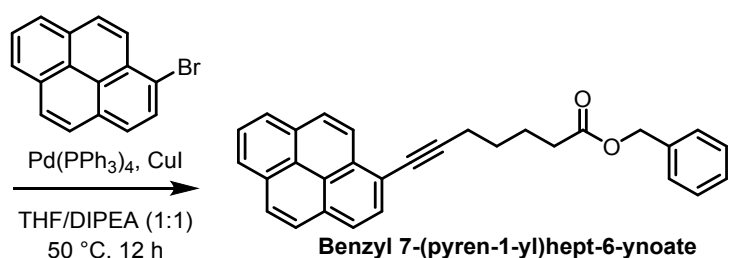

Benzyl 7-(pyren-1-yl)hept-6-ynoate

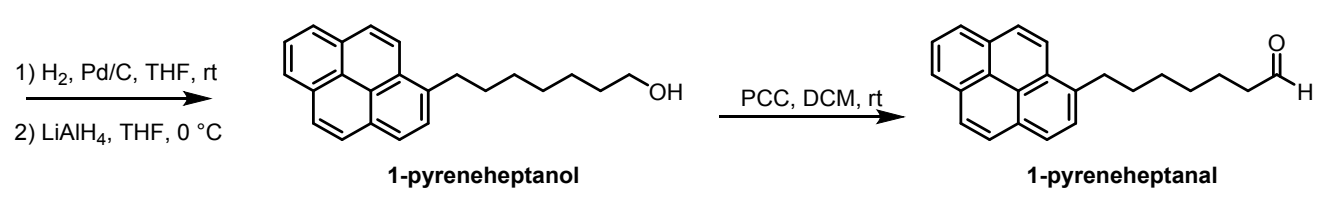

\section{Benzyl 6-heptynoate}

To a stirred solution of 6-heptynoic acid (300 mg, $2.14 \mathrm{mmol})$ in $11 \mathrm{~mL}$ dimethylformamide (DMF), cesium carbonate $(767 \mathrm{mg}, 2.35 \mathrm{mmol}$ ) was added and stirred for 10 minutes. To this solution, benzyl bromide (403 mg, $2.35 \mathrm{mmol}$ ) was added dropwise and left to react overnight at ambient temperature. The reaction mixture was concentrated down in vacuo. The residue was taken up in ethyl acetate and washed with $1 \mathrm{M} \mathrm{HCl}$. The aqueous layer was extracted three times with ethyl acetate and the combined organic layers were dried with $\mathrm{MgSO}_{4}$. The organic layer was concentrated in vacuo. The crude material was purified by flash column chromatography with $5 \%$ ethyl acetate/hexanes to afford the product ( $428 \mathrm{mg}$, $88 \%$ yield). ${ }^{1} \mathrm{H}$ NMR (400 MHz, $\left.\mathrm{CDCl}_{3}\right) \delta 7.43-7.29$ (m, 5H), 5.14 (s, 2H), 2.40 (t, $\left.J=7.5 \mathrm{~Hz}, 2 \mathrm{H}\right), 2.22$ (m, 2H), $2.00(\mathrm{t}, J=2.5 \mathrm{~Hz}, 1 \mathrm{H}), 1.84-1.74(\mathrm{~m}, 2 \mathrm{H}), 1.64-1.51(\mathrm{~m}, 2 \mathrm{H})$.

\section{Benzyl 7-(pyren-1-yl)hept-6-ynoate}

To a solution of anhydrous THF/DIPEA (1:1) was added 1-bromopyrene (500 mg, $1.71 \mathrm{mmol}$ ), benzyl 6heptynoate (428 mg, $1.88 \mathrm{mmol})$, Pd tetrakis(triphenylphosphine) (98 mg, $0.0854 \mathrm{mmol})$ and $\mathrm{CuI}(33.2$ $\mathrm{mg}, 0.171 \mathrm{mmol})$. The reaction mixture was purged with nitrogen and stirred overnight hours at $50^{\circ} \mathrm{C}$. The solution was filtered, and the filtrate was extracted three times with ethyl acetate and saturated $\mathrm{NH}_{4} \mathrm{Cl}$ solution. The organic layer was washed with brine, dried with anhydrous $\mathrm{MgSO} 4$, and evaporated under reduced pressure to yield a brown oil. The crude material was purified by flash column chromatography with $10 \%$ ethyl acetate in hexanes to give the product as an oil $\left(568 \mathrm{mg}, 80 \%\right.$ yield) ${ }^{1} \mathrm{H}$ NMR ( $400 \mathrm{MHz}$, $\left.\mathrm{CDCl}_{3}\right) \delta 8.58(\mathrm{~d}, J=9.0 \mathrm{~Hz}, 1 \mathrm{H}), 8.26-7.99(\mathrm{~m}, 8 \mathrm{H}), 7.44-7.29(\mathrm{~m}, 5 \mathrm{H}), 5.19(\mathrm{~s}, 2 \mathrm{H}), 2.72(\mathrm{t}, J=7.0$ 
$\mathrm{Hz}, 2 \mathrm{H}), 2.55(\mathrm{t}, J=7.5 \mathrm{~Hz}, 2 \mathrm{H}), 2.08-1.95(\mathrm{~m}, 2 \mathrm{H}), 1.92-1.77(\mathrm{~m}, 2 \mathrm{H}) .{ }^{13} \mathrm{C} \mathrm{NMR}\left(100 \mathrm{MHz}, \mathrm{CDCl}_{3}\right)$ $\delta 173.3,136.1,131.9,131.3,131.1,130.7,129.7128 .6,128.2,128.1,127.8,127.3,126.1,125.6,125.4$, $125.3,124.5,124.44,124.40,118.7,95.5,80.1,66.3,33.9,28.4,24.4,19.7$. LRMS (ESI+) m/z calc'd for $\mathrm{C}_{30} \mathrm{H}_{24} \mathrm{O}_{2} \mathrm{Na}^{+}[\mathrm{M}+\mathrm{Na}]^{+} 439.17$, found 439.34 .

\section{1-pyreneheptanol}

Benzyl 7-(pyren-1-yl)hept-6-ynoate (535 mg, $1.28 \mathrm{mmol}$ ) was dissolved in THF and 10\% Pd/C (13.7 mg, $0.128 \mathrm{mmol}$ ) was added. The flask was purged first with nitrogen, and then purged three times with hydrogen. After stirring at room temperature overnight, the reaction was filtered through celite, washed with ethyl acetate, and concentrated in vacuo to give a crude white solid. Subsequently, the crude material was dissolved in anhydrous THF $(13 \mathrm{~mL})$ and cooled to $0^{\circ} \mathrm{C}$ in an ice bath. To this solution was added 1.0 $\mathrm{M} \mathrm{LiAlH}_{4}$ THF solution $(2.7 \mathrm{~mL}, 2.7 \mathrm{mmol})$, and the reaction mixture was stirred under nitrogen for 2 hours before being quenched by the slow addition of $\mathrm{NH}_{4} \mathrm{Cl}$. The solution was washed with $1 \mathrm{M} \mathrm{HCl}$, dried over MgSO4, and concentrated by evaporation. The crude material was purified by flash column chromatography with 20-40\% ethyl acetate in hexanes to give the product (365 mg, 90\%); ${ }^{1} \mathrm{H}$ NMR (400 $\left.\mathrm{MHz} \mathrm{CDCl}_{3}\right) \delta 8.31(\mathrm{~d}, J=9.0 \mathrm{~Hz}, 1 \mathrm{H}), 8.23-7.97(\mathrm{~m}, 7 \mathrm{H}), 7.89(\mathrm{~d}, J=8.0 \mathrm{~Hz}, 1 \mathrm{H}), 3.65(\mathrm{t}, J=6.5$ $\mathrm{Hz}, 2 \mathrm{H}), 3.40-3.29(\mathrm{~m}, 2 \mathrm{H}), 1.95-1.83(\mathrm{~m}, 2 \mathrm{H}), 1.65-1.56(\mathrm{~m}, 2 \mathrm{H}), 1.56-1.48(\mathrm{~m}, 2 \mathrm{H}), 1.41(\mathrm{~m}$, 4H). ${ }^{13} \mathrm{C} \mathrm{NMR}\left(100 \mathrm{MHz}, \mathrm{CDCl}_{3}\right) \delta 137.2,131.5,131.0,129.7,128.6,127.6,127.5,127.1,126.5,125.8$, $125.12,125.10,124.81,124.80,124.6,123.5,63.0,33.6,32.8,31.9,29.8,29.4,25.8$.

\section{1-pyreneheptanal}

Pyridinium chlorochoromate (307 mg, $1.42 \mathrm{mmol}$ ) was suspended in 4.75 mL DCM and 1-pyreneheptanol (300 mg, $0.948 \mathrm{mmol}$ ) in $4.75 \mathrm{~mL}$ DCM was rapidly added at room temperature. Reaction was warmed to $36{ }^{\circ} \mathrm{C}$. Solubilization of the pyrenebutanol and black insoluble reduced reagent deposited out. After 3 hours, the oxidation, followed by TLC was complete, the black reaction mixture was diluted with 5 volumes of anhydrous ether. The solvent was decanted, and the black solid was washed twice with ether. Evaporation of the solvent at reduced pressure. Further purified with a silica gel column using an eluent of $10 \%$ ethyl acetate in hexanes to afford desired product as pale yellow solid (200 mg, 67\% yield); ${ }^{1} \mathrm{H}$ NMR (400 MHz, $\left.\mathrm{CDCl}_{3}\right) \delta 9.78(\mathrm{t}, J=2.0 \mathrm{~Hz}, 1 \mathrm{H}), 8.30(\mathrm{~d}, J=9.0 \mathrm{~Hz}, 1 \mathrm{H}), 8.21-7.99(\mathrm{~m}, 7 \mathrm{H}), 7.88$ $(\mathrm{d}, J=8.0 \mathrm{~Hz}, 1 \mathrm{H}), 3.36(\mathrm{t}, J=7.5 \mathrm{~Hz}, 2 \mathrm{H}), 2.44(\mathrm{~m}, 2 \mathrm{H}), 1.95-1.83(\mathrm{~m}, 2 \mathrm{H}), 1.67(\mathrm{~m}, 2 \mathrm{H}), 1.58-1.39$ $(\mathrm{m}, 4 \mathrm{H}) .{ }^{13} \mathrm{C} \mathrm{NMR}\left(100 \mathrm{MHz}, \mathrm{CDCl}_{3}\right) \delta 202.8,137.0,131.5,130.9,129.8,128.6,127.5,127.2,127.7$, 
126.6, 125.8, 125.11, 125.07, 124.8, 124.8, 124.7, 123.4, 43.9, 33.5, 31.7, 29.5, 29.1, 22.1. LRMS (ESI+) $\mathrm{m} / \mathrm{z}$ calc'd for $\mathrm{C}_{23} \mathrm{H}_{22} \mathrm{ONa}^{+}[\mathrm{M}+\mathrm{Na}]^{+} 337.16$, found 337.24 .

\section{7-C Cyclen}

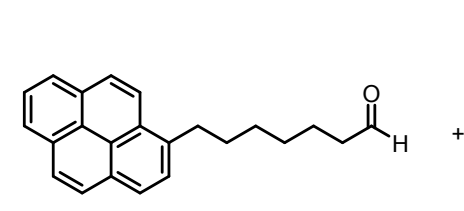

1-pyreneheptanal

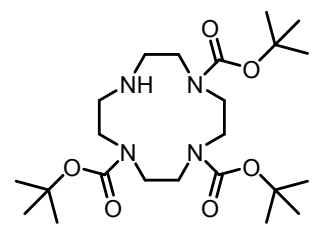

$\mathrm{Boc}_{3}$ Cyclen

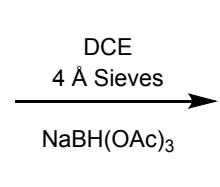

$\mathrm{NaBH}(\mathrm{OAc})_{3}$

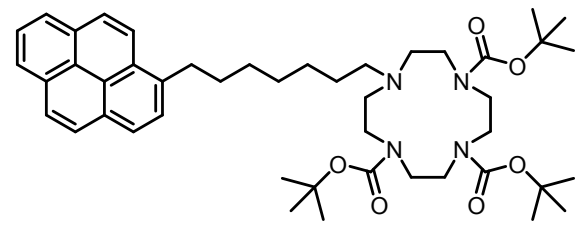

tri-tert-butyl 10-(7-(pyren-1-yl)heptyl)-1,4,7,10tetraazacyclododecane-1,4,7-tricarboxylate

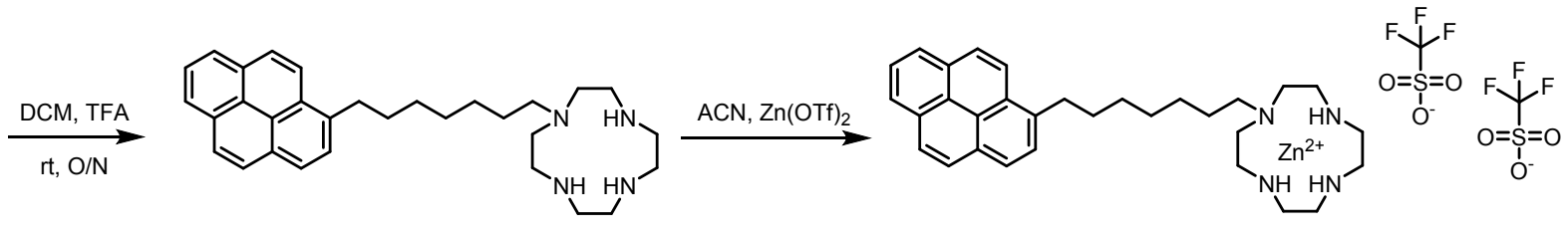

1-(7-(pyren-1-yl)heptyl)-1,4,7,10-tetraazacyclododecane

7-C Cyclen

\section{Tri-tert-butyl 10-(7-(pyren-1-yl)heptyl)-1,4,7,10-tetraazacyclododecane-1,4,7-tricarboxylate}

To a solution of 1-pyreneheptanal $(50 \mathrm{mg}, 0.159 \mathrm{mmol})$ in $3.2 \mathrm{~mL} \mathrm{DCE}, \mathrm{Boc}_{3}$ Cyclen $(82.7 \mathrm{mg}, 0.175$ mmol) was added and stirred together with $4 \AA$ molecular sieves for $2 \mathrm{~h}$ under $\mathrm{N}_{2}$ atmosphere. To this solution, sodium triacetoxyborohydride $(67.4 \mathrm{mg}, 0.318 \mathrm{mmol})$ was added and the reaction mixture was left to stir at ambient temperature overnight under $\mathrm{N}_{2}$ atmosphere. The mixture was extracted with $\mathrm{DCM} /$ sodium bicarbonate. The extract was purified by flash chromatography ( $35 \%$ ethyl acetate/hexanes) to give tri-tert-butyl 10-(7-(pyren-1-yl)heptyl)-1,4,7,10-tetraazacyclododecane-1,4,7-tricarboxylate as a white solid (compound 2a) (95 mg, 78\%); ${ }^{1} \mathrm{H}$ NMR (400 MHz, $\left.\mathrm{CDCl}_{3}\right) \delta 8.30(\mathrm{dd}, J=9,1 \mathrm{~Hz}, 1 \mathrm{H}), 8.21$ $-7.95(\mathrm{~m}, 7 \mathrm{H}), 7.88$ (dd, $J=8,1 \mathrm{~Hz}, 1 \mathrm{H}), 3.65-3.17(\mathrm{~m}, 14 \mathrm{H}), 2.65$ (d, $J=21 \mathrm{~Hz}, 4 \mathrm{H}), 2.50$ (t, $J=8$ $\mathrm{Hz}, 2 \mathrm{H}), 1.89$ (q, $J=7.5 \mathrm{~Hz}, 2 \mathrm{H}), 1.49$ (d, $J=8.5 \mathrm{~Hz}, 27 \mathrm{H}), 1.41$ (ddd, $J=15,9,7 \mathrm{~Hz}, 4 \mathrm{H}), 1.28$ (qd, $J=$ 7, 5.5, $3 \mathrm{~Hz}, 4 \mathrm{H})$.

\section{1-(7-(pyren-1-yl)heptyl)-1,4,7,10-tetraazacyclododecane}

To a solution of compound $\mathbf{2 a}(85 \mathrm{mg}, 0.11 \mathrm{mmol})$ in $1 \mathrm{~mL}$ DCM, $0.5 \mathrm{~mL}$ TFA was added. The reaction mixture was stirred at room temperature. The progress of the reaction was monitored using MS. The reaction mixture was concentrated down in vacuo and the TFA was azeotroped off in vacuo with $\mathrm{MeOH}$. The crude product was taken up in $\mathrm{MeOH}$ and passed through a column packed with Amberlite IRN-78. 
The solvent was evaporated in vacuo. The mixture was then purified by preparative HPLC to give 1-(7(pyren-1-yl)heptyl)-1,4,7,10-tetraazacyclododecane (compound 2b) (38 mg, 73\%); ${ }^{1} \mathrm{H}$ NMR (400 MHz, $\left.\mathrm{CD}_{3} \mathrm{OD}\right) \delta 8.28(\mathrm{dd}, J=9.5,6.5 \mathrm{~Hz}, 1 \mathrm{H}), 8.20-7.93(\mathrm{~m}, 7 \mathrm{H}), 7.86(\mathrm{dd}, J=8.0,5.0 \mathrm{~Hz}, 1 \mathrm{H}), 3.43-3.28$ (m, 4H), $3.12-2.35(\mathrm{~m}, 16 \mathrm{H}), 1.90-1.76(\mathrm{~m}, 2 \mathrm{H}), 1.50-1.13(\mathrm{~m}, 8 \mathrm{H}) .{ }^{13} \mathrm{C}$ NMR (100 MHz, $\left.\mathrm{CD}_{3} \mathrm{OD}\right)$ $\delta$ 137.0, 131.4, 130.9, 129.7, 128.4, 127.2, 127.1, 126.8, 126.2, 125.6, 124.80, 124.75, 124.5, 124.4, 123.2, 123.1, 56.4, 52.7, 45.9, 45.6, 45.2, 43.9, 43.5, 42.1, 41.8, 32.9, 31.5, 29.0, 26.8, 26.7, 23.4; LRMS (ESI+) $\mathrm{m} / \mathrm{z}$ calc'd for $\mathrm{C}_{31} \mathrm{H}_{43} \mathrm{~N}_{4}[\mathrm{M}+\mathrm{H}]^{+} 471.35$, found 471.53. HRMS (ESI+) m/z calc'd for $\mathrm{C}_{31} \mathrm{H}_{43} \mathrm{~N}_{4}[\mathrm{M}+$ $\mathrm{H}]^{+}$471.3482, found 471.3489. rpHPLC $\mathrm{t}_{\mathrm{R}}$ : condition (A) $11.373 \mathrm{~min}$., condition (B) $14.853 \mathrm{~min}$., purity $98.3 \%$ and $98.9 \%$ respectively.

\section{7-C Cyclam}

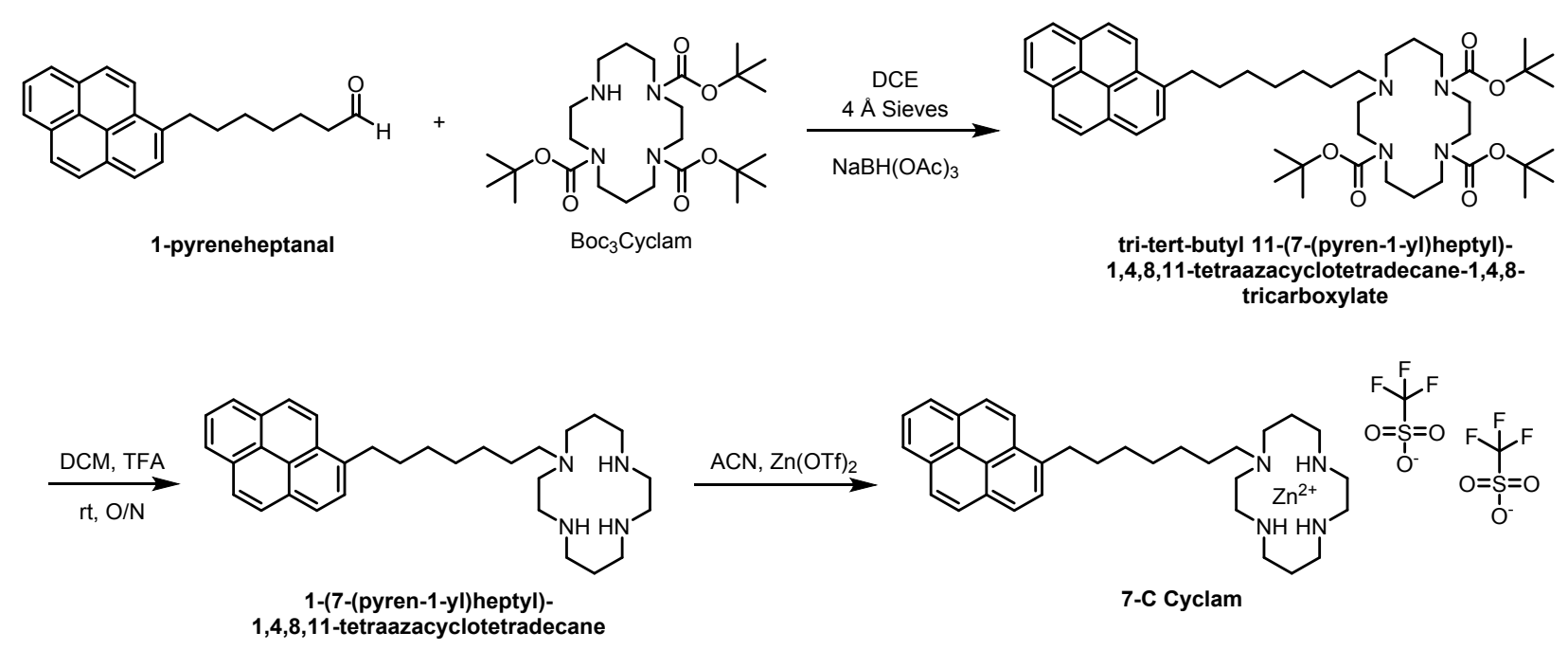

\section{Tri-tert-butyl 11-(7-(pyren-1-yl)heptyl)-1,4,8,11-tetraazacyclotetradecane-1,4,8-tricarboxylate}

To a solution of 1-pyreneheptanal (50 mg, $0.159 \mathrm{mmol})$ in $3.2 \mathrm{~mL}$ DCE, Boc ${ }_{3}$ Cyclam ( $87.6 \mathrm{mg}, 0.175$ mmol) was added and stirred together with $4 \AA$ molecular sieves for $2 \mathrm{~h}$ under $\mathrm{N}_{2}$ atmosphere. To this solution, sodium triacetoxyborohydride $(67.4 \mathrm{mg}, 0.318 \mathrm{mmol})$ was added and the reaction mixture was left to stir at ambient temperature overnight under $\mathrm{N}_{2}$ atmosphere. The mixture was extracted with DCM/sodium bicarbonate. The extract was purified by flash chromatography (50\% ethyl acetate/hexanes) to give tri-tert-butyl 11-(7-(pyren-1-yl)heptyl)-1,4,8,11-tetraazacyclotetradecane-1,4,8-tricarboxylate as a 
white solid (compound 3a) (103 mg, 81\%); ${ }^{1} \mathrm{H}$ NMR (400 MHz, $\left.\mathrm{CDCl}_{3}\right) \delta 8.28(\mathrm{~d}, J=9.2 \mathrm{~Hz}, 1 \mathrm{H}), 8.20$ - $7.94(\mathrm{~m}, 7 \mathrm{H}), 7.87$ (d, $J=7.8 \mathrm{~Hz}, 1 \mathrm{H}), 3.43-3.14(\mathrm{~m}, 14 \mathrm{H}), 2.62-2.48(\mathrm{~m}, 2 \mathrm{H}), 2.42-2.31(\mathrm{~m}, 4 \mathrm{H})$, $1.94-1.80(\mathrm{~m}, 4 \mathrm{H}), 1.71-1.62(\mathrm{~m}, 2 \mathrm{H}), 1.51-1.46(\mathrm{~m}, 27 \mathrm{H}), 1.46-1.39(\mathrm{~m}, 4 \mathrm{H}), 1.30-1.24(\mathrm{~m}, 4 \mathrm{H})$. ${ }^{13} \mathrm{C}$ NMR $\left(100 \mathrm{MHz}, \mathrm{CDCl}_{3}\right) \delta 155.7,137.2,131.5,130.9,129.7,128.6,127.5,127.2,127.1,126.5,125.8$, $125.09,125.07,124.8,124.6,123.5,79.5,79.3,55.5,53.4,51.4,47.0,45.7,33.6,31.9,29.8,29.6,28.6$, 28.5, 27.6, 26.5. LRMS (ESI+) m/z calc'd for $\mathrm{C}_{48} \mathrm{H}_{70} \mathrm{~N}_{4} \mathrm{O}_{6} \mathrm{Na}[\mathrm{M}+\mathrm{Na}]^{+}$821.52, found 821.89.

\section{1-(7-(pyren-1-yl)heptyl)-1,4,8,11-tetraazacyclotetradecane}

To a solution of compound 3a (103 mg, $0.129 \mathrm{mmol})$ in $1 \mathrm{~mL}$ DCM, $0.5 \mathrm{~mL}$ TFA was added. The reaction mixture was stirred at room temperature. The progress of the reaction was monitored using MS. The reaction mixture was concentrated down in vacuo and the TFA was azeotroped off in vacuo with $\mathrm{MeOH}$. The crude product was taken up in $\mathrm{MeOH}$ and passed through a column packed with Amberlite IRN-78. The solvent was evaporated in vacuo. The mixture was then purified by preparative HPLC to give 1-(7(pyren-1-yl)heptyl)-1,4,8,11-tetraazacyclotetradecane (compound 3b) (45 mg, 70\%); ${ }^{1} \mathrm{H}$ NMR (400 $\left.\mathrm{MHz}, \mathrm{CD}_{3} \mathrm{OD}\right) \delta 8.56(\mathrm{~s}, 1 \mathrm{H}), 8.27-7.80(\mathrm{~m}, 8 \mathrm{H}), 3.35-3.16(\mathrm{~m}, 4 \mathrm{H}), 3.10-2.45(\mathrm{~m}, 14 \mathrm{H}), 2.40-2.12$ (m, 2H), $1.89-1.64(\mathrm{~m}, 6 \mathrm{H}), 1.48-1.15(\mathrm{~m}, 8 \mathrm{H}) ;{ }^{13} \mathrm{C} \mathrm{NMR}\left(100 \mathrm{MHz}, \mathrm{CD}_{3} \mathrm{OD}\right) \delta 138.5,132.9,132.4$, 131.2, 129.9, 128.7, 128.7, 128.3, 127.7, 127.2, 126.31, 126.26, 126.1, 126.0, 125.9, 124.7, 54.2, 52.3, $51.8,50.7,50.4,48.6,47.5,46.1,45.8,34.4,33.0,30.5,30.4,28.3,25.5,24.2,23.5$. LRMS (ESI+) m/z

calc'd for $\mathrm{C}_{33} \mathrm{H}_{47} \mathrm{~N}_{4}[\mathrm{M}+\mathrm{H}]^{+} 499.38$, found 499.49. HRMS (ESI+) $\mathrm{m} / \mathrm{z}$ calc'd for $\mathrm{C}_{33} \mathrm{H}_{47} \mathrm{~N}_{4}[\mathrm{M}+\mathrm{H}]^{+}$ 499.3795, found 499.3800. rpHPLC $t_{\mathrm{R}}$ : condition (A) 15.986 min., condition (B) 22.345 min., purity $99.5 \%$ and $99.1 \%$ respectively. 


\section{7-C DPA}

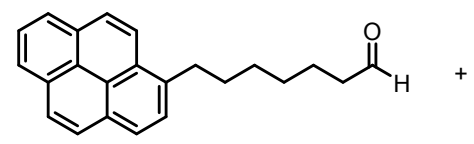

1-pyreneheptanal

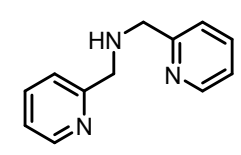

bis(pyridin-2-ylmethyl)amine

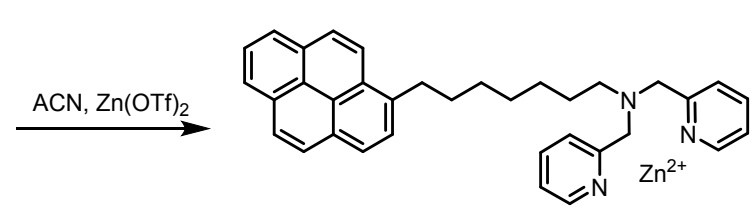

7-C DPA
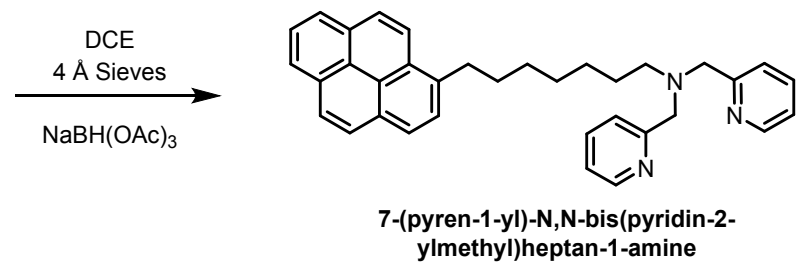

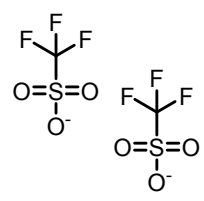

\section{7-(pyren-1-yl)-N,N-bis(pyridin-2-ylmethyl)heptan-1-amine}

To a solution of 1-pyreneheptanal (50 mg, $0.159 \mathrm{mmol})$ in $3.2 \mathrm{~mL}$ DCE, di-(2-picolyl)amine (DPA) (34.3 $\mu \mathrm{L}, 0.191 \mathrm{mmol}$ ) was added and stirred together with $4 \AA$ molecular sieves for $2 \mathrm{~h}$ under $\mathrm{N}_{2}$ atmosphere. To this solution, sodium triacetoxyborohydride $(67.4 \mathrm{mg}, 0.318 \mathrm{mmol})$ was added and the reaction mixture was left to stir at ambient temperature overnight under $\mathrm{N}_{2}$ atmosphere. The mixture was extracted with $\mathrm{DCM} /$ sodium bicarbonate. The extract was purified by flash chromatography $(96 \% \mathrm{DCM}, 3.5 \% \mathrm{MeOH}$, $0.5 \% \mathrm{NH}_{4} \mathrm{OH}$ ) to give 7-(pyren-1-yl)- $N, N$-bis(pyridin-2-ylmethyl)heptan-1-amine as an oil (compound 4a) $(62 \mathrm{mg}, 78 \%) ;{ }^{1} \mathrm{H} \mathrm{NMR}\left(400 \mathrm{MHz}, \mathrm{CDCl}_{3}\right) \delta 8.58-8.51(\mathrm{~m}, 2 \mathrm{H}), 8.28(\mathrm{~d}, J=9.0 \mathrm{~Hz}, 1 \mathrm{H}), 8.21-$ $7.94(\mathrm{~m}, 7 \mathrm{H}), 7.86(\mathrm{~d}, J=8.0 \mathrm{~Hz}, 1 \mathrm{H}), 7.62(\mathrm{td}, J=7.5,1.5 \mathrm{~Hz}, 2 \mathrm{H}), 7.55(\mathrm{dt}, J=7.5,1.5 \mathrm{~Hz}, 2 \mathrm{H}), 7.16$ - $7.08(\mathrm{~m}, 2 \mathrm{H}), 3.85(\mathrm{~s}, 4 \mathrm{H}), 3.36-3.28(\mathrm{~m}, 2 \mathrm{H}), 2.61-2.53(\mathrm{~m}, 2 \mathrm{H}), 1.89-1.77(\mathrm{~m}, 2 \mathrm{H}), 1.62-1.52$ $(\mathrm{m}, 2 \mathrm{H}), 1.46(\mathrm{tt}, J=9.5,4.0 \mathrm{~Hz}, 2 \mathrm{H}), 1.35-1.29(\mathrm{~m}, 4 \mathrm{H}) ;{ }^{13} \mathrm{C} \mathrm{NMR}\left(100 \mathrm{MHz}, \mathrm{CDCl}_{3}\right) \delta 160.0,148.9$, $137.3,136.4,131.5,131.0,129.7,128.6,127.5,127.2,127.1,126.5,125.8,125.10,125.08,124.79$, $124.77,124.6,123.5,122.88,121.86,77.3,74.7,60.5,54.4,33.6,31.9,29.7,29.4,27.3,27.1$. LRMS (ESI+) $\mathrm{m} / \mathrm{z}$ calc'd for $\mathrm{C}_{35} \mathrm{H}_{36} \mathrm{~N}_{3}[\mathrm{M}+\mathrm{H}]^{+}$498.28, found 498.47. HRMS (ESI+) m/z calc'd for $\mathrm{C}_{35} \mathrm{H}_{36} \mathrm{~N}_{3}$ $[\mathrm{M}+\mathrm{H}]^{+}$498.2909, found 499.3806. $\mathrm{rpHPLC}_{\mathrm{R}}$ : condition (A) 13.844 min., condition (B) 19.487 min., purity $94.8 \%$ and $94.4 \%$ respectively. 


\section{S5.3 Synthesis of 1-(4-Aminobutyl)pyrene}

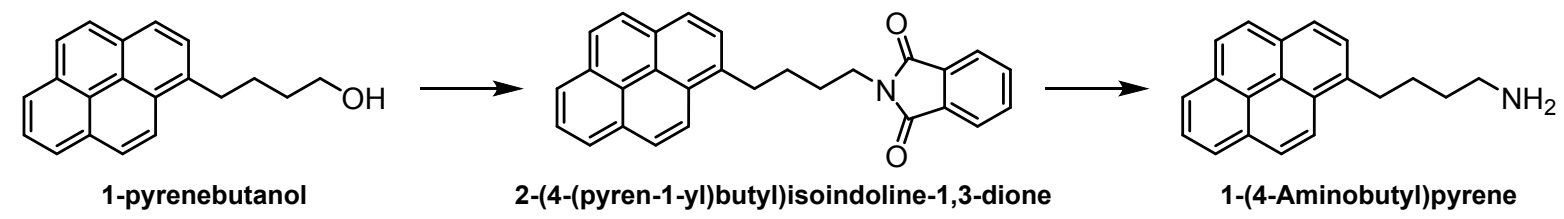

\section{2-(4-(Pyren-1-yl)butyl)isoindoline-1,3-dione}

To a solution of 1-pyrenebutanol (100 mg, $0.364 \mathrm{mmol})$ in THF $(1 \mathrm{~mL})$ was added triphenylphosphine (115 mg, $0.437 \mathrm{mmol}$ ), phthalimide (65 mg, $0.437 \mathrm{mmol}$ ) and diethyl azodicarboxylate ( $80 \mu \mathrm{L}, 0.437$ $\mathrm{mmol}$ ) at room temperature. The reaction was stirred for 2 hours, quenched with the addition of a few drops of methanol, and concentrated by evaporation. The residue was taken up with DCM, extracted and washed with water, sodium bicarbonate and brine. The collected organic layers were dried on magnesium sulfate and concentrated by evaporation. The crude material was purified by flash column chromatography (10-40\% EtOAc in hexanes) to provide the product as a yellow solid (112 $\mathrm{mg}, 0.279 \mathrm{mmol}, 77 \%$ yield); ${ }^{1} \mathrm{H} \mathrm{NMR}\left(400 \mathrm{MHz}, \mathrm{CDCl}_{3}\right) \delta 8.25(\mathrm{~d}, J=9.2 \mathrm{~Hz}, 1 \mathrm{H}), 8.16(\mathrm{~m}, 2 \mathrm{H}), 8.09(\mathrm{t}, J=8.0 \mathrm{~Hz}, 2 \mathrm{H}), 8.00(\mathrm{~m}$, $3 \mathrm{H}), 7.86(\mathrm{~d}, J=7.8 \mathrm{~Hz}, 1 \mathrm{H}), 7.74(\mathrm{dd}, J=5.5,3.0 \mathrm{~Hz}, 2 \mathrm{H}), 7.55$ (dd, $J=5.5,3.0 \mathrm{~Hz}, 2 \mathrm{H}), 3.77$ (t, $J=$ $6.6 \mathrm{~Hz}, 2 \mathrm{H}), 3.38$ (t, $J=7.2 \mathrm{~Hz}, 2 \mathrm{H}), 1.93(\mathrm{~m}, 4 \mathrm{H}) .{ }^{13} \mathrm{C} \mathrm{NMR}\left(100 \mathrm{MHz}, \mathrm{CDCl}_{3}\right) \delta 168.38,136.26,133.66$, $131.96,131.44,130.90,129.85,128.59,127.54,127.34,127.27,126.60,125.79,125.05,125.00,124.85$, $124.71,123.36,122.99,37.82,33.00,28.88,28.58$.

\section{1-(4-Aminobutyl)pyrene}

To a solution of 2-(4-(pyren-1-yl)butyl)isoindoline-1,3-dione $(110 \mathrm{mg}, 0.273 \mathrm{mmol})$ in a 1:1 mixture of ethanol and DCM $(2.7 \mathrm{~mL})$ was added hydrazine monohydrate $(54.6 \mathrm{mg}, 1.7 \mathrm{mmol})$ at room temperature for $72 \mathrm{~h}$. Afterwards, the reaction mixture was filtered, and the filtrate was concentrated by evaporation. The crude material was purified by flash column chromatography (92:7:1 DCM-MeOH-NEt ${ }_{3}$ ) to provide the product as a white solid (72 $\mathrm{mg}, 0.263 \mathrm{mmol}, 96 \%$ yield). ${ }^{1} \mathrm{H}$ NMR (400 MHz, DMSO- $\left.d_{6}\right) \delta 8.36$ (d, $J=9.3 \mathrm{~Hz}, 1 \mathrm{H}), 8.30-8.03$ (m, 7H), 7.96 (d, $J=7.8 \mathrm{~Hz}, 1 \mathrm{H}), 5.35$ (s, 2H), 3.34 (t, $J=7.7 \mathrm{~Hz}, 2 \mathrm{H}), 2.76$ (t, $J=7.3 \mathrm{~Hz}, 2 \mathrm{H}), 1.82(\mathrm{~m}, 2 \mathrm{H}), 1.65$ (m, 2H); ${ }^{13} \mathrm{C}$ NMR (100 MHz, DMSO- $\left.d_{6}\right) \delta 137.11,131.37,130.89$, 129.74, 128.56, 127.96, 127.92, 127.68, 126.96, 126.60, 125.41, 125.38, 125.24, 124.71, 124.63, 123.98, 40.06, 32.71, 29.54, 28.97; LR-MS (ESI + ) $m / z$ calc'd for $\left[\mathrm{C}_{20} \mathrm{H}_{20} \mathrm{~N}\right]^{+}: 274.16$, found: 274.10 . rpHPLC $t_{\mathrm{R}}$ : condition (A) 14.902 min., condition (B) 20.803 min., purity $99.6 \%$ and $99.6 \%$ respectively. 


\section{S5.4 NMR Spectra}

\section{Benzyl 6-heptynoate}

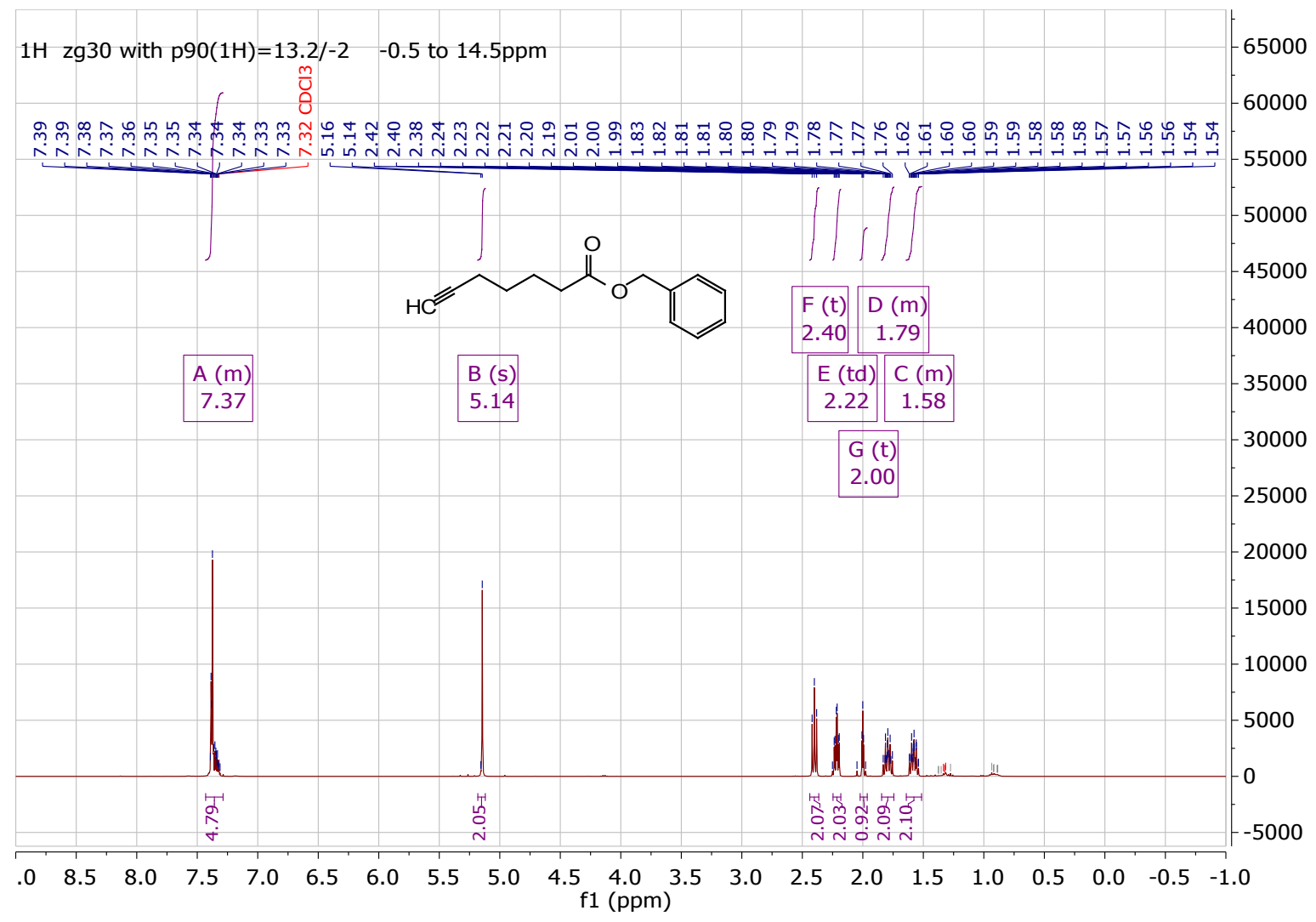




\section{Benzyl 7-(pyren-1-yl)hept-6-ynoate}
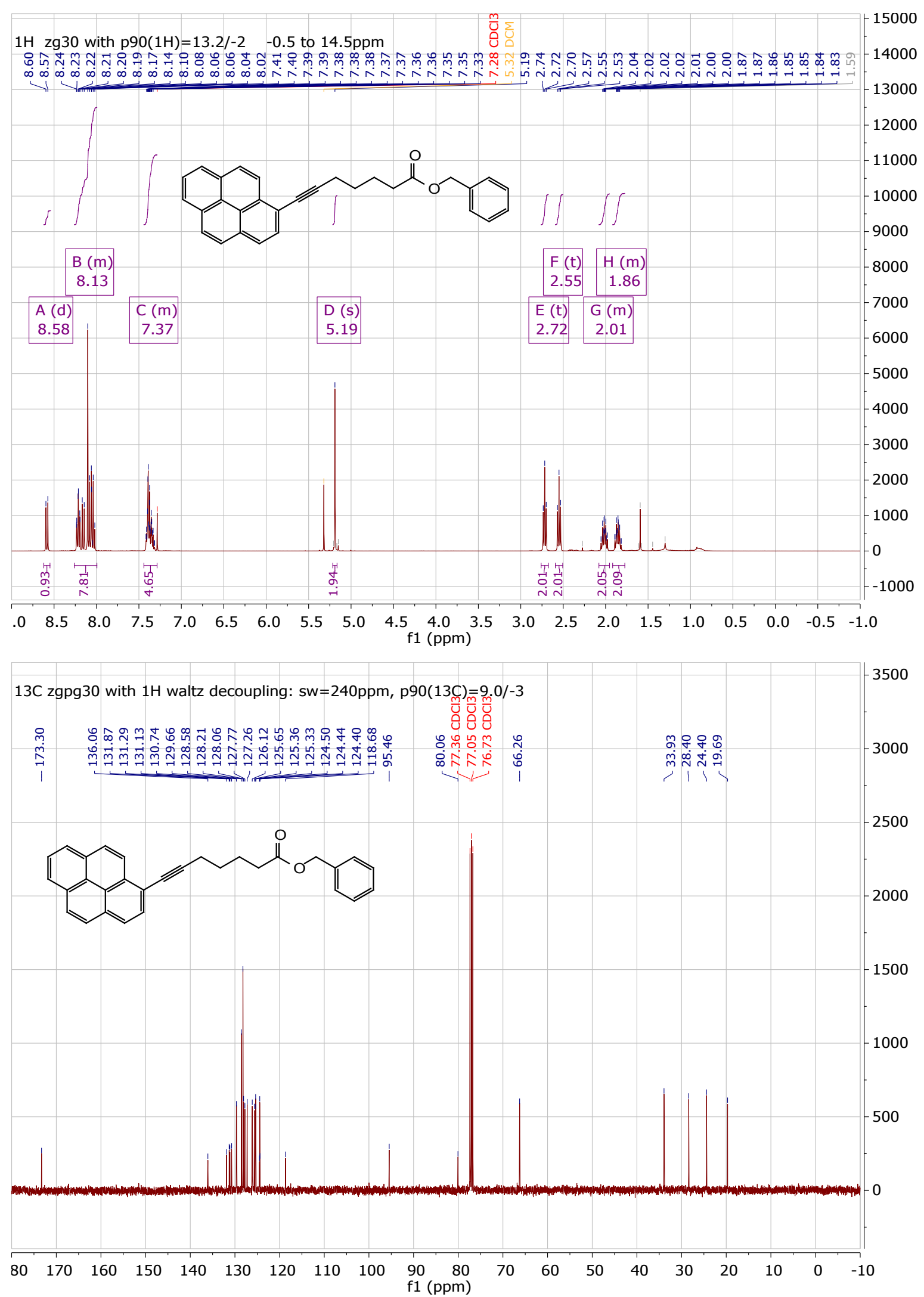


\section{1-pyreneheptanol}

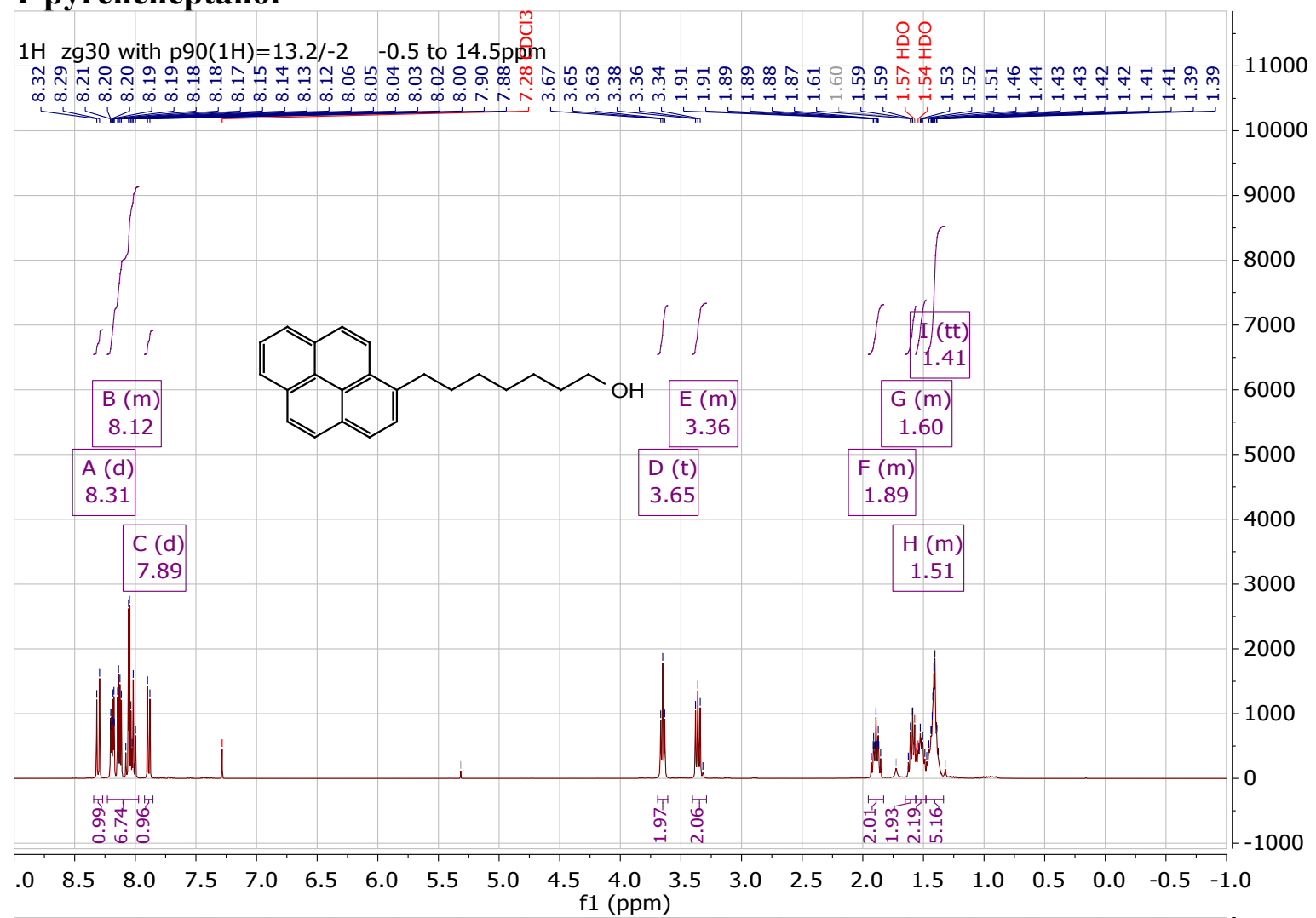

$13 \mathrm{C}$ zgpg30 with $1 \mathrm{H}$ waltz decoupling: $\mathrm{sw}=240 \mathrm{ppm}, \mathrm{p} 90(13 \mathrm{C})=9.0 /-3$

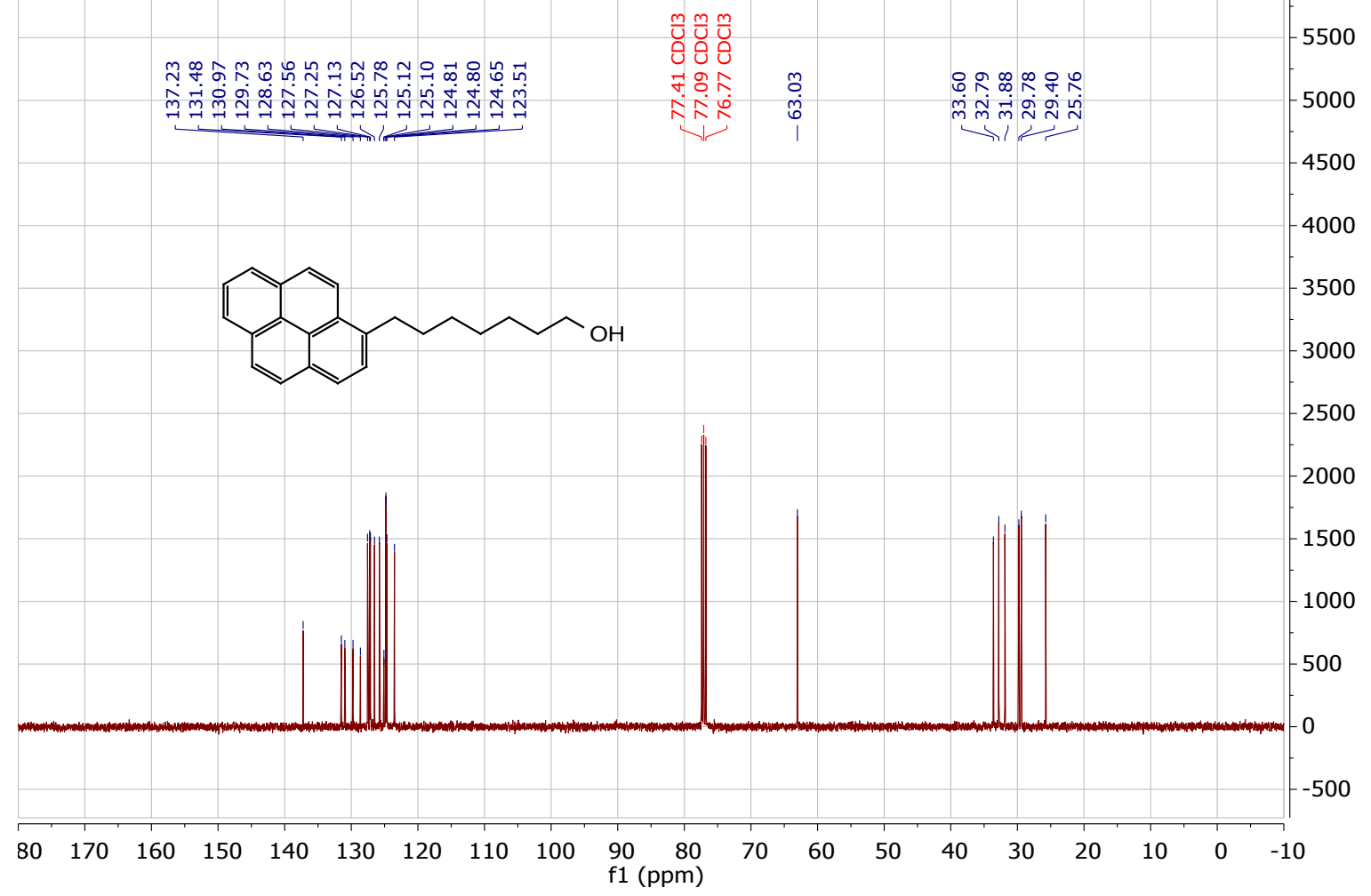




\section{1-pyreneheptanal}
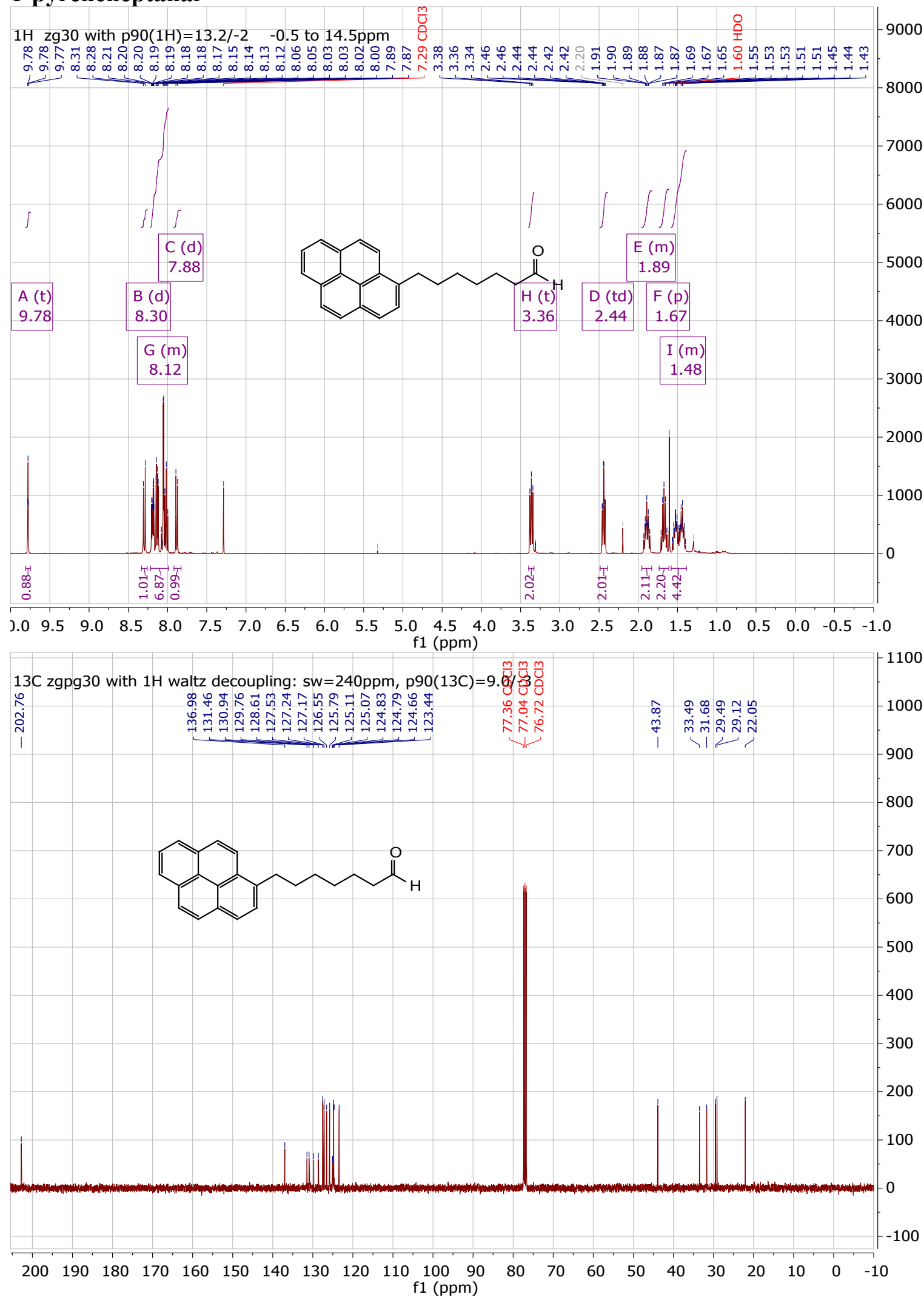
tri-tert-butyl 10-(7-(pyren-1-yl)heptyl)-1,4,7,10-tetraazacyclododecane-1,4,7-tricarboxylate

$1 \mathrm{H}$ zg30 with $\mathrm{p} 90(1 \mathrm{H})=13.2 /-2 \quad-0.5$ to $14.5 \mathrm{ppm}$

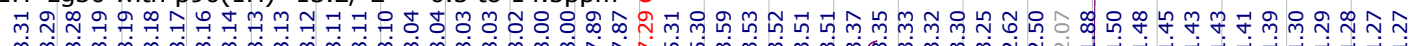

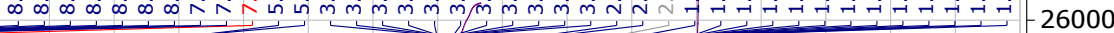

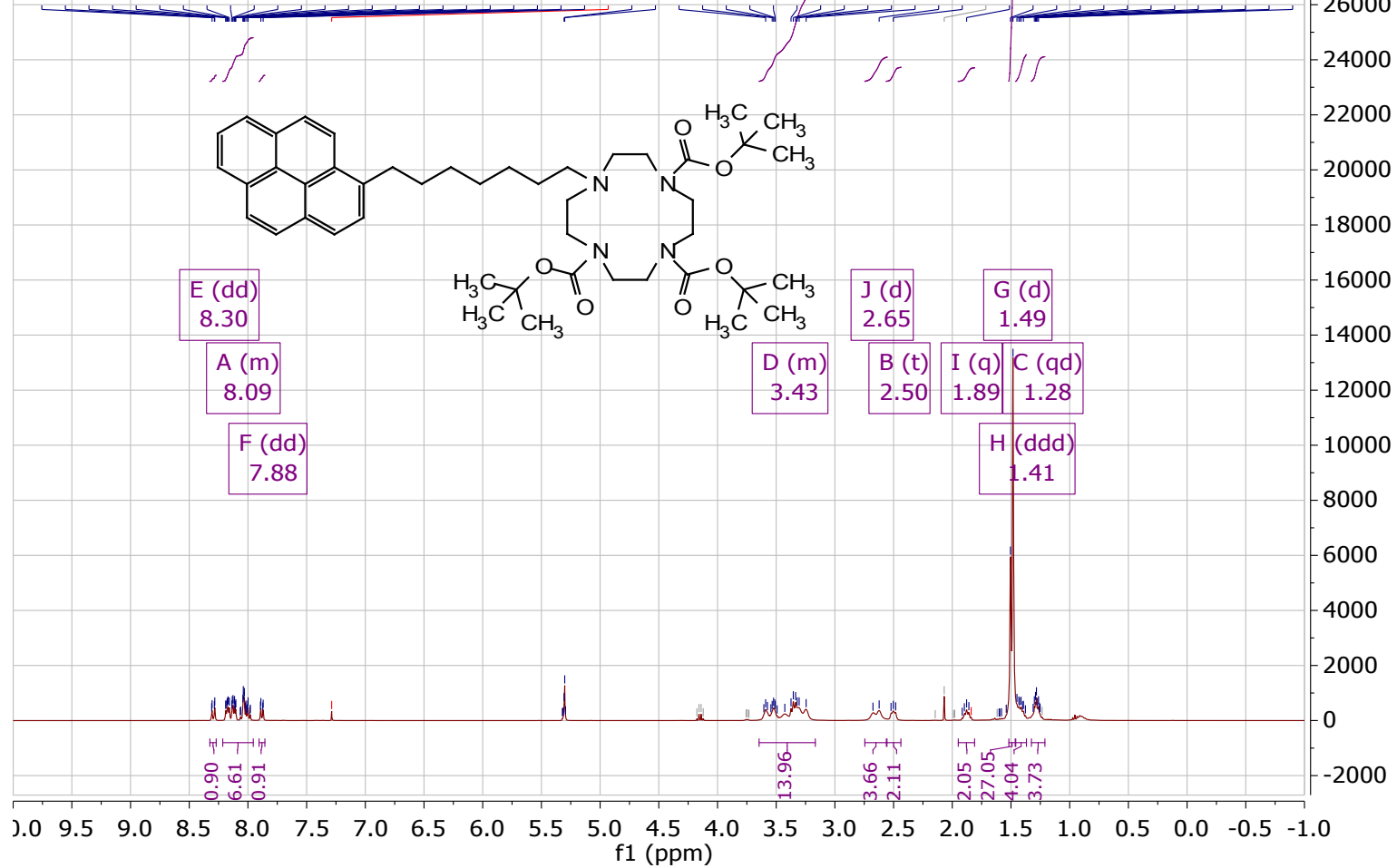




\section{1-(7-(pyren-1-yl)heptyl)-1,4,7,10-tetraazacyclododecane}

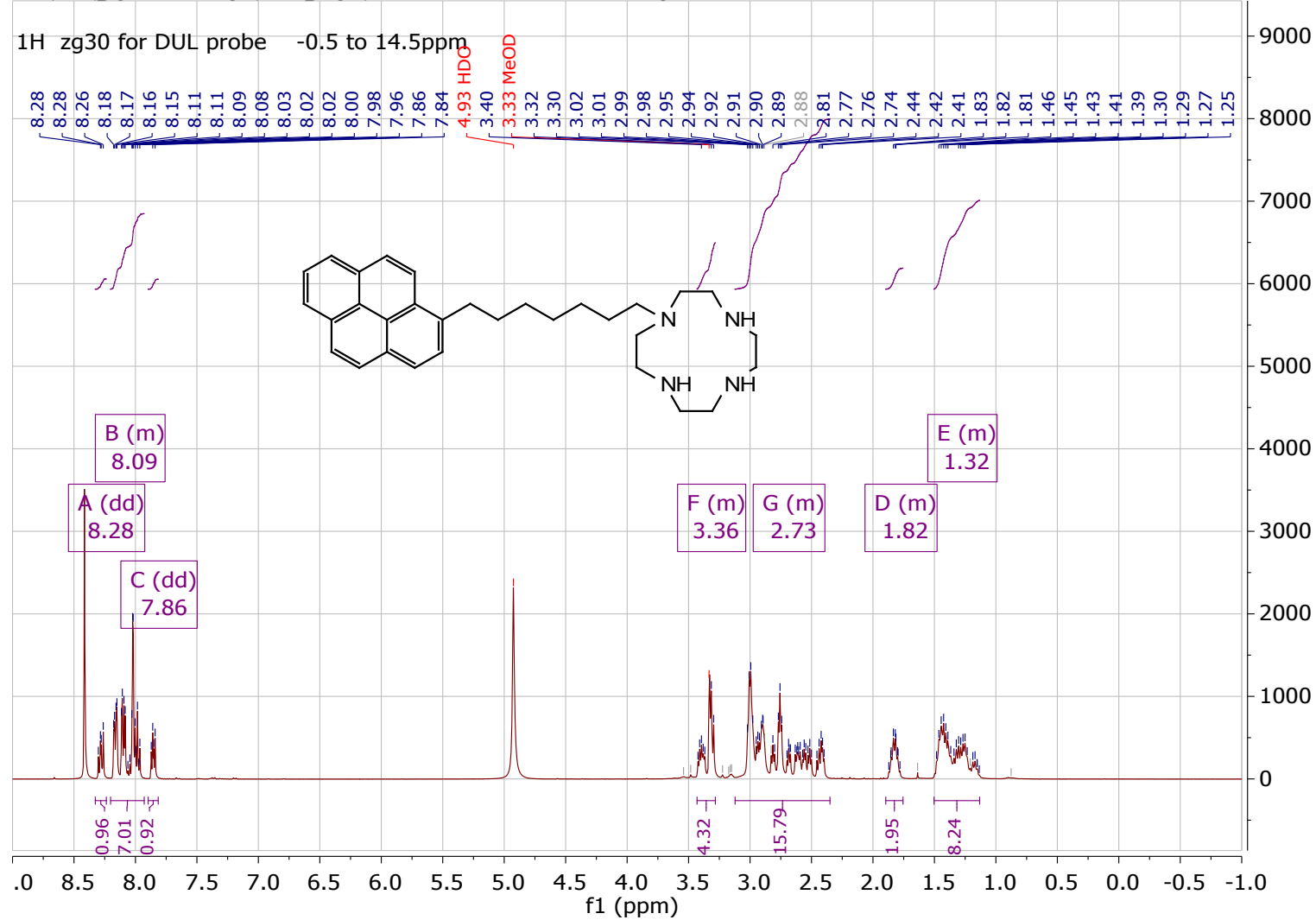

$13 \mathrm{C}$ zgpg30 with $1 \mathrm{H}$ waltz decoupling: $\mathrm{sw}=240 \mathrm{ppm}, \mathrm{p} 90(13 \mathrm{C})=9.0 /-3$

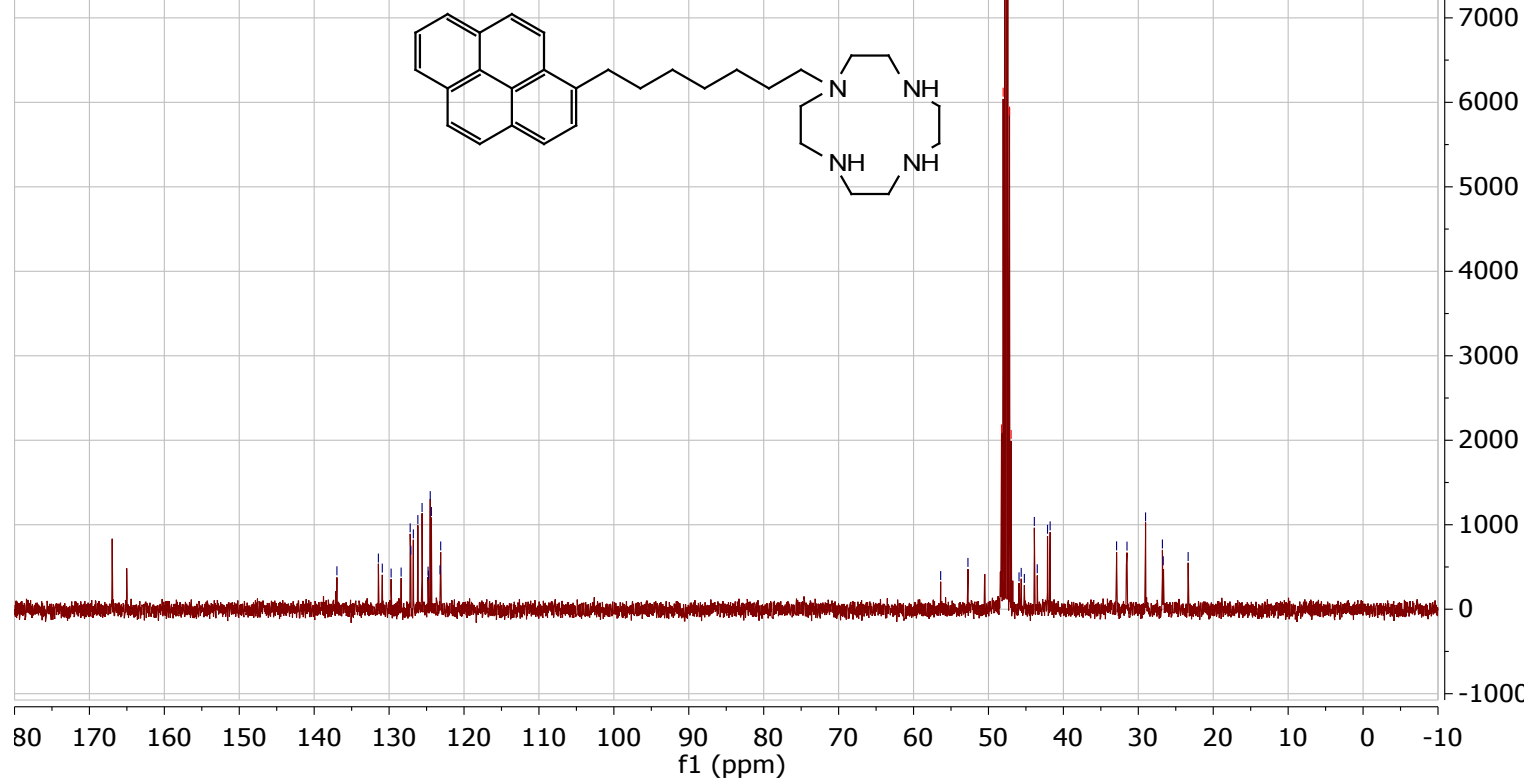




\section{tri-tert-butyl 11-(7-(pyren-1-yl)heptyl)-1,4,8,11-tetraazacyclotetradecane-1,4,8-tricarboxylate}

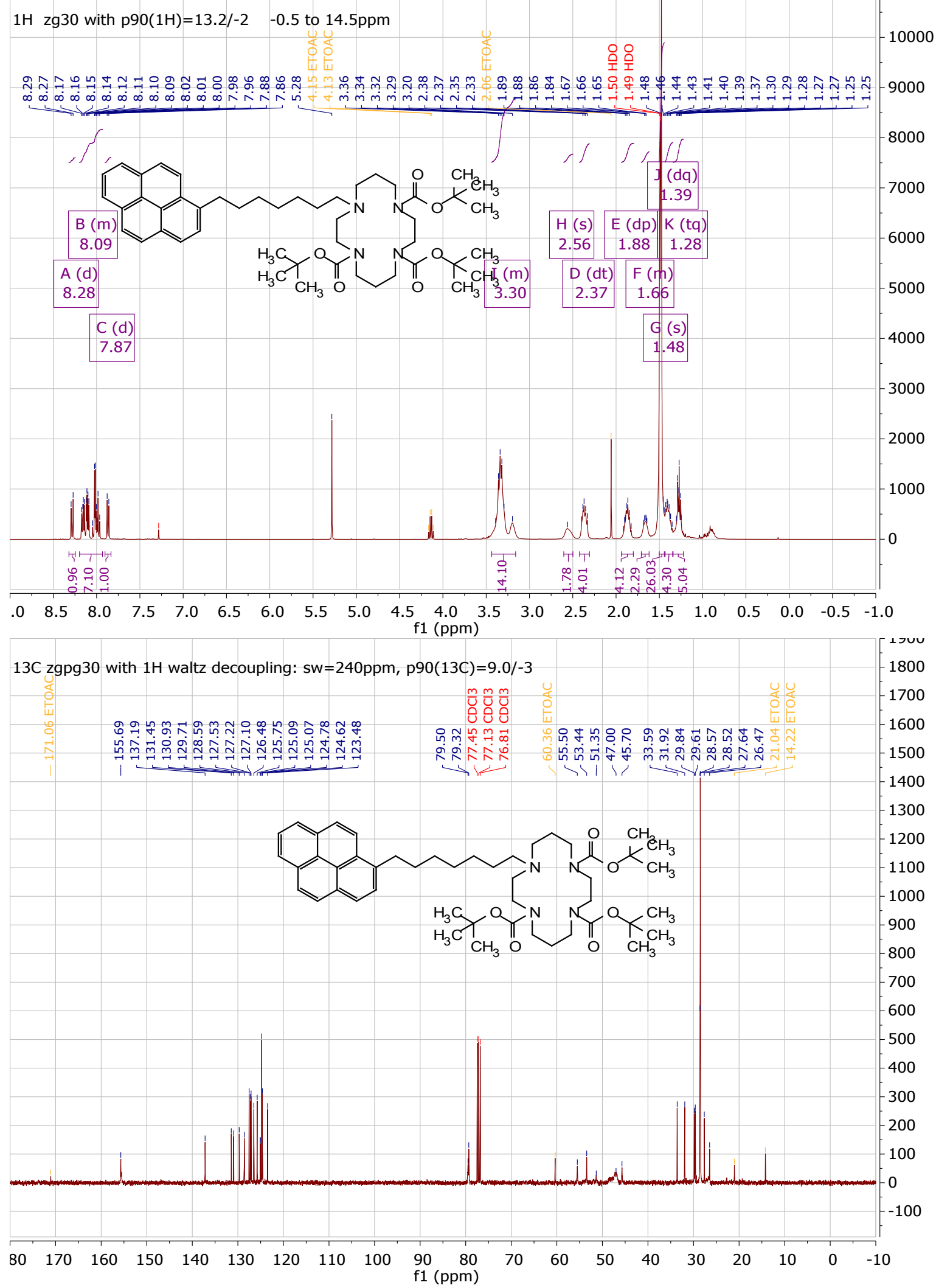


1-(7-(pyren-1-yl)heptyl)-1,4,8,11-tetraazacyclotetradecane ADC-223.3.fid

$1 \mathrm{H}$ zg30 with $\mathrm{p} 90(1 \mathrm{H})=13.2 /-2 \quad-0.5$ to $14.5 \mathrm{ppm}$

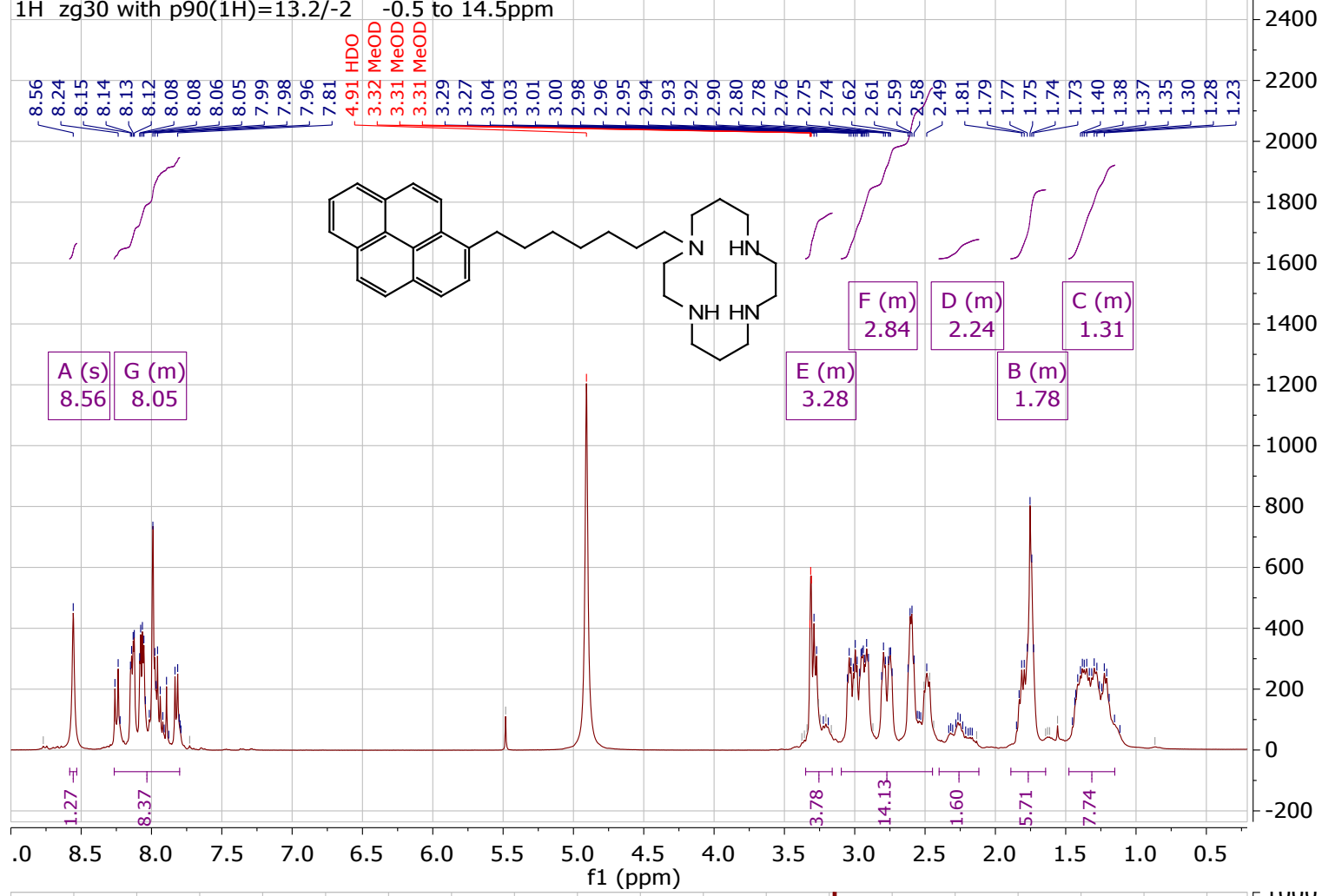

$13 \mathrm{C}$ zgpg30 with $1 \mathrm{H}$ waltz decoupling: $\mathrm{sw}=240 \mathrm{ppm}, \mathrm{p} 90(13 \mathrm{C})=9.0 /-3$

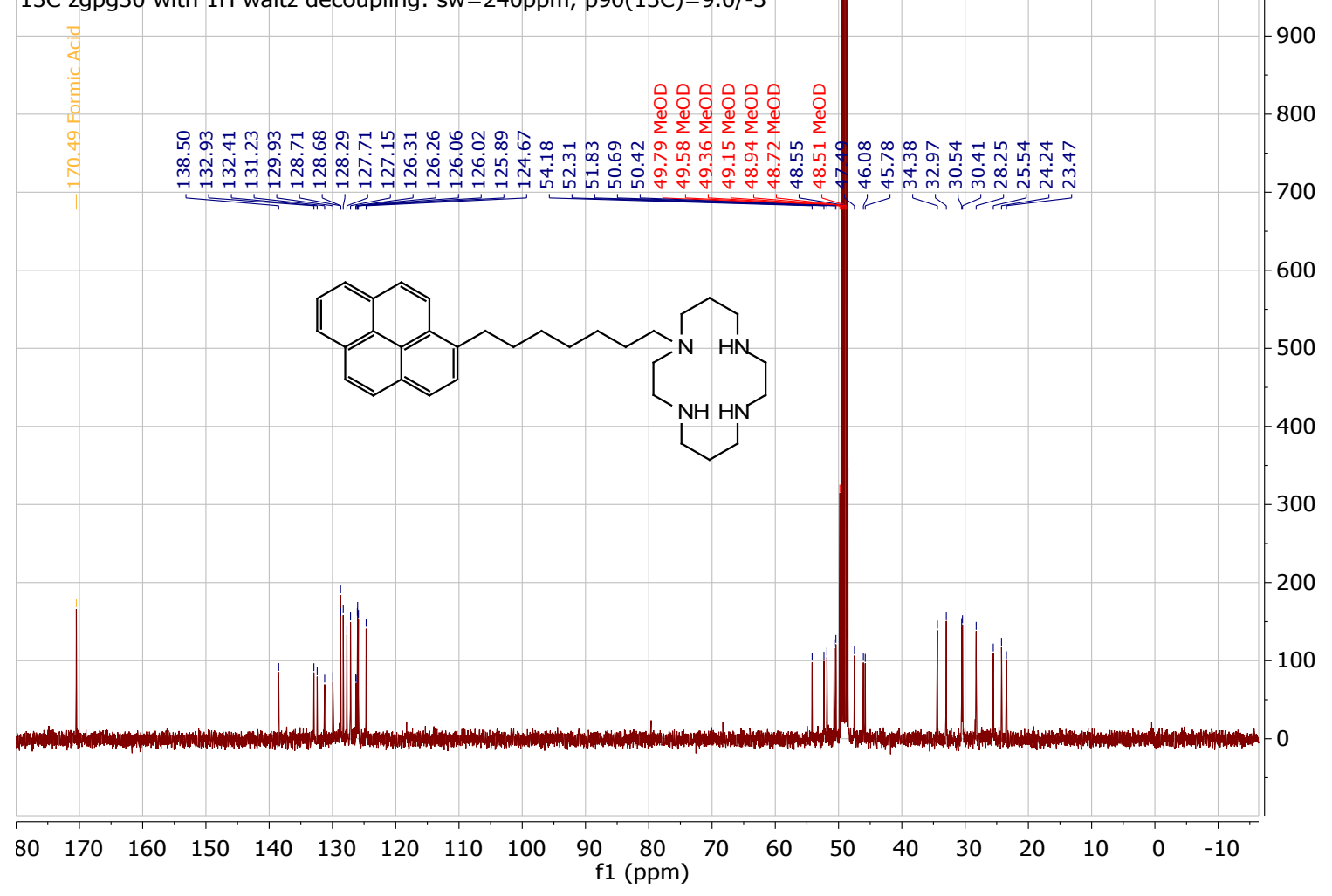




\section{7-(pyren-1-yl)- $N, N$-bis(pyridin-2-ylmethyl)heptan-1-amine}
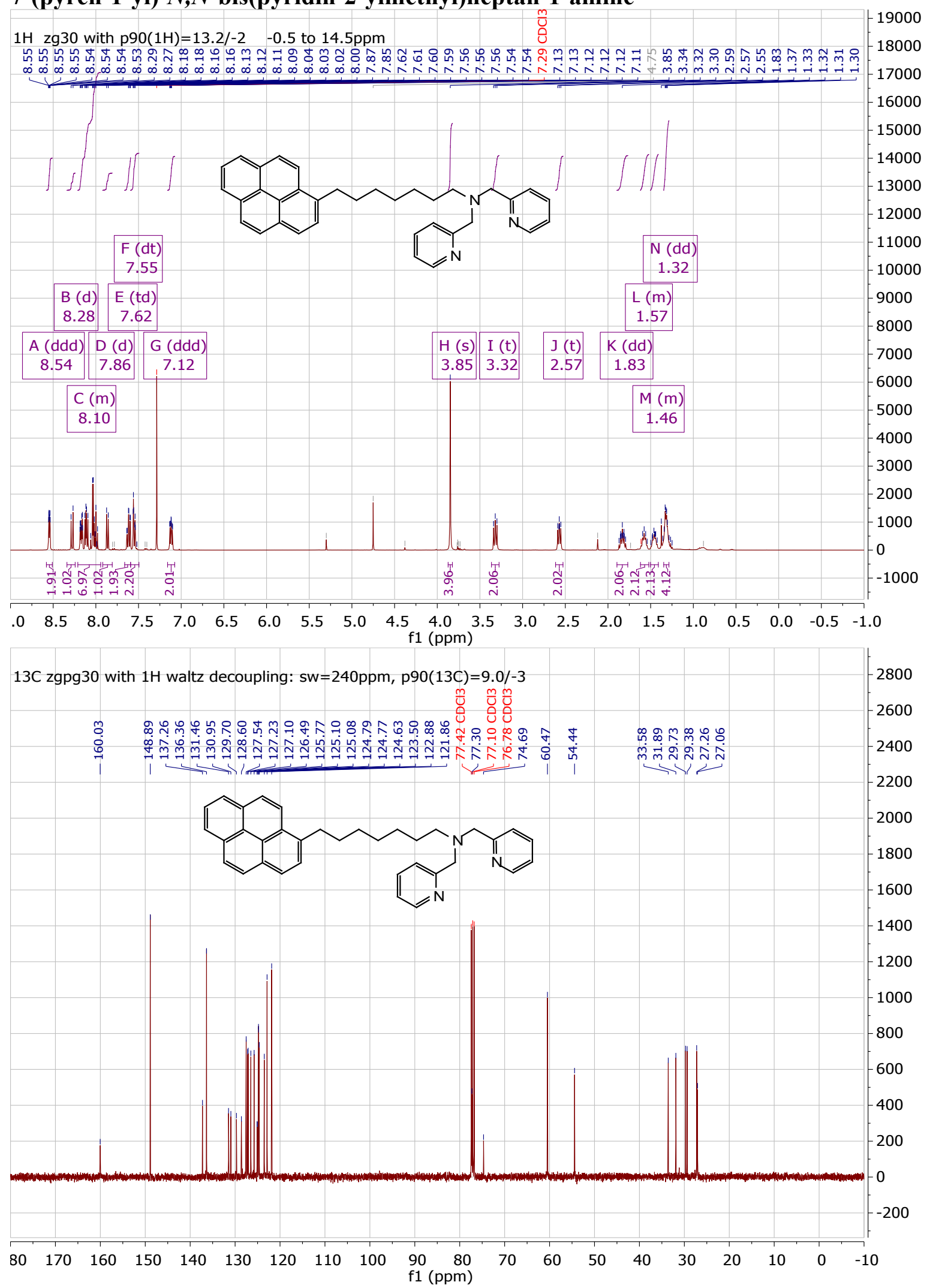


\section{2-(4-(Pyren-1-yl)butyl)isoindoline-1,3-dione}
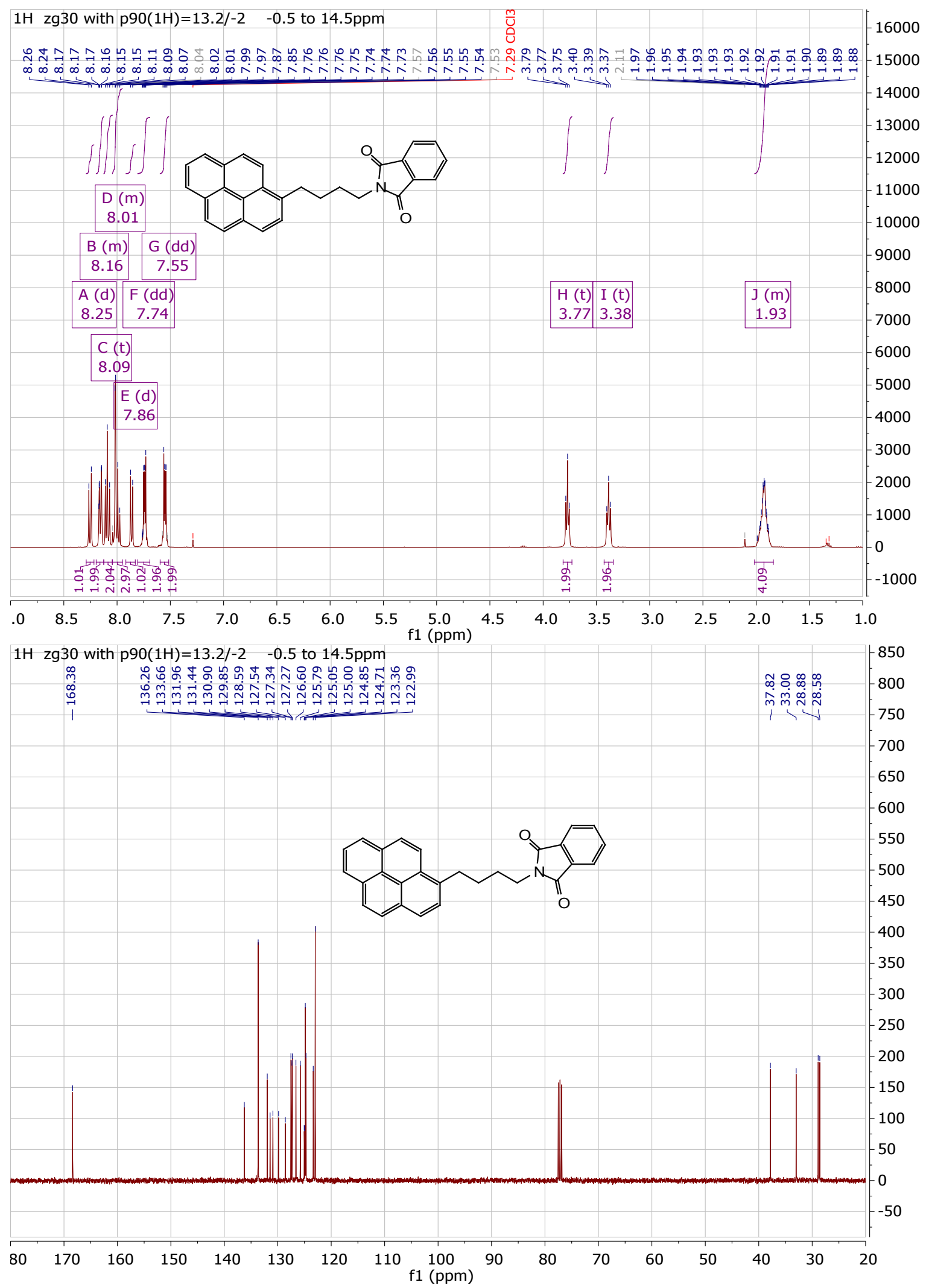


\section{4-(Pyren-1-yl)butan-1-amine}

\section{$1 \mathrm{H}$ zg30 with $\mathrm{p} 90(1 \mathrm{H})=13.2 /-2 \quad-0.5$ to $14.5 \mathrm{ppm}$}

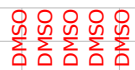

슬

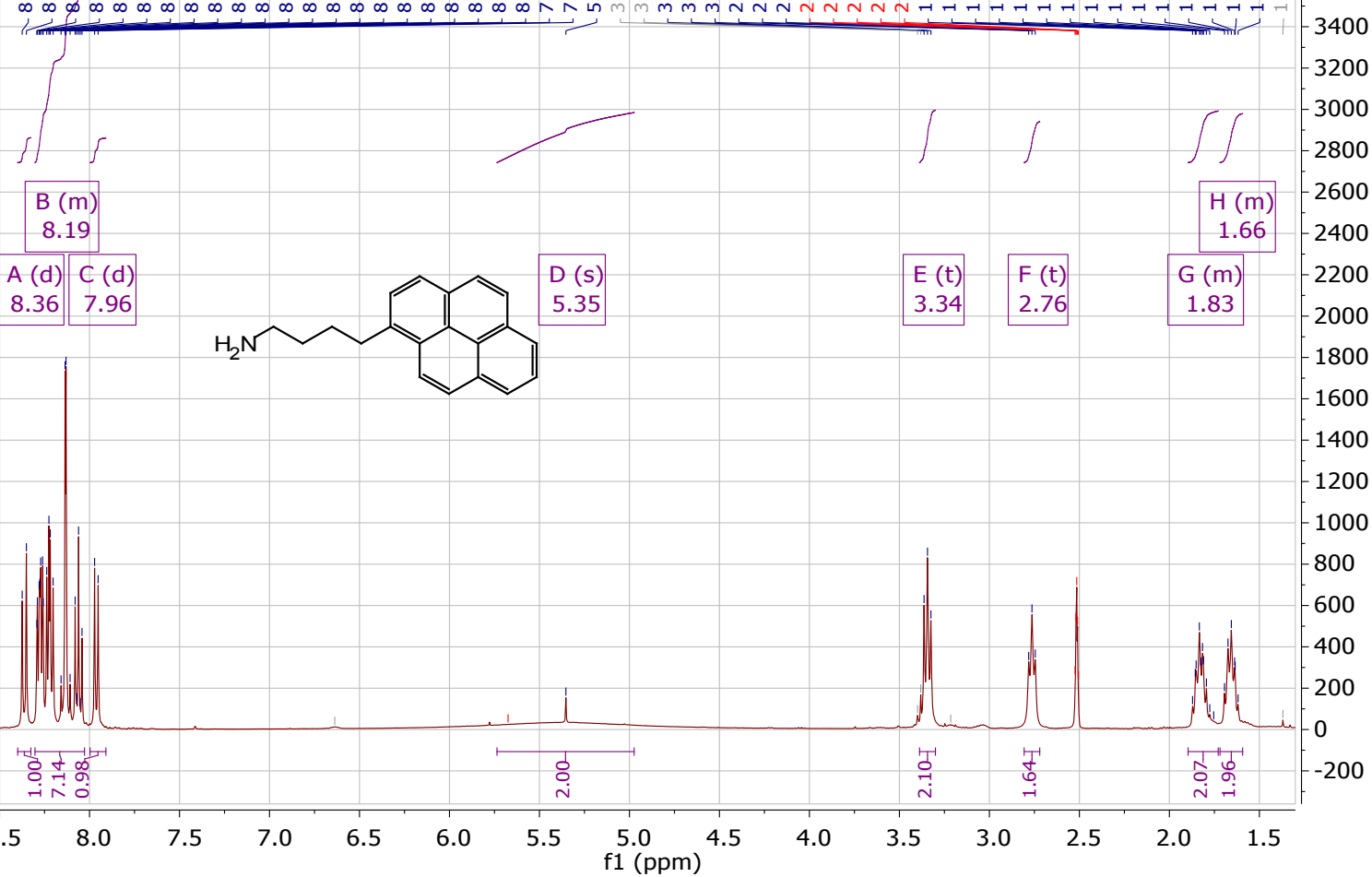

$1 \mathrm{H} \mathrm{zg} 30$ with $\mathrm{p} 90(1 \mathrm{H})=13.2 /-2 \quad-0.5$ to $14.5 \mathrm{ppm}$

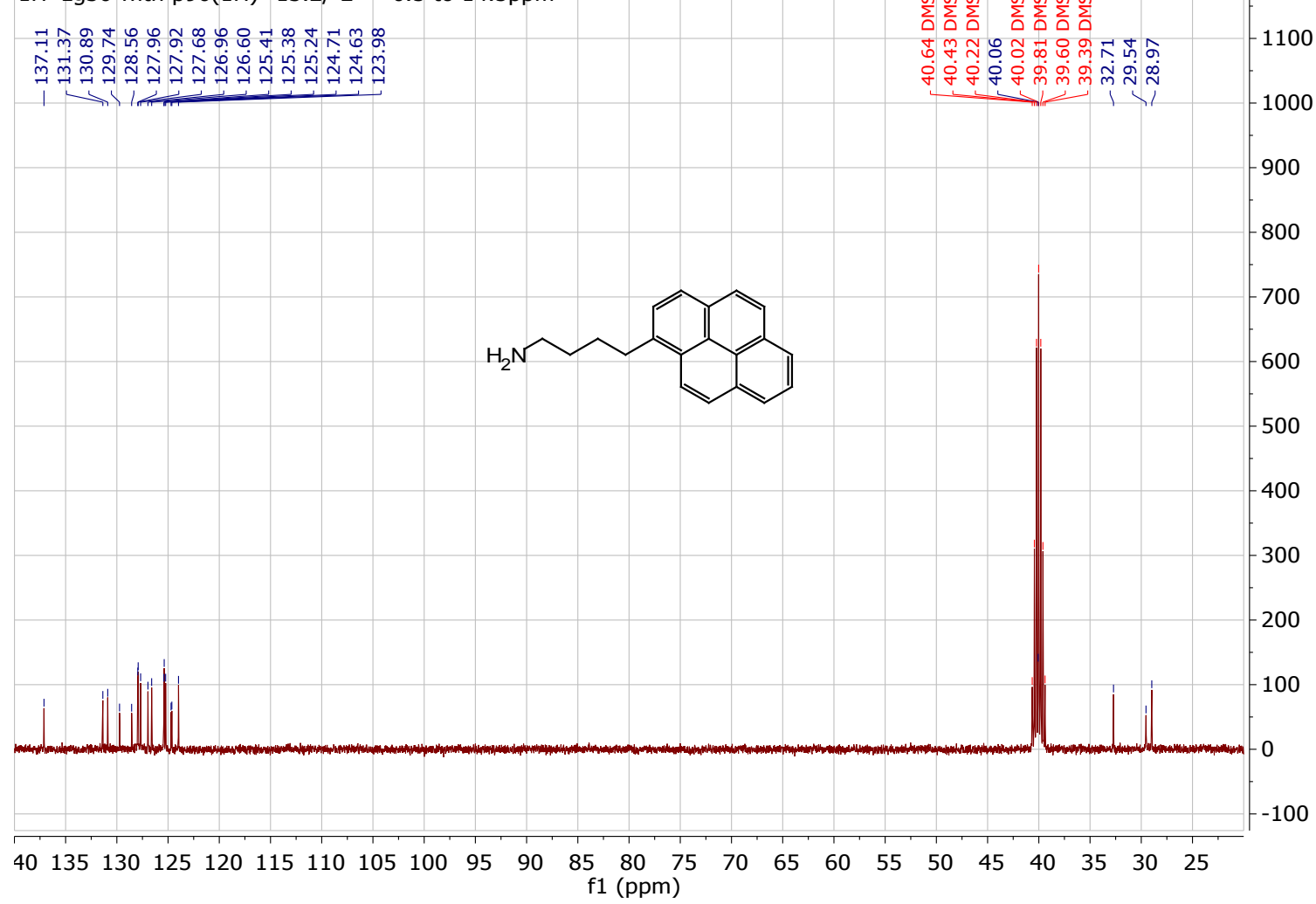




\section{S5.5 HRMS Spectra}

\section{1-(7-(pyren-1-yl)heptyl)-1,4,7,10-tetraazacyclododecane}
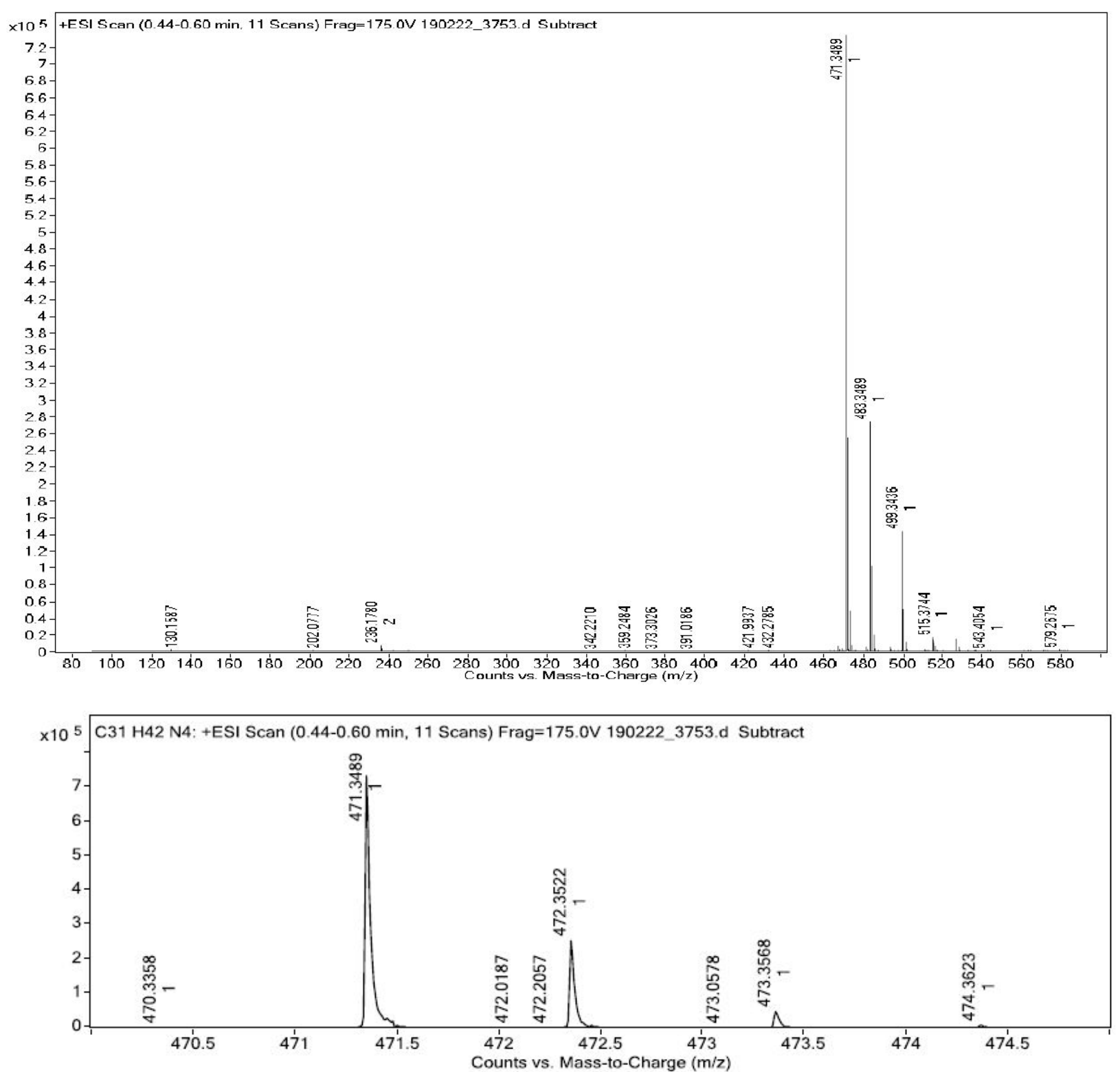

Predicted Isotope Match Table

\begin{tabular}{|c|c|c|c|c|c|c|}
\hline Isotope & $\mathrm{m} / \mathrm{z}$ & Calc $\mathrm{m} / \mathrm{z}$ & Diff (mDa) & Abund (\%) & Calc Abund ( $\%)$ & $+1-$ \\
\hline 1 & 471.3489 & 471.3482 & 0.7 & 100.0 & 100.0 & 0.0 \\
\hline 2 & 472.3522 & 472.3514 & 0.8 & 34.4 & 35.5 & 1.1 \\
\hline 3 & 473.3568 & 473.3545 & 2.3 & 6.4 & 6.1 & -0.3 \\
\hline
\end{tabular}




\section{1-(7-(pyren-1-yl)heptyl)-1,4,8,11-tetraazacyclotetradecane}
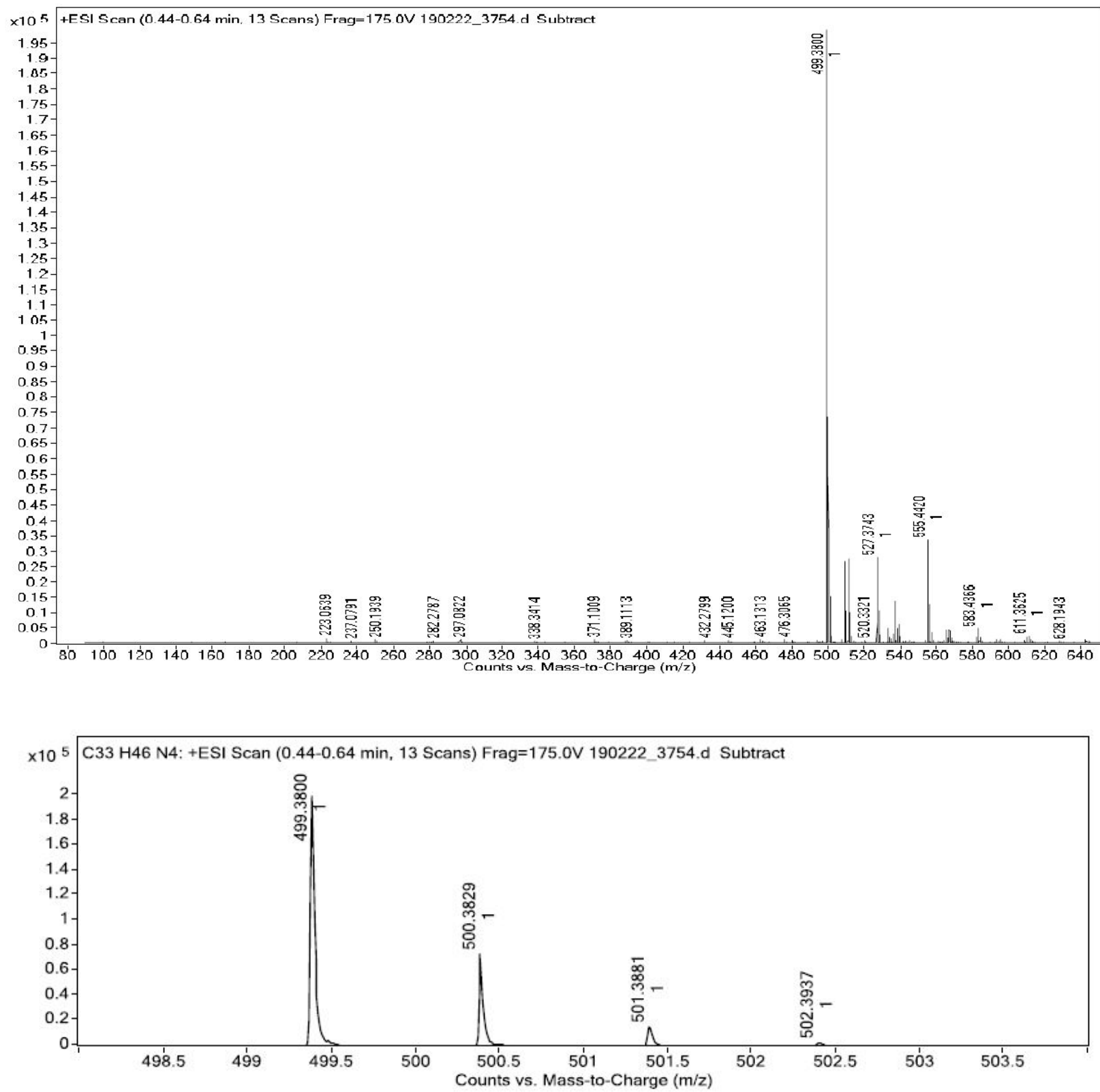

Predicted Isotope Match Table

Isotope

$m / z$

499.3800

Calc $\mathrm{m} / \mathrm{z}$

Diff (mDa)

Abund (\%)

Calc Abund (\%) +/-

500.3829

499.3795

0.5

100.0

100.0

0.0

501.3881

500.3827

0.2

37.0

37.7

0.7

3

502.3937

502.3890

2.3

7.8

$\begin{array}{ll}6.9 & -0.9\end{array}$

4

4.7

1.2

$0.8 \quad-0.4$ 
7-(pyren-1-yl)-N,N-bis(pyridin-2-ylmethyl)heptan-1-amine

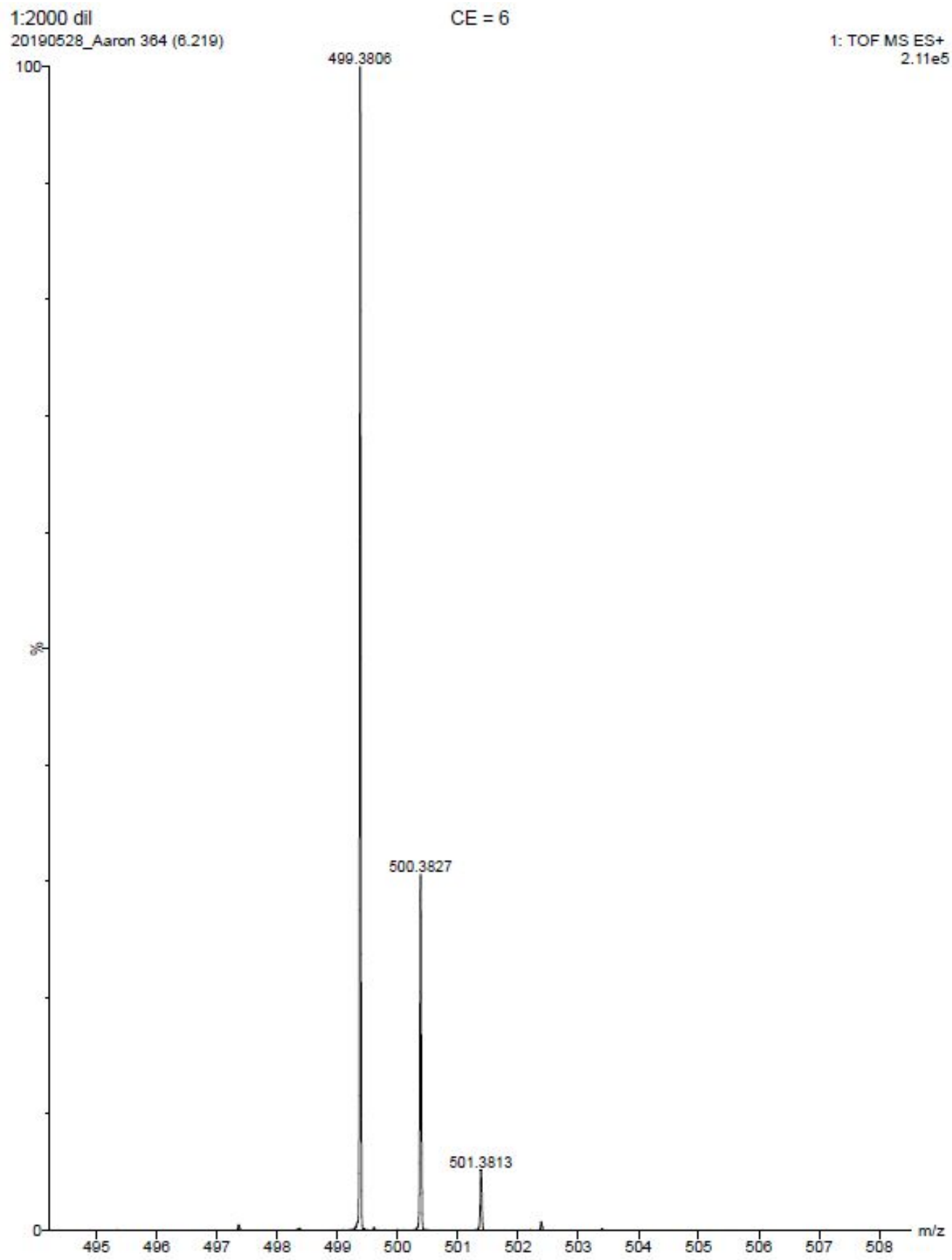




\section{S5.6 Analytical HPLC Spectra}

\section{1-(7-(pyren-1-yl)heptyl)-1,4,7,10-tetraazacyclododecane}

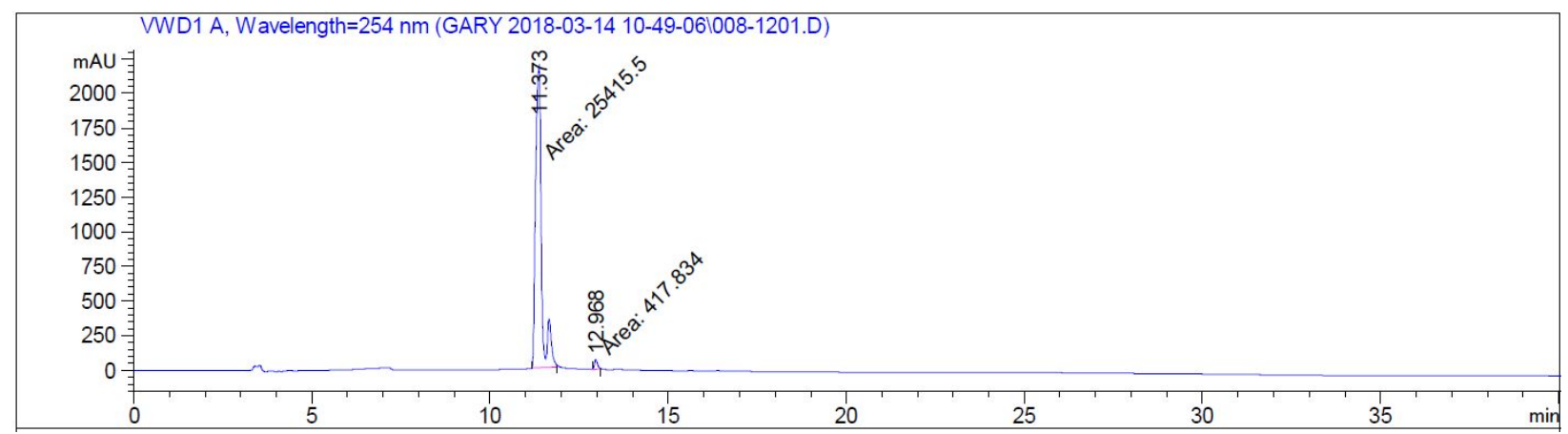

Signal 1: VWD1 A, Wavelength=254 nm

\begin{tabular}{|c|c|c|c|c|c|c|}
\hline $\begin{array}{c}\text { Peak } \\
\#\end{array}$ & $\begin{array}{c}\text { RetTime } \\
\text { [min] }\end{array}$ & Type & $\begin{array}{l}\text { Width } \\
\text { [min] }\end{array}$ & $\begin{array}{c}\text { Area } \\
{\left[\mathrm{mAU}{ }^{*} \mathrm{~s}\right]}\end{array}$ & $\begin{array}{l}\text { Height } \\
\text { [mAU] }\end{array}$ & $\begin{array}{c}\text { Area } \\
\frac{\circ}{6}\end{array}$ \\
\hline & & & ------ & |--------- & 1--------- & -------- \\
\hline 1 & 11.373 & MM & 0.1938 & $2.54155 \mathrm{e} 4$ & 2185.41797 & 98.3826 \\
\hline 2 & 12.968 & MM & 0.0973 & 417.83356 & 71.58804 & 1.6174 \\
\hline t & & & & $2.58333 \mathrm{e} 4$ & 2257.00601 & \\
\hline
\end{tabular}

HPLC Method 1 (35 min)

\begin{tabular}{|c|c|c|c|c|}
\hline \multirow{2}{*}{ Time (min) } & $\begin{array}{c}\mathrm{H}_{2} \mathrm{O}+\mathbf{0 . 1} \% \\
\mathrm{HCO}_{2} \mathbf{H}(\%)\end{array}$ & $\operatorname{MeCN}(\%)$ & \multirow{2}{*}{$\boldsymbol{\lambda}(\mathbf{m m})$} & \multirow{2}{*}{$\mathbf{R}_{\mathbf{t}}(\mathbf{m i n})$} \\
\cline { 1 - 3 } & $\mathbf{9 8}$ & $\mathbf{2}$ & \multirow{2}{*}{254} & \multirow{2}{*}{11.373} \\
\hline 35 & 0 & 100 & & \\
\hline
\end{tabular}

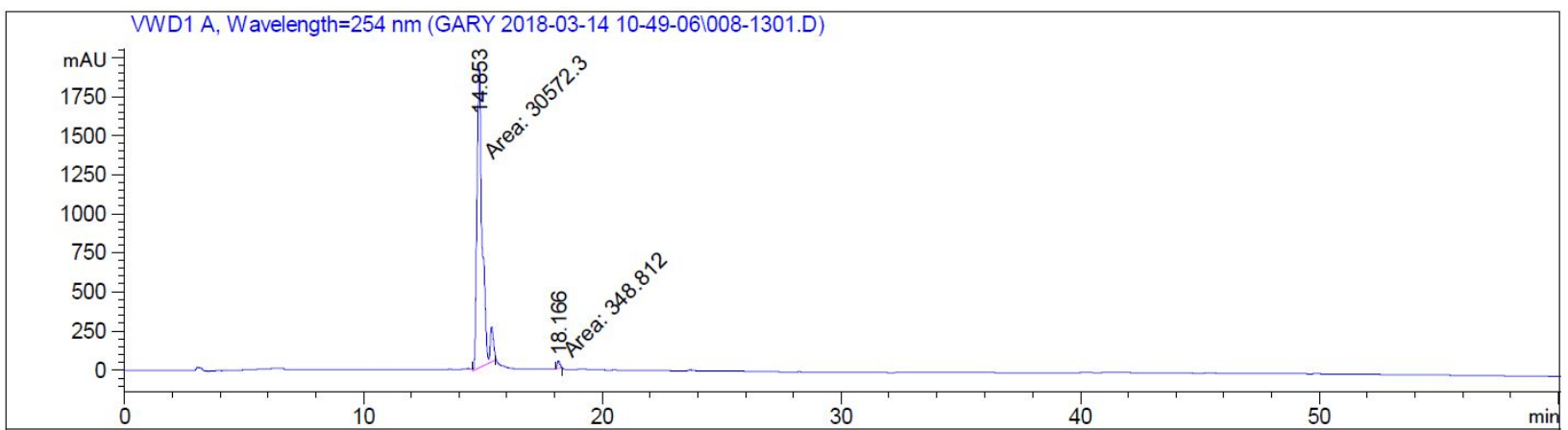

Signal 1: VWD1 A, Wavelength=254 nm

\begin{tabular}{|c|c|c|c|c|c|c|}
\hline $\begin{array}{c}\text { Peak } \\
\#\end{array}$ & $\begin{array}{c}\text { RetTime } \\
\text { [min] }\end{array}$ & Type & $\begin{array}{l}\text { Width } \\
\text { [min] }\end{array}$ & $\begin{array}{c}\text { Area } \\
{\left[\mathrm{mAU}^{\star} \mathrm{s}\right]}\end{array}$ & $\begin{array}{l}\text { Height } \\
\text { [mAU] }\end{array}$ & $\begin{array}{c}\text { Area } \\
\frac{\circ}{6}\end{array}$ \\
\hline \multicolumn{7}{|c|}{ 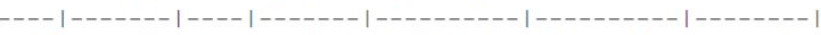 } \\
\hline 1 & 14.853 & MM & 0.2625 & $3.05723 e 4$ & 1941.20093 & 98.8719 \\
\hline 2 & 18.166 & MM & 0.1275 & 348.81229 & 45.61195 & 1.1281 \\
\hline otal & 5. & & & $3.09211 e 4$ & 1986.81287 & \\
\hline
\end{tabular}


HPLC Method 2 (60 min)

\begin{tabular}{|c|c|c|c|c|}
\hline \multirow{2}{*}{ Time (min) } & $\begin{array}{c}\mathrm{H}_{2} \mathrm{O}+\mathbf{0 . 1} \% \\
\mathrm{HCO}_{2} \mathrm{H}(\%)\end{array}$ & $\operatorname{MeCN}(\%)$ & $\boldsymbol{\lambda}(\mathbf{n m})$ & \multirow{2}{*}{$\mathbf{R}_{\mathbf{t}}(\mathbf{m i n})$} \\
\hline 0 & 98 & 2 & \multirow{2}{*}{254} & \multirow{2}{*}{14.853} \\
\hline 55 & 0 & 100 & & \\
\hline 60 & 0 & 100 & & \\
\hline
\end{tabular}

1-(7-(pyren-1-yl)heptyl)-1,4,8,11-tetraazacyclotetradecane

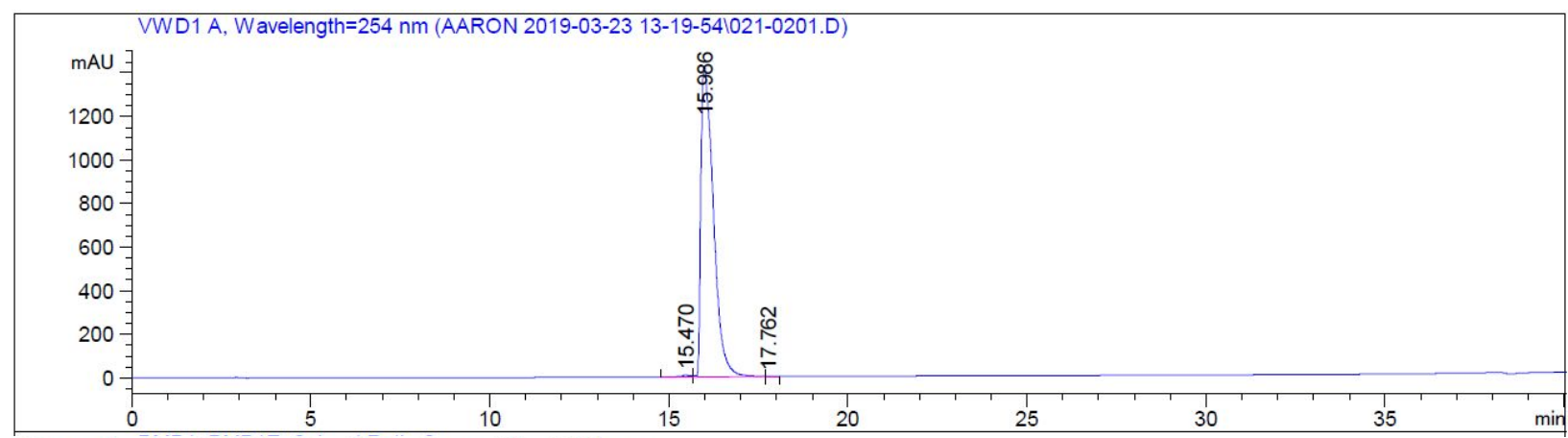

Signal 1: VWD1 A, Wavelength=254 nm

\begin{tabular}{|c|c|c|c|c|c|c|}
\hline $\begin{array}{c}\text { eak } \\
\#\end{array}$ & $\begin{array}{c}\text { RetTime } \\
\text { [min] }\end{array}$ & Type & $\begin{array}{l}\text { Width } \\
\text { [min] }\end{array}$ & $\begin{array}{c}\text { Area } \\
{\left[\mathrm{mAU}^{*} \mathrm{~S}\right]}\end{array}$ & $\begin{array}{l}\text { Height } \\
{[\mathrm{mAU}]}\end{array}$ & $\begin{array}{c}\text { Area } \\
\frac{8}{6}\end{array}$ \\
\hline \multicolumn{7}{|c|}{---|-------|----|-------|----------|----------|-------- } \\
\hline 1 & 15 & BV & & 141.03107 & 8.21449 & 0.4067 \\
\hline & 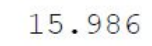 & VV & & $3.45291 e 4$ & 243 & 748 \\
\hline & 7.762 & VB & 3 & 6.40979 & $5.19481 e-1$ & 0185 \\
\hline
\end{tabular}

Totals : $\quad 3.46765 e 4 \quad 1434.22640$

HPLC Method 1 (35 min)

\begin{tabular}{|c|c|c|c|c|}
\hline \multirow{2}{*}{ Time (min) } & $\begin{array}{c}\mathrm{H}_{2} \mathrm{O}+0.1 \% \\
\mathrm{HCO}_{2} \mathrm{H}(\%)\end{array}$ & $\operatorname{MeCN}(\%)$ & \multirow{2}{*}{$\boldsymbol{\lambda}(\mathbf{m m})$} & \multirow{2}{*}{$\mathbf{R}_{\mathbf{t}}(\mathbf{m i n})$} \\
\hline 0 & 98 & 2 & \multirow{2}{*}{254} & \multirow{2}{*}{15.986} \\
\hline 35 & 0 & 100 & & \\
\hline
\end{tabular}

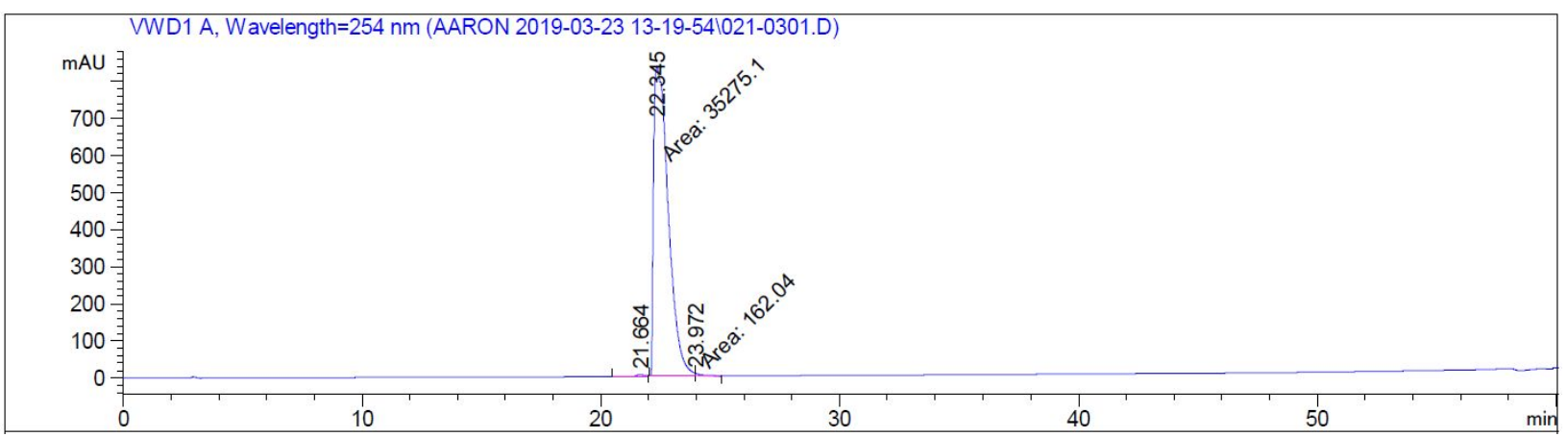


Signal 1: VWD1 A, Wavelength=254 nm

\begin{tabular}{|c|c|c|c|c|c|c|}
\hline $\begin{array}{c}\text { Peak } \\
\#\end{array}$ & $\begin{array}{c}\text { RetTime } \\
\text { [min] }\end{array}$ & Type & $\begin{array}{l}\text { Width } \\
\text { [min] }\end{array}$ & $\begin{array}{c}\text { Area } \\
{\left[\mathrm{mAU}^{\star} \mathrm{s}\right]}\end{array}$ & $\begin{array}{l}\text { Height } \\
{[\mathrm{mAU}]}\end{array}$ & $\begin{array}{c}\text { Area } \\
\frac{\circ}{\circ}\end{array}$ \\
\hline & & & & ---------- & 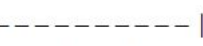 & ------ \\
\hline 1 & 21.664 & $\mathrm{BV}$ & 0.3226 & 131.71330 & 5.26331 & 0.3703 \\
\hline 2 & 22.345 & MM & 0.7058 & $3.52751 \mathrm{e} 4$ & 832.93347 & 1741 \\
\hline 3 & 23.972 & MM & 0.4987 & 162.04019 & 5.43984 & 0.4556 \\
\hline
\end{tabular}

Totals : $\quad 3.55689 \mathrm{e} 4 \quad 843.63662$

HPLC Method 2 (60 min)

\begin{tabular}{|c|c|c|c|c|}
\hline Time (min) & $\begin{array}{c}\mathrm{H}_{2} \mathrm{O}+0.1 \% \\
\mathrm{HCO}_{2} \mathrm{H}(\%)\end{array}$ & $\operatorname{MeCN}(\%)$ & $\lambda(\mathrm{nm})$ & $\mathbf{R}_{\mathrm{t}}(\min )$ \\
\hline $\mathbf{0}$ & 98 & 2 & \multirow{3}{*}{254} & \multirow{3}{*}{22.345} \\
\hline 55 & $\mathbf{0}$ & 100 & & \\
\hline 60 & $\mathbf{0}$ & 100 & & \\
\hline
\end{tabular}

\section{7-(pyren-1-yl)- $N, N$-bis(pyridin-2-ylmethyl)heptan-1-amine}

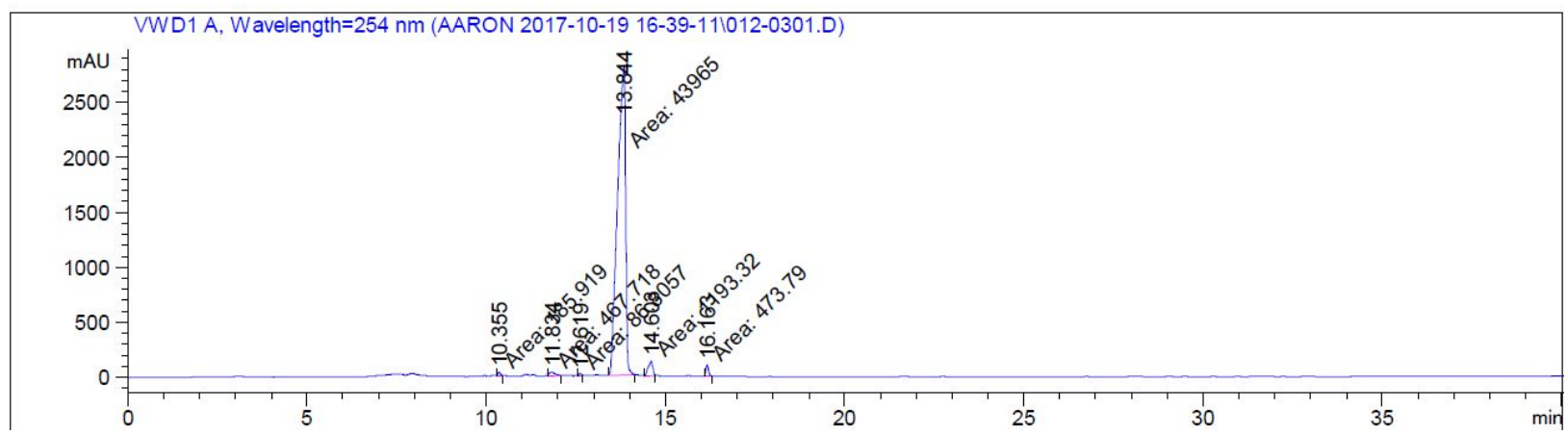

Signal 1: VWD1 A, Wavelength=254 nm

\begin{tabular}{|c|c|c|c|c|c|c|}
\hline $\begin{array}{c}\text { Peak } \\
\#\end{array}$ & $\begin{array}{c}\text { RetTime } \\
\text { [min] }\end{array}$ & Type & $\begin{array}{l}\text { Width } \\
\text { [min] }\end{array}$ & $\begin{array}{c}\text { Area } \\
{\left[\mathrm{mAU}^{*} \mathrm{~s}\right]}\end{array}$ & $\begin{array}{l}\text { Height } \\
{[\mathrm{mAU}]}\end{array}$ & $\begin{array}{c}\text { Area } \\
\frac{8}{8}\end{array}$ \\
\hline \multicolumn{7}{|c|}{$----|-------|----|-------|----------|----------|--------\mid$} \\
\hline 1 & 10.355 & MM & 0.0878 & 185.91949 & 35.27974 & 0.4009 \\
\hline 2 & 11.834 & MM & 0.2078 & 467.71762 & 37.51497 & 1.0086 \\
\hline 3 & 12.619 & MM & 0.0762 & 86.80566 & 18.99326 & 0.1872 \\
\hline 4 & 13.844 & $\mathrm{MM}$ & 0.2595 & $4.39650 e 4$ & 2823.42749 & 94.8082 \\
\hline 5 & 14.603 & MM & 0.1486 & 1193.32458 & 133.87260 & 2.5733 \\
\hline 6 & 16.163 & MM & 0.0809 & 473.78952 & 97.56487 & 1.0217 \\
\hline$a \perp$ & 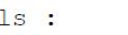 & & & $4.63725 e 4$ & 65293 & \\
\hline
\end{tabular}


HPLC Method 1 (35 min)

\begin{tabular}{|c|c|c|c|c|}
\hline \multirow{2}{*}{ Time (min) } & $\begin{array}{c}\mathbf{H}_{2} \mathbf{O}+\mathbf{0 . 1} \% \\
\mathbf{H C O}_{2} \mathrm{H}(\%)\end{array}$ & $\operatorname{MeCN}(\%)$ & \multirow{2}{*}{$\boldsymbol{\lambda}(\mathbf{n m})$} & \multirow{2}{*}{$\mathbf{R}_{\mathbf{t}}(\mathbf{m i n})$} \\
\hline 0 & 98 & 2 & \multirow{2}{*}{254} & \multirow{2}{*}{13.844} \\
\hline 35 & 0 & 100 & & \\
\hline 40 & 0 & 100 & & \\
\hline
\end{tabular}

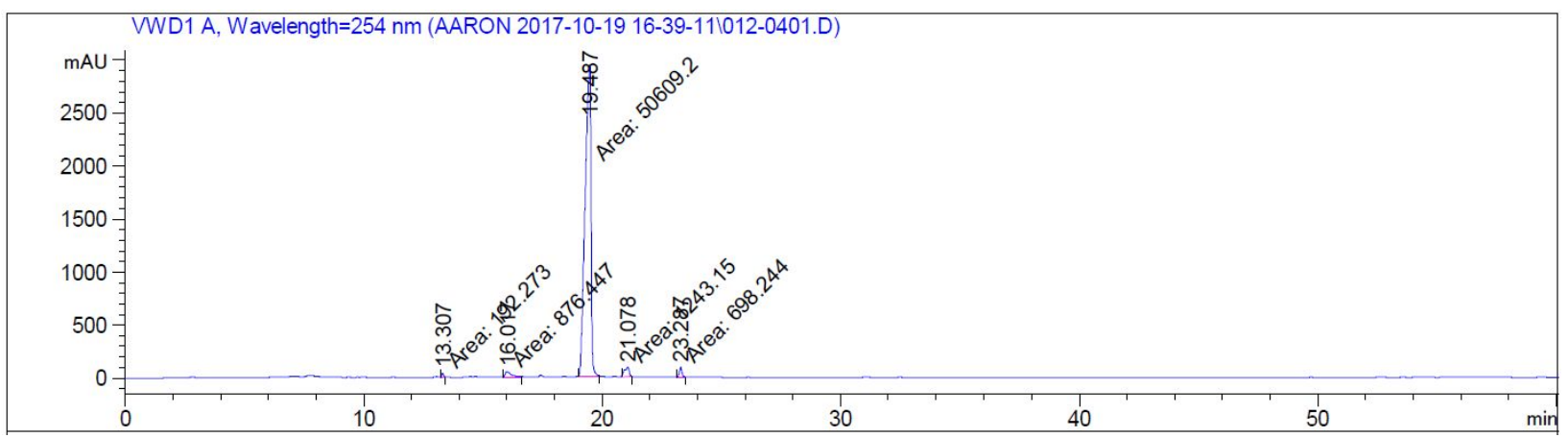

Signal 1: VWD1 A, Wavelength=254 nm

\begin{tabular}{|c|c|c|c|c|c|c|}
\hline $\begin{array}{c}\text { Peak } \\
\quad \#\end{array}$ & $\begin{array}{c}\text { RetTime } \\
\text { [min] }\end{array}$ & Type & $\begin{array}{l}\text { Width } \\
\text { [min] }\end{array}$ & $\begin{array}{c}\text { Area } \\
{\left[m A U^{*} s\right]}\end{array}$ & $\begin{array}{l}\text { Height } \\
{[\mathrm{mAU}]}\end{array}$ & $\begin{array}{c}\text { Area } \\
\quad \%\end{array}$ \\
\hline \multicolumn{7}{|c|}{$----|-------|----|-------|----------|----------|--------\mid$} \\
\hline 1 & 13.307 & MM & 0.0881 & 192.27267 & 36.36291 & 0.3586 \\
\hline 2 & 16.017 & MM & 0.2995 & 876.44733 & 48.78036 & 1.6346 \\
\hline 3 & 19.487 & MM & 0.2879 & $5.06092 e 4$ & 2929.54297 & 94.3861 \\
\hline 4 & 21.078 & $\mathrm{MM}$ & 0.2297 & 1243.14880 & 90.19165 & 2.3185 \\
\hline 5 & 23.287 & MM & 0.1244 & 698.24414 & 93.52579 & 1.3022 \\
\hline Tot & : & & & $5.36193 e 4$ & 368 & \\
\hline
\end{tabular}

HPLC Method $2(60 \mathrm{~min})$

\begin{tabular}{|c|c|c|c|c|}
\hline Time (min) & $\begin{array}{c}\mathrm{H}_{2} \mathrm{O}+0.1 \% \\
\mathrm{HCO}_{2} \mathrm{H}(\%) \\
\end{array}$ & $\operatorname{MeCN}(\%)$ & $\lambda(\mathrm{nm})$ & $\mathbf{R}_{\mathrm{t}}(\min )$ \\
\hline $\mathbf{0}$ & 98 & 2 & \multirow{3}{*}{254} & \multirow{3}{*}{19.487} \\
\hline 55 & $\mathbf{0}$ & 100 & & \\
\hline 60 & $\mathbf{0}$ & 100 & & \\
\hline
\end{tabular}




\section{1-(4-Aminobutyl)pyrene}

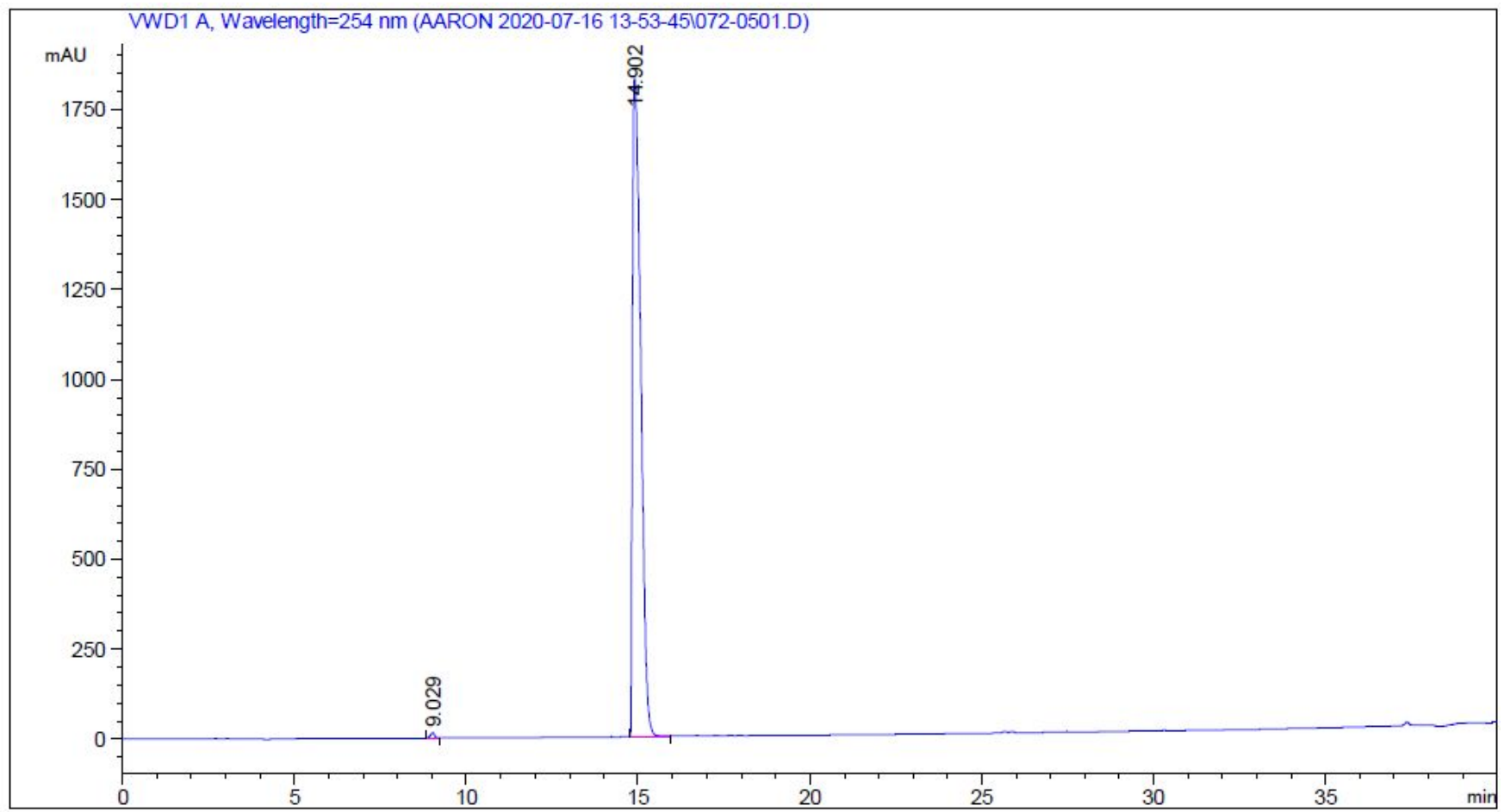

Signal 1: VWD1 A, Wavelength=254 nm

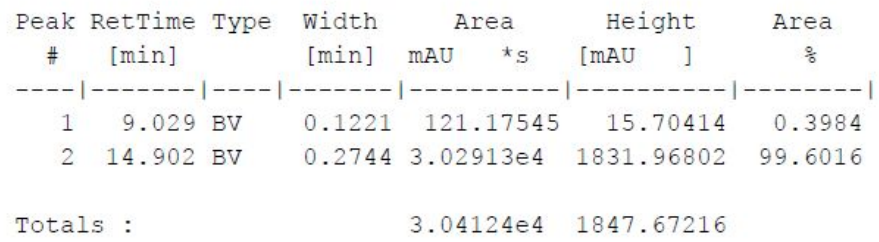

HPLC Method 1 (35 min)

\begin{tabular}{|c|c|c|c|c|}
\hline Time (min) & $\begin{array}{c}\mathrm{H}_{2} \mathrm{O}+0.1 \% \\
\mathrm{HCO}_{2} \mathrm{H}(\%)\end{array}$ & $\operatorname{MeCN}(\%)$ & $\lambda(\mathrm{nm})$ & $\mathbf{R}_{\mathrm{t}}(\mathrm{min})$ \\
\hline $\mathbf{0}$ & 98 & 2 & \multirow{3}{*}{254} & \multirow{3}{*}{14.902} \\
\hline 35 & $\mathbf{0}$ & 100 & & \\
\hline 40 & $\mathbf{0}$ & 100 & & \\
\hline
\end{tabular}




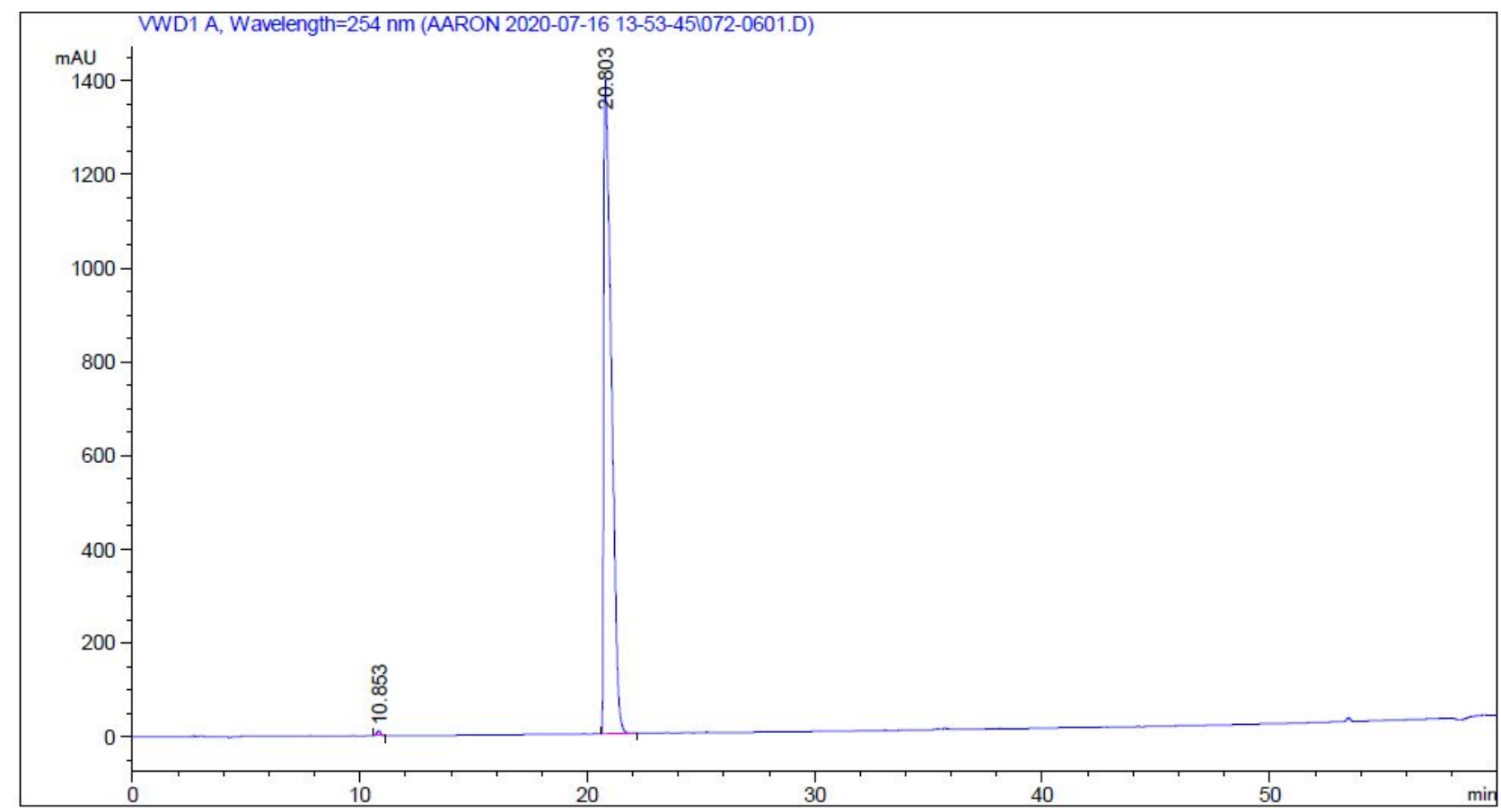

Signal 1: VWD1 A, Wavelength=254 nm

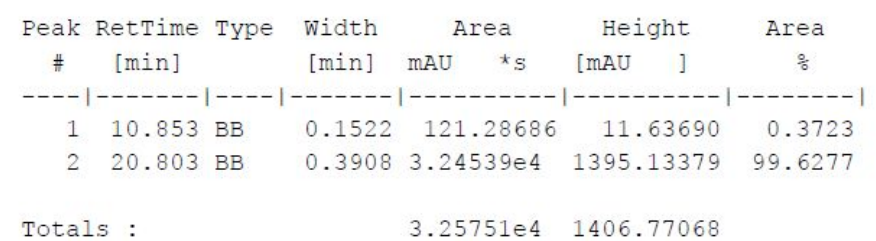

HPLC Method 2 (60 min)

\begin{tabular}{|c|c|c|c|c|}
\hline \multirow{2}{*}{ Time (min) } & $\begin{array}{c}\mathrm{H}_{2} \mathrm{O}+\mathbf{0 . 1} \% \\
\mathrm{HCO}_{2} \mathrm{H}(\%)\end{array}$ & $\operatorname{MeCN}(\%)$ & \multirow{2}{*}{$\boldsymbol{\lambda}(\mathbf{m m})$} & \multirow{2}{*}{$\mathbf{R}_{\mathbf{t}}(\mathbf{m i n})$} \\
\hline 0 & 98 & 2 & \multirow{2}{*}{254} & \multirow{2}{*}{20.803} \\
\hline 55 & 0 & 100 & & \\
\hline
\end{tabular}




\section{S6. References}

(1) Cabral, A. D.; Murcar-Evans, B. I.; Toutah, K.; Bancerz, M.; Rosa, D.; Yuen, K.; Radu, T. B.; Ali, M.; Penkul, A.; Kraskouskaya, D.; et al. Structure-Activity Relationship Study of ProxyPhos Chemosensors for the Detection of Proximal Phosphorylation and Other Phosphate Species. Analyst 2017, 142 (20), 3922-3933. https://doi.org/10.1039/C7AN00722A.

(2) Kraskouskaya, D.; Bancerz, M.; Soor, H. S.; Gardiner, J. E.; Gunning, P. T. An Excimer-Based, Turn-On Fluorescent Sensor for the Selective Detection of Diphosphorylated Proteins in Aqueous Solution and Polyacrylamide Gels. J. Am. Chem. Soc. 2014, 136 (4), 1234-1237. https://doi.org/10.1021/ja411492k.

(3) Edelstein, A.; Amodaj, N.; Hoover, K.; Vale, R.; Stuurman, N. Computer Control of Microscopes Using MManager. Curr. Protoc. Mol. Biol. 2010, 92 (1), 14.20.1-14.20.17. https://doi.org/10.1002/0471142727.mb1420s92.

(4) Schneider, C. A.; Rasband, W. S.; Eliceiri, K. W. NIH Image to ImageJ: 25 Years of Image Analysis. Nat. Methods 2012, 9 (7), 671-675. https://doi.org/10.1038/nmeth.2089.

(5) Murcar-Evans, B. I.; Cabral, A. D.; Toutah, K.; de Araujo, E. D.; Lai, A.; Macdonald, P. M.; BergerBecvar, A.; Kraskouskaya, D.; Gunning, P. T. ProxyPhos Sensors for the Detection of Negatively Charged Membranes. The Analyst 2017, 142 (23), 4511-4521. https://doi.org/10.1039/c7an00568g. 